\title{
Cost Effective Recovery of Low-TDS Frac Flowback Water for Re-use Department of Energy: DE-FE0000784
}

\author{
Final Report \\ Reporting Period: October 1, 2009 - March 31, 2011 \\ Harish R. Acharya \\ Principal Investigator \\ 518-387-5875 (Telephone) \\ 518-387-7403 (Fax) \\ Claire Henderson \\ Hope Matis \\ Hareesh Kommepalli \\ Brian Moore \\ Hua Wang \\ GE Global Research \\ 1 Research Circle, Niskayuna, NY 12309-1027
}

June 2011

Submitted to

United States Department of Energy

National Energy Technology Laboratory, Morgantown, WV 


\section{DISCLAIMER}

"This report was prepared as an account of work sponsored by an agency of the United States Government. Neither the United States Government nor any agency thereof, nor any of their employees, makes any warranty, express or implied, or assumes any legal liability or responsibility for the accuracy, completeness, or usefulness of any information, apparatus, product, or process disclosed, or represents that its use would not infringe privately owned rights. Reference herein to any specific commercial product, process, or service by trade name, trademark, manufacturer, or otherwise does not necessarily constitute or imply its endorsement, recommendation, or favoring by the United States Government or any agency thereof. The views and opinions of authors expressed herein do not necessarily state or reflect those of the United States Government or any agency thereof."

\section{ABSTRACT}

The project goal was to develop a cost-effective water recovery process to reduce the costs and environmental impact of shale gas production. This effort sought to develop both a flowback water pretreatment process and a membrane-based partial demineralization process for the treatment of the low-Total Dissolved Solids (TDS) portion of the flowback water produced during hydrofracturing operations. The TDS cutoff for consideration in this project is $<35,000 \sim 45,000 \mathrm{ppm}$, which is the typical limit for economic water recovery employing reverse osmosis (RO) type membrane desalination processes. The ultimate objective is the production of clean, reclaimed water suitable for re-use in hydrofracturing operations.

The team successfully compiled data on flowback composition and other attributes across multiple shale plays, identified the likely applicability of membrane treatment processes in those shales, and expanded the proposed product portfolio to include four options suitable for various reuse or discharge applications. Pretreatment technologies were evaluated at the lab scale and down-selected based upon their efficacy in removing key contaminants. The chosen technologies were further validated by performing membrane fouling studies with treated flowback water to demonstrate the technical feasibility of flowback treatment with RO membranes. Process flow schemes were constructed for each of the four product options based on experimental performance data from actual flowback water treatment studies. For the products requiring membrane treatment, membrane system modeling software was used to create designs for enhanced water recovery beyond the typical seawater desalination benchmark. System costs based upon vendor and internal cost information for all process flow schemes were generated and are below target and in line with customer expectations. Finally, to account for temporal and geographic variability in flowback characteristics as well as local disposal costs and regulations, a parametric value assessment tool was created to assess the economic attractiveness of a given flowback recovery process relative to conventional disposal for any combination of anticipated flowback TDS and local disposal cost. It is concluded that membrane systems in combination with appropriate pretreatment technologies can provide cost-effective recovery of low-TDS flowback water for either beneficial reuse or safe surface discharge. 


\section{ACKNOWLEDGEMENT}

This material is based upon work supported by the Department of Energy, National Energy Technology Laboratory under Award Number DE-FE0000784

The authors would also to thank the following individuals: Dr. James Silva, GEGR for collaboration and consulting - Dr. Silva is the PI for the RPSEA 08122-36 investigating the treatment of NORM containing frac flowback waters. Steven Rice for conducting several membrane desalination experiments. Paul Wilson for setting up and trouble-shooting the complex membrane module testing setup. The GE Water Commercial team, including Mark Wilson, Todd Langford, Joseph Tinto, and Kyle Wendell for continuously updating market information and arranging for site-visits and contacts with gas-producers. Tom Hook and Preston Nelms for diligently acquiring frac flowback samples from Woodford and Fayetteville shales. Bill Walton and the GE Water Analytical team for the numerous water sample analyses. Larry Costa, David Polizzotti, Steve Vasconceles, John Piechel, Peter Ericksson, Tom Ciarra, and Irving Elyanow for their recommendations of water pretreatment and membrane systems, design and costing information, and the many reviews with very valuable feedback. 


\section{Table of Contents}

\begin{tabular}{|c|c|}
\hline & R \\
\hline 5 & \\
\hline & \\
\hline & \\
\hline & SUMMARY ........................ \\
\hline & Project Narrative ......... \\
\hline & Project Objectives and Approach.. \\
\hline & Budget ............ \\
\hline & Results and Discussions...... \\
\hline & Task 1: Project management. \\
\hline 2 & Task 2: Obtain Flowback Attribut \\
\hline 2.1 & Objectives and Approach .... \\
\hline 2.2 & Water usage in shale gas exploration.. \\
\hline 2.3 & rious fluids used in shale gas exploration - Fracturing, Flowback/ Produced \\
\hline 2.4 & Water Chemistry of the fracturing fluids used for shale gas exploration \\
\hline 2.5 & Flowback \\
\hline 2.6 & Sumn \\
\hline 2.7 & Flowback volumes amenable to "Low-TDS" membrane-recovery.. \\
\hline 2.8 & Flow \\
\hline 2.9 & Frac \\
\hline 2.10 & Flowback samples.. \\
\hline 2.1 & Flowback \\
\hline .1 & Flow \\
\hline 2.1 & Flow \\
\hline 2.11 & k water recovery $\mathrm{p}$ \\
\hline .1 & ack process ... \\
\hline &. .42 \\
\hline 21 & . \\
\hline 2.12 & is for recovery for frac re-use ................... \\
\hline 2.13 &  \\
\hline 3 & Task 3: Define conceptual process alterna \\
\hline 3.1 & Frac Flowback Water Rec \\
\hline 3.2 & Key contaminants in frac flowback of concern for reuse ............ \\
\hline 3.3 & Considerations for evaluating technology \& process options ......... \\
\hline 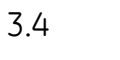 & ses in bench-scale experiments.....58 \\
\hline .4 .1 & Objectives and Approach ................... \\
\hline 4.2 & Bench-scale experimental approach ... \\
\hline 4.3 & Process Step: "Clarify" .......... \\
\hline & . \\
\hline
\end{tabular}


3.4.3.2 Nature of the organics in frac flowback waters - novel analytical technique



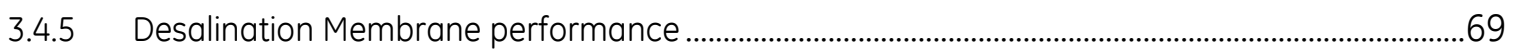

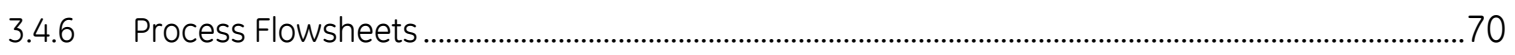

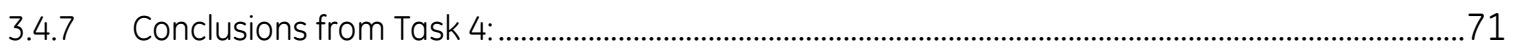

3.5 Task 5: Obtain bench-scale experimental data suitable for process modeling .............................72

3.5.1 Objectives and Approach .......................................................................................................................

3.5.2 Membrane performance parameters vs. Feed composition ..............................................................74

3.5.3 Evaluation of Desalination Membrane Fouling .......................................................................................77

3.6 Task 6-Develop system performance and cost models ...................................................................81

3.6.1 Objectives and Approach: ......................................................................................................................81

3.6.2 Membrane Desalination Mobile Rig - FWRP costs \& economical "cut-off" TDS .............................82

3.6.3 Hybrid Membrane+Thermal Mobile system - FWRP costs \& economical "cut-off" TDS ..............86

$4 \quad$ Summary and Conclusions .................................................................................................................90

APPENDIX: Water Chemistry of Drilling and Hydrofracturing Fluids .............................................................93

Drilling fluid 93

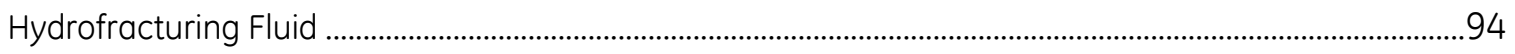

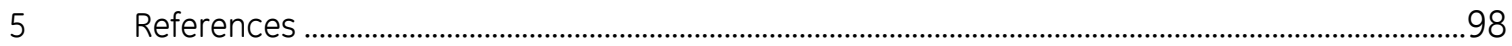

\section{List of Tables}

Table 1. Water usage (average) per well and water requirements for the various shale plays (as estimated by Chesapeake Energy ${ }^{7}$.

Table 2. Salinity of the flowback waters from various shales expressed in terms of Total Dissolved

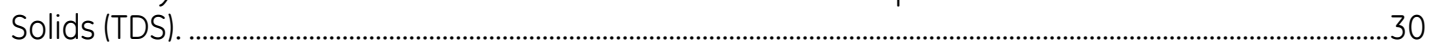

Table 3. Compositions of the three 55-gal drums obtained from the Woodford shale that were used for bench-mark testing in Tasks 4 and 5............................................................................................................... 41

Table 4. The following specifications for re-use frac water in the Marcellus shale were apparently developed with data supplied by Halliburton and XTO Energy .....................................................................45

Table 5. Composition analyses for the Site-2 Day-26 waters: raw, pretreated by softening, and after 24-hr membrane fouling test. . .80

\section{List of Figures}

Figure 1 Simplified frac flowback water handling and disposal operation at a shale gas well site...........14 Figure 2. Conceptual Flowback Water Recovery Process (FWRP) for re-use in hydrofracturing.................15

Figure 3. Schedule and milestones for the program. ....................................................................................................17

Figure 4. Task interrelationships and Go/No-go decisions.......................................................................................18

Figure 5. Flowback from a few wells in the Marcellus shale (Gaudlip et al)........................................................24

Figure 6 Flow rates vs. Flowback time for a few wells in the Marcellus shale (Gaudlip ${ }^{4}$ )...............................25

Figure 7. Flowback rate vs. time for a Woodford shale (re-plotted from the data shown in Horn ${ }^{10}$ )........25

Figure 8. Flowrate profiles for frac flowback from three Woodford shales.........................................................26

Figure 9. Composition of a flowback sample from a Marcellus shale site (reproduced from Gaudlip4)..26 
Figure 10. Variation of flowback composition with time for a Marcellus shale site (reproduced from

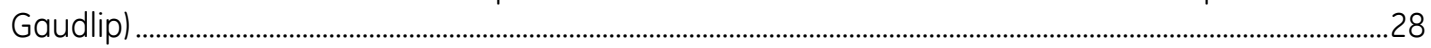

Figure 11. Variation of Sulfates and Ba/Sr concentrations as a function of flowback volume for a

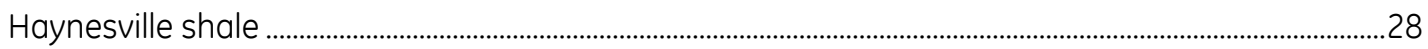

Figure 12. Total Dissolved Solids (TDS) concentration profiles for flowback waters from a few Woodford shale wells

Figure 13. Photograph shows a saline water disposal (SWD) well co-located with three hydrofractured wells producing gas. ...31

Figure 14. Profiles of the flowback water rate and water temperature are plotted vs. flowback time for the Site-1 in Woodford shale.

Figure 15. Concentration profiles for Total Dissolved Solids (TDS) for the two Woodford frac sites...........33

Figure 16. Concentration profiles for Total Suspended Solids (TSS) and Turbidity for the two Woodford

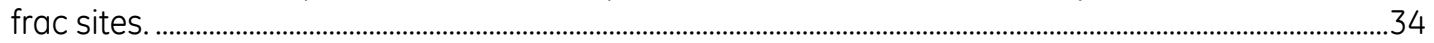

Figure 17. Concentration profiles for Hexane Extractables and Total Organic Carbon for the two

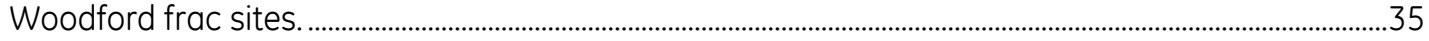

Figure 18. Concentration profiles for Total Hardness and Alkalinity for the two Woodford frac sites.......36

Figure 19. Plot of Total Hardness (mg/l CaCO3) vs. Total Dissolved Solids (TDS) for the various frac flowback water samples collected from the two Woodford frac sites. .........................................................

Figure 20. Profiles for the contributions of Calcium, Magnesium and Others ( $\mathrm{Fe}, \mathrm{Sr}, \mathrm{Ba}$ ) in terms of $\mathrm{mg} / \mathrm{l}$ $\mathrm{CaCO} 3$ for the two Woodford frac sites................................................................................................................ 37

Figure 21. Concentration profiles for Barium, Strontium and Sulfate for the two Woodford frac sites. ..38

Figure 22. Concentration profiles for Iron, Manganese and Boron for the two Woodford frac sites..........39

Figure 23. Concentration profiles for Total and Reactive Silica for the two Woodford frac sites. ...............40

Figure 24. Photographs of vials containing frac flowback samples from Woodford shale Site-1 Days1-

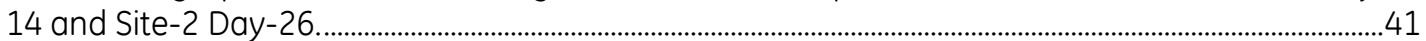

Figure 25. Simplified frac flowback water handling and disposal operation at a shale gas well site. .......42

Figure 26. Conceptual Flowback Water Recovery Process (FWRP) for re-use in hydrofracturing...............43

Figure 27. Key contaminants in frac flowback water and their impact on re-use in hydrofracturing.....44

Figure 28. Summary of chemical characteristics of the waters used in conventional and blended Marcellus waters used for hydrofracturing by the Range Resources Company ${ }^{4}$.....................................45

Figure 29. . Product Options for frac flowback water recovery. The target contaminants are listed for each process step in the respective boxes. The target contaminants to be removed in each process step are indicated inside the boxes...

Figure 30. Specifications for the various Product Options described in Figure 29...........................................47

Figure 31. Plot of extent of product recovery, $x$ as a function of the flowback water concentration and desired permeate product water concentrations when retentate concentration is limited to 70,000 ppm TDS.

Figure 32. Verification of success criteria for the Low-TDS frac flowback recovery process .......................51

Figure 33. Conceptual representation of a frac flowback recovery process to treat the frac flowback waters to provide the product options in Figure 30. The target contaminants to be removed in each process step are indicated inside the boxes.

. .53

Figure 34. Technology options evaluated in the preliminary screening in Task 3 for removal of the various contaminants in frac flowback water. ..................................................................................................5

Figure 35. Clarification of frac flowback waters. Results of bench-scale experiments with the "composite" Days 1-14 Woodford Site-1 sample.............................................................................................59

Figure 36. Clarification of frac flowback waters. Results of bench-scale experiments with the Day-26

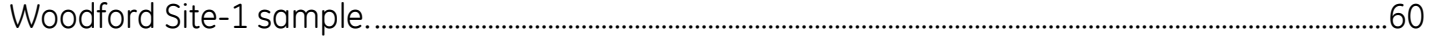

Figure 37. Clarification of frac flowback waters. Results of bench-scale experiments with the Day-1

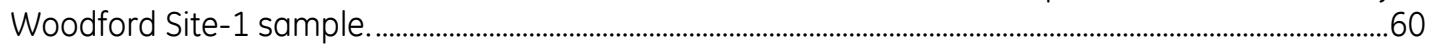

Figure 38. Clarification of frac flowback waters with coagulation and ultrafiltration. Results of benchscale experiments with the Site-1 Day-1 and Site-2 Day-26 Woodford samples.

Figure 39. Removal of organics from Woodford shale flowback samples. Comparison of adsorption isotherms of three sorbents for the Site-1 Day-1 sample and "Composite" Days 1-14 sample......62 
Figure 40. GCXGC-MS 2-D plots for the Control and Day-26 (frac) raw water. Note the presence of hydrocarbons of various polarities and boiling points (molecular weight) in the Site-2 Day-26



Figure 41. GCXGC-MS 3-D plot for the Control methylene chloride (with $10 \mathrm{ppb}$ methyl eiosonoate)....64

Figure 42. GCXGC-MS 3-D plot for the Day-26 and Day-1 frac water field samples. Day-1 sample has more polar hydrocarbons and in general, higher intensities corresponding to the overall higher TOC content.

.64

Figure 43. Effect of Treatment\#1 on the organic contaminant levels of the Day-26 frac flowback water sample. Observe the appearance of peaks associated with surfactant molecules..............................65

Figure 44. Comparison of GCxGC-MS 2-D plots for Day-26 raw water and after Treatment\#5 and

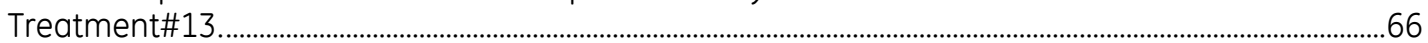

Figure 45. Comparison of GCxGC-MS 3-D plots for Day-26 raw water and after Treatment\#13 for two



Figure 46. Clarification of frac flowback waters with coagulation and ultrafiltration. Results of benchscale experiments with the Site-1 Day-1 and Site-2 Day-26 Woodford samples. .................................68

Figure 47. Maximizing RO-desalination water recovery of pretreated Site-2 Day-26 flowback water via simulation studies using GE Winflows software 20 .

Figure 48. A conceptual process flowsheet for treating frac flowback waters to produce waters meeting Product-1 quality specs (cf. Figure 30).....................................................................................70

Figure 49. Operating cost breakdown for a $50 \mathrm{gpm}$ mobile membrane rig capable of producing $<500$ ppm TDS product.

Figure 50. Membrane module testing rig for conducting desalination experiments with pretreated field frac flowback samples at GE Global Research. ………...............................................................................73

Figure 51. Permeate TDS vs. Feed TDS for the 2" spiral wound RO module runs using 10 15 liters of pretreated field frac flowback samples. See text for details...........................................................................75

Figure 52. Water flux parameter vs. Feed TDS for the 2" spiral wound RO module runs using 10 15 liters of pretreated field frac flowback samples. See text for details........................................................76

Figure 53. Salt-flux parameter vs. Feed TDS for the 2" spiral wound RO module runs using 10 15 liters of pretreated field frac flowback samples. See text for details. .......................................................................76

Figure 54. Salt-rejection parameter vs. Feed TDS for the 2" spiral wound RO module runs using 10 15 liters of pretreated field frac flowback samples. See text for details.......................................................77

Figure 55. Comparison of water-flux parameter change due to desalination membrane fouling for pretreated Site-1 Day-26 field frac flowback sample and pure $\mathrm{NaCl} /$ de-ionized water solution. ...78

Figure 56. Comparison of salt-flux parameter change due to desalination membrane fouling for pretreated "Day-26" field frac flowback sample and pure $\mathrm{NaCl} /$ de-ionized water solution..............79

Figure 57. Comparison of salt-rejection parameter change due to desalination membrane fouling for pretreated "Day-26" field frac flowback sample and pure $\mathrm{NaCl} /$ de-ionized water solution..............79

Figure 58. System configurations for the conventional frac flowback disposal via underground saline water disposal and the Flowback Water Recovery Process 50-gpm mobile rig under

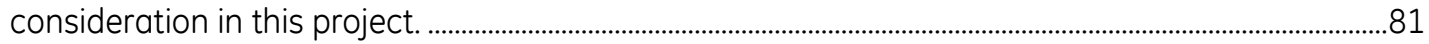

Figure 59. Cost parameters, units and correlations for the FWRP \& Conventional processes described in Figure 58

Figure 60. Mass balance profiles for membrane desalination based FWRP for Product-3 (20,000 ppm) and Product-4 (500 ppm).

Figure 61. Cost components for the membrane-based FWRP: C Recovery, $_{\text {C Conc_disposal }}$ and $C_{\text {FWRP }}$ for the operating and cost parameters developed in this project and for an assumed value of $\mathrm{C}_{\text {Disposal... } 84}$

Figure 62. Cost of membrane-based FWRP vs. feed TDS concentrations forProduct-3 and Product-4 quality specifications........................................................................................................................................ 85

Figure 63. Profiles for CFWRP/CConventional for the membrane system vs. Concentrate disposal costs at varying feed TDS concentrations. ................................................................................................................... 86

Figure 64. Hybrid system incorporating pretreatment, membrane desalination and thermal distillation to yield Product- 4 quality (500 ppm TDS); the $90 \mathrm{~K} \mathrm{ppm}$ TDS retentate from the membrane unit is distilled in the mobile evaporator to yield a 280,000 ppm TDS concentrate. . .87 
Figure 65. Cost profiles for the Membrane system alone, Mobile evaporator alone and the Hybrid membrane+thermal systems as a function of feed TDS concentration.....................................................8

Figure 66. Profiles for $\mathrm{CFWRP}_{\mathrm{F}} / \mathrm{C}_{\text {Conventional }}$ ratio vs Concentrate disposal costs for varying feed TDS concentrations.

Figure 67. Volumetric composition of a representative hydraulic fracturing fluid excluding the proppants (reproduced from D. Arthur et al., ALL Consulting 25) ....................................................................95

Figure 68. Additives in the hydrofracturing fluid .......................................................................................................96

Figure 69. Additives used in the hydrofracturing fluid, as reproduced from information published by Talisman Energy, Inc 28 


\section{List of Acronyms}

\begin{tabular}{|c|c|}
\hline Acronym & Definition \\
\hline & Barrel (1 bbl = 42 gallons) \\
\hline Conventional & Conventional Flowback Water Disposal Process based on Class II SWD \\
\hline Chemicals & Cost of process chemicals, $\$ /$ bbl flowback \\
\hline CConventional & Cost of Conventional Flowback Water Disposal Process, \$ \\
\hline$C_{\text {Disposal }}$ & Cost of flowback disposal $\left(=C_{\text {Transport }}+C_{\text {Swo }}\right), \$ / b b l$ \\
\hline CFWRP $_{\text {FW }}$ & Cost of Flowback Water Recovery Process, $\$$ \\
\hline CFresh Water & Cost of fresh water for frac use, $\$ / b b l$ \\
\hline CMaintenance & Cost of annual maintenance per annual feed processed, $\$ /$ bbl flowback \\
\hline CPenalty_Avoid & Value of penalty avoided due to flowback re-use \\
\hline Cprocess & Cost of process steps (capital and operating expenses), \$/bbl feed \\
\hline CProduct Delivery & Cost of product delivery to re-use site, $\$ / \mathrm{bbl}$ product \\
\hline CProduct_Value & Value of fresh water avoided due to flowback re-use, $\$ / \mathrm{bbl}$ product \\
\hline CRecovery & $\begin{array}{l}\text { Cost of product recovery }\left(=C_{\text {Treatment }}+C_{\text {Product Delivery }}-C_{\text {Product_value }}+C_{\text {Penalty_Avoid }}\right) \text {, } \\
\$ / \text { bbl product }\end{array}$ \\
\hline$C_{S W D}$ & Cost of saline water disposal by deep well injection, $\$ / b b l$ \\
\hline$C_{\text {setup }}$ & Cost of mobile rig transportation and setup at the frac site, $\$ / \mathrm{bbl}$ feed \\
\hline $\mathrm{C}_{\text {Treatment }}$ & Cost of flowback treatment to produce product $\left(=C_{\text {setup }}+C_{\text {process }}\right), \$ / b b l$ feed \\
\hline $\mathrm{C}_{\text {Transport }}$ & Cost of transportation of disposal water, $\$ / \mathrm{bbl}$ flowback or concentrate \\
\hline CWaste & Cost of FWRP process waste disposal, \$/bbl flowback \\
\hline "Cut-off" TDS & $\begin{array}{l}\text { The value of } y F \text { where the } C_{F W R P} / C_{\text {conventional }}=1 \text { represents the economical } \\
\text { "cut-off" TDS for that particular frac flowback site. }\end{array}$ \\
\hline $\mathrm{F}$ & Flowback volume, bbls \\
\hline FWRP & Flowback Water Recovery Process \\
\hline GE & General Electric \\
\hline GEGR & General Electric Global Research \\
\hline GEW\&PT & General Electric Water \& Process Technologies \\
\hline MF & Microfiltration \\
\hline MMcf & Million cubic feet \\
\hline NF & Nanofiltration \\
\hline NTU & Turbidity measurement unit \\
\hline $\mathrm{RO}$ & Reverse Osmosis \\
\hline SWD & Saline water disposal - deep injection Class II well \\
\hline SRB & Sulfate reducing bacteria \\
\hline TDS & Total Dissolved Solids \\
\hline TSS & Total Suspended Solids \\
\hline UF & Ultrafiltration \\
\hline$x$ & Extent of flowback recovered, bbl product/bbl flowback \\
\hline X Pretreatment & $\begin{array}{l}\text { Extent of flowback recovered after pretreatment prior to membrane desalina- } \\
\text { tion), bbl/bbl flowback }\end{array}$ \\
\hline$y_{F}$ & Feed TDS concentration, ppm \\
\hline yconcentrate & Concentrate (sent to SWD) TDS concentration, ppm \\
\hline YDistillate & Distillate (from thermal evaporator) TDS concentration, ppm \\
\hline YPermeate & Permeate (from membrane) TDS concentration, ppm \\
\hline YProduct & Product TDS concentration, ppm \\
\hline$y_{\text {Retentate }}$ & Membrane retentate (reject) TDS concentration, ppm \\
\hline
\end{tabular}




\section{EXECUTIVE SUMMARY}

This is the final report for this project supported by U.S. DOE NETL (Contract No. DE-FE0000784) and GE Global Research (GEGR). This report provides a project narrative and a summary of project activities and accomplishments for the reporting period, beginning October 1, 2009 and ending March 30, 2011.

The project goal was to develop a cost-effective water recovery process to reduce the costs and environmental impact of shale gas production. This effort sought to develop both a flowback water pretreatment process and a membrane-based partial demineralization process for the treatment of the low-Total Dissolved Solids (TDS) portion of the flowback water produced during hydrofracturing operations. The TDS cutoff for consideration in this project is $<35,000 \sim 45,000 \mathrm{ppm}$, which is the typical limit for economic water recovery employing reverse osmosis (RO) type membrane desalination processes. The ultimate objective is the production of clean, reclaimed water suitable for re-use in hydrofracturing operations.

Over the past year, the shale gas industry appears to be continuously evolving in terms of methodologies and technologies used for hydrofracturing. Moreover, the various States have been active on the regulatory front in terms of water sourcing and disposal for this very important energy sector. It was necessary to understand this dynamic nature of the shale gas market and the potential impact that has on the specifications and costs for our product water for frac re-use. The team reviewed information published in open literature and obtained feedback from frac operators. The team also visited frac flowback and underground injection disposal sites to get a better understanding of the operation logistics and specifications for water re-use.

Consequently, it became necessary to update the product water scope from the one product with 20,000 ppm TDS initially proposed to potentially four alternative products with varying levels of purification:

- Product-1: Clarified only (removal of suspended matter, free oil \& grease, Fe, and microbiological contaminants)

- Product-2: Softened and Clarified (removal of hardness ions, namely Ba, Sr, Ca, Mg besides the purity specs for Product-1)

- Product-3: Partially desalinated to $<20,000$ ppm TDS (besides the purity specs for Product-2)

- Product-4: Substantially desalinated to < 500ppm TDS (besides the purity specs for Product-2). Product-3 above now represents the initial product target.

For this project, the verification of success criteria for critical go/no-go decisions were determined to be:

- Product quality specifications for the Products 1-4 to their respective target applications. Water recovery $>95 \%$ for Product- 1 and $>90 \%$ for Product- 2 . For flowback water with $<40,000$ ppm TDS, water recovery $>50 \%$ for Product-3 and $>40 \%$ for Product -4 .

- Cost of the overall Flowback Water Recovery Process (FWRP) < Cost of Conventional Saline Water Disposal. The FWRP includes Treatment Costs (mobile rig related process equipment, transportation \& setup, chemicals and waste disposal, power) and Concentrate Disposal Costs. For the shale plays under consideration, this translates to target Treatment Cost < $\$ 2 /$ bbl flowback water. 
- Separation process operable in a 50-gpm mobile rig configuration

Information on frac flowback attributes (flow rate vs. time and corresponding water analysis) is not readily available, as frac operators tend to keep their data proprietary and confidential. Nevertheless, relevant information on the flowback and produced waters in the Marcellus, Haynesville, Barnett, Fayetteville, and Woodford shales was acquired, albeit under non-disclosure agreements.

Flowback water is not a uniform "raw material" from a process development perspective. The physical and chemical properties of flowback water vary considerably depending on the geographic location of the shale play, the geological formation, and the chemicals introduced during the drilling and fracturing operations. Moreover, flowback volume and water properties vary throughout the lifetime of the well. The components in the flowback water of interest in this project are particulates $(>5 \mu \mathrm{m})$, suspended solids $(<5 \mu \mathrm{m}$, colloids), free oil, dissolved organics, volatile organics, hardness ions ( $\mathrm{Ca}, \mathrm{Mg}, \mathrm{Ba}$, $\mathrm{Sr}$, sulfates, carbonates), Fe, silica, and bacteria that may affect the product quality and/or the desalination membrane performance.

The flowback rate is highest initially and then decreases. Although there could be wide variation across geographical locations and due to operator bias, general flow profiles are shown below:

$\begin{array}{lcc}\text { Time } & \text { Flowback rate } & \text { Flowback recovery, \% frac fluid } \\ \text { 1-5 days: } & 100-150 \mathrm{bbl} / \mathrm{hr} & 10 \sim 25 \% \\ 5-15 \text { days: } & 20-60 \mathrm{bbl} / \mathrm{hr} & 8 \sim 12 \% \\ \text { 15-30 days } & 5-10 \mathrm{bbl} / \mathrm{hr} & 1 \sim 5 \% \\ 30-90 \text { days: } & 10 \mathrm{bbl} / \mathrm{day} & 1 \sim 2 \%\end{array}$

The overall flowback after 90 days is in the range of $15 \sim 40 \%$, but could be higher in certain wells.

Based on surveys of the TDS content of the flowback waters from the different shales, the team's present view on the extent of applicability of our low-TDS $(<40,000 \mathrm{ppm})$ recovery approach is as follows: In Fayetteville and Woodford, almost $90-100 \%$, since the flowback has generally $<40,000$ ppm TDS. In Barnett, by selectively directing the flowback from the first 5 days, $30-40 \%$ of the flowback may qualify as low-TDS, but recovery may not be considered at all since disposal via underground injection is readily and cheaply available. In Marcellus, overall only a small fraction $(<10 \%)$ of the flowback may be amenable to low-TDS recovery. However, $10-20 \%$ of the flowback may be amenable at certain locations with appropriate water management to isolate the first $3 \sim 5$ days of flowback water. In the Haynesville shale, due to the high TDS salinity and the availability of saline water disposal sites in East Texas, there is limited scope for membrane-based frac flowback recovery.

Frac flowback samples were obtained from wells in the Woodford shale in Oklahoma. These are daily samples from Day-1 through Day-14, along with two 55-gal drums of water samples from Day-1 and a composite of several daily samples. Another 55 -gal drum sample was obtained from the Day-26 flowback from another nearby well. These water samples were used in experiments for assessing pretreatment and membrane options.

Bench-scale experiments have been successful in identifying process technologies and associated operating conditions for the removal of key contaminants pursuant to the product quality specifications for the alternative Products-1, $-2,-3$ and -4 . However, removal of organic contaminants proved to be a greater challenge for frac flowback waters than anticipated. This was solved with use of a novel ultrafiltration membrane. A novel analysis technique developed by Hans Grade at GE Global Research that uses a 2-column gas chromatography (GC) method for separation of the components 
based on polarity and boiling point, followed by analysis with a Time of Flight Mass Spectrometer, was applied to understand the nature of organics in frac flowback water samples. This technique was found useful in providing a qualitative understanding of the effect of pretreatment methods on the presence and disappearance of organic compounds in the treated frac flowback waters.

For Products-3 and -4 that require RO membrane desalination, key membrane foulants, namely inorganic compounds that could physically precipitate inside the membrane module and inorganic and organic contaminants that could foul the membrane surface, were shown to be successfully removed in in these bench-scale experiments. For demonstration, RO membrane fouling experiments were conducted using commercially available 2" diameter spiral wound RO modules with 10 liters of pretreated Woodford Site-2 Day-26 35K ppm TDS flowback sample over 24 hours at 800 psig \& 25C. The water-flux and salt-rejection vs. time profiles for this run were identical to those for a similar run with a "control" solution of 35K ppm TDS NaCl in deionized water. This indicated the effectiveness of the down-selected pretreated conditions in removal of potential membrane foulants.

For Product-3 and Product-4, various membrane system configurations were evaluated and optimized via performance modeling with GE Winflows software to increase water product recovery. For a feed solution composition similar to that obtained after pretreating (lime softened and filtered) Site-2 Day26 sample, the identified configurations increased the recovery from $49 \%$ for a standard seawaterdesalination design to as high as $61.5 \%$. The maximum retentate concentration correspondingly increased from $68 \mathrm{~K} \mathrm{ppm}$ to $90 \mathrm{~K} \mathrm{ppm}$ TDS for these conditions. The increase in capital costs due to additional pumps, membrane modules, interconnected piping and controls for the new configuration were more than offset by the increased water recovery when the overall Flowback Water Recovery Process (FWRP) was considered.

Using the information from the bench-scale experiments for the various pretreatment steps, detailed conceptual flowsheets for the treatment processes were constructed for each of the Products 1-4 under consideration. These were evaluated for technical performance, costs and mobility for a 50 -gpm feed (frac flowback) mobile rig system. Technical performance evaluation included mass and energy balances, including waste generation and handling. Costs included capital expenses for equipment and assembly and operating expenses for amortization of capital equipment, rig transportation and labor for rig-setup, chemicals, membranes, power, and waste removal. The cost estimations were based on reliable values obtained either from vendors or internal cost information for the desired equipment. Mobility included the preliminary assessment of the rig configurations and footprint suitable to treat $50 \mathrm{gpm}$ of the frac flowback water.

The Treatment Cost target of $<\$ 2 / \mathrm{bbl}$ was satisfied for all product options, in line with preliminary feedback on customer expectations. For the 50-gpm mobile rig configuration, the "fixed" expenses (capital-related costs, rig transportation \& setup, maintenance) dominated the Treatment costs at $\sim 75 \%$ followed by chemicals \& solids waste disposal at $18 \%$, while the costs of replacement membranes and electrical power were only $2 \%$ and $5 \%$, respectively

A value-assessment cost model was developed for the overall FWRP for the Products $-3 \&-4$ that use RO membrane desalination to compare with the conventional disposal method. The conventional disposal cost included transportation of all flowback water and injection in Class II SWD wells while the FWRP cost included treatment costs, product delivery and remaining concentrate disposal (transport + SWD injection) costs. The sensitivities of the FWRP cost to prevailing concentrate disposal conditions




nomical "cut-off" TDS is defined as that feed TDS concentration when $\mathrm{C}_{\mathrm{FWRP}} / \mathrm{C}_{\text {conventional }}=1$. For Product4 (500 ppm TDS), this "cut-off" TDS is in the range of 20,000 ppm to 65,000 ppm depending on the local saline water disposal costs. These sensitivity charts thus provide a means of comparing the relative value of FWRP for a well flowback treatment opportunity based on prevailing disposal costs and anticipated flowback TDS levels. Note that the other drivers, such as penalty avoidance or cost incentives due to frac flowback re-use due to local regulations have not been considered. In some cases, these non-technical issues may be the economic driver for FWRP.

To increase the overall system water recovery, a Hybrid membrane + thermal system was also considered. In this approach, the retentate $(90,000$ ppm TDS) from the membrane system is further concentrated by distillation in a mobile evaporator (such as that introduced by GE Water recently22) to yield a distillate with $<500$ ppm TDS but more importantly, a concentrate with 280,000 ppm TDS. The Hybrid system yields higher recovery; for example, $85 \%$ for a feed with yF $=35,000$ ppm TDS vs. $61 \%$ for the membrane rig alone. However, the Hybrid process costs more than individual process options alone due to the high fixed costs for such small throughput $(50 \mathrm{gpm})$ systems. The sensitivity plots of

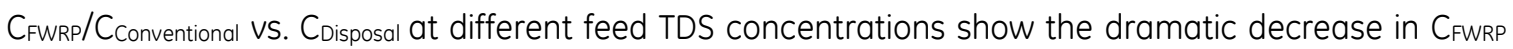
for the Hybrid due to increased water recovery. The Membrane alone case is more economical for the lower CDisposal cases mainly due to the lower overall capital costs. However, the Hybrid case becomes more economically attractive for the high CDisposal $(>\$ 5 / \mathrm{bbl}$ ) shale plays where local SWD sites are unavailable, thus leading to higher flowback water transportation costs for the conventional disposal method.

It is concluded that membrane systems in combination with appropriate pretreatment technologies can provide cost-effective recovery of low-TDS frac flowback water for either beneficial reuse in hydrofracturing or safe surface discharge. 


\section{Project Narrative}

\subsection{Project Objectives and Approach}

Two significant barriers to the development of many shale gas plays are water availability for drilling and hydrofracturing and disposal options for the water coproduced with gas ("frac flowback water"). In this project, GE Global Research (GEGR) evaluated technology that reduces the cost of treating flowback water for re-use in the hydrofracturing process.

The principal goal of this project was to define a mobile, cost-effective membrane-based process to treat low-TDS frac flowback water for re-use as hydrofracturing fluid. The TDS cutoff for consideration in this project is $<35,000 \sim 45,000 \mathrm{ppm}$, which is the typical limit for economic water recovery employing reverse osmosis (RO) type membrane desalination processes.

The conventional frac flowback water handling process, although quite complex in terms of the safety and operational logistics, is shown simplified for our purposes in Figure 1. The flowback water is directed to a separator to separate the water from the gas and the solid proppants. The flowback water is stored in interim storage tanks and then trucked to water disposal sites, typically Class II deep saline water disposal sites (SWD). At initial flowback rates, typically 100 150 bbl/hr, this translates to roughly one truck/hour for the first 5-10 days of flowback. This has implications for traffic, road infrastructure and noise pollution, as well as the loss of water from useful surface applications.

\section{Conventional Flowback Water Disposal Process}



$$
\mathrm{C}_{\text {Disposal }}=\mathrm{C}_{\text {Transport }}+\mathrm{C}_{\mathrm{swD}} \quad(\$ / \mathrm{bbl} \text { water) }
$$

Figure 1 Simplified frac flowback water handling and disposal operation at a shale gas well site.

A conceptual process considered in this project for recovering all or part of the flowback water for re-use in hydrofracturing operations is shown in Figure 2. The flowback water recovery process (FWRP) is desired to be located physically close to the well operations to minimize water hauling costs. It includes a mobile unit equipped with the necessary treatment operations to provide "product" water that meets specifications for re-use in hydrofracturing. Only 
a portion of the flowback water may be recovered as product, while the rest may have to be disposed of either in conventional saline water disposal Class II wells or via further recovery by methods suitable for desalination of high-TDS waters (> 80,000ppm), such as thermal processes.

\section{Flowback Water Recovery Process for Frac Re-use}



Figure 2. Conceptual Flowback Water Recovery Process (FWRP) for re-use in hydrofracturing.

The overall cost will depend on the extent of water recovery, $x$, in the FWRP.

The chief benefits are greatly reduced fresh water consumption, up to $50 \%$ less watertransportation related traffic on roads, reduced water disposal costs, and a greatly reduced impact on the environment.

\section{Budget}

\begin{tabular}{|c|c|c|c|}
\hline Budget Periods & $\begin{array}{l}\text { Government } \\
\text { Funding }\end{array}$ & $\begin{array}{c}\text { GE GRC } \\
\text { costshare } \\
\text { amount }\end{array}$ & Total costs \\
\hline $10 / 1 / 2009-9-30-2010$ & 628.075 & 157.019 & $\begin{array}{ll}5 & 785.094 \\
\end{array}$ \\
\hline $10 / 1 / 2010-3 / 31 / 2011$ & 152,769 & 38,192 & $5 \quad 190,961$ \\
\hline TOTALS & 780,844 & 195.211 & S 976.055 \\
\hline
\end{tabular}




\begin{tabular}{|c|c|c|c|c|c|c|c|c|c|c|c|c|}
\hline \multirow{5}{*}{$\begin{array}{l}\text { Baseline Reporting } \\
\text { Quarter }\end{array}$} & \multirow{2}{*}{\multicolumn{8}{|c|}{$\frac{\text { COST PLAN/STATUS }}{\text { Year } 1}$}} & \multirow{2}{*}{\multicolumn{4}{|c|}{ Year 2}} \\
\hline & \multirow{2}{*}{\multicolumn{2}{|c|}{ Q1 }} & & & $\operatorname{ar} 1$ & & & & & & & \\
\hline & & & \multicolumn{2}{|c|}{ Q2 } & \multicolumn{2}{|c|}{ Q3 } & \multicolumn{2}{|c|}{ Q4 } & \multicolumn{2}{|c|}{ Q1 } & \multicolumn{2}{|c|}{ Q2 } \\
\hline & \multicolumn{2}{|c|}{ 10/1/'09 - 12/31/'09 } & \multicolumn{2}{|c|}{$1 / 1 / ' 10-3 / 31 / ' 10$} & \multicolumn{2}{|c|}{$4 / 1 / ' 10-6 / 30 / / 10$} & \multicolumn{2}{|c|}{$7 / 1 / ' 10-9 / 30 /{ }^{\prime} 10$} & \multicolumn{2}{|c|}{$10 / 1 / ' 10-12 / 31 / ' 10$} & \multicolumn{2}{|c|}{$1 / 1 / ' 11-3 / 31 / ' 11$} \\
\hline & Q1 & Total & Q2 & Total & Q3 & Total & Q4 & Total & Q1 & Total & Q2 & Total \\
\hline \multicolumn{13}{|l|}{ Baseline Cost Plan } \\
\hline Federal Share & 131,587 & 131,587 & 132,825 & 264,412 & 179,065 & 443,477 & 184,598 & 628,075 & 76,560 & 704,635 & 76,209 & 780,844 \\
\hline Non-Federal Share & 32,897 & 32,897 & 33,206 & 66,103 & 44,766 & 110,869 & 46,150 & 157,019 & 19,140 & 176,159 & 19,052 & 195,211 \\
\hline Total Planned & 164,484 & 164,484 & 166,031 & 330,515 & 223,831 & 554,346 & 230,748 & 785,094 & 95,700 & 880,794 & 95,261 & 976,055 \\
\hline \multicolumn{13}{|l|}{ Actual Incurred Costs } \\
\hline Federal Share & 68,328 & 68,328 & 163,173 & 231,500 & 149,290 & 380,791 & 97508 & 478,299 & 104,443 & 582,742 & 145,448 & 728,190 \\
\hline Non-Federal Share & 17,082 & 17,082 & 40,793 & 57,875 & 37,323 & 95,198 & 24377 & 119,575 & 26,111 & 145,685 & 36,362 & 182,047 \\
\hline Total Incurred Costs & 85,410 & 85,410 & 203,966 & 289,375 & 186,613 & 475,988 & 121,885 & 597,873 & 130,554 & 728,427 & 181,810 & 910,237 \\
\hline \multicolumn{13}{|l|}{ Variance } \\
\hline Federal Share & $(63,260)$ & $(63,260)$ & 30,348 & $(32,912)$ & $(29,775)$ & $(62,686)$ & $(87,090)$ & $(149,777)$ & 27,883 & $(121,894)$ & 69,239 & $(52,654)$ \\
\hline Non-Federal Share & $(15,815)$ & $(15,815)$ & 7,587 & $(8,228)$ & $(7,444)$ & $(15,672)$ & $(21,773)$ & $(37,444)$ & 6,971 & $(30,473)$ & 17,310 & $(13,164)$ \\
\hline Total Variance & $(79,074)$ & $(79,074)$ & 37,935 & $(41,140)$ & $(37,218)$ & $(78,358)$ & $(108,863)$ & $(187,221)$ & 34,854 & $(152,367)$ & 86,549 & $(65,818)$ \\
\hline
\end{tabular}

Total funding for this program was approximately $\$ 1$ MM including a 20\% cost share contributed by GE Global Research, as seen in Table 1. Quarterly variances in spending were due to initial non-availability of frac flowback water samples. However, these mismatches were fully accounted for by the end of the program. Table 1 indicates that the program was underspent by $\$ 65 \mathrm{~K}$ at the end of March 2011. However, final report and report-out is anticipated to bring this number to about $\$ 20 \mathrm{~K}$ which is within $2 \%$ of the original budget amount.

This project was organized into six interrelated tasks including:

- Project Management Plan

- Obtain flowback attributes (flow rate and composition profiles vs. time) and define specifications for water re-use

- Define conceptual process alternatives for low-TDS water recovery for re-use

- Evaluate key pretreatment and membrane processes in bench-scale experiments

- Obtain bench-scale experimental data suitable for process modeling

- Develop system performance and cost models for a mobile rig configuration of the downselected process to determine the commercial feasibility of the overall process for low-TDS flowback water recovery for reuse.

The project timeline and a task interrelationship chart summarizing the logic that connects the various tasks are shown in Figure 3 and Figure 4. 


\begin{tabular}{|c|c|c|c|c|c|c|c|}
\hline \multirow{3}{*}{\multicolumn{2}{|c|}{ Program Activities }} & \multicolumn{6}{|c|}{$\begin{array}{c}\text { Project Duration } \\
\text { Start: October } 12009 \\
\text { End: March } 312011\end{array}$} \\
\hline & & \multicolumn{4}{|c|}{ PY1 } & \multicolumn{2}{|c|}{ PY2 } \\
\hline & & Q1 & Q2 & Q3 & Q4 & Q1 & Q2 \\
\hline \multicolumn{2}{|c|}{ Task 1: Project Management Plan } & ב & & & & & \\
\hline Milestone: & :Updated Project Management Plan completed & $\mathbf{A}$ & & & & & \\
\hline \multirow[t]{2}{*}{ Deliverables: } & Technology Status Summary & $\mathrm{O}$ & & & & & \\
\hline & Quarterly, annual, and final reports. & Q & & C & & & \\
\hline \multicolumn{8}{|c|}{ Task 2: Obtain Flowback Attributes and Define Feed \& Product Specs for water re-use } \\
\hline \multirow[t]{3}{*}{ Milestones: } & $\begin{array}{l}\text { Frac flowback water flowrate \& composition profiles for } 1 \text { or } 2 \text { shale-gas sites } \\
\text { available }\end{array}$ & & & & & & \\
\hline & Specifications for recovered water for re-use as frac water obtained. & & & & & & \\
\hline & Field water samples for bench-scale testing acquired & & & & & & \\
\hline \multicolumn{8}{|c|}{ Task 3: Define conceptual process alternatives for low-TDS water recovery } \\
\hline \multirow[t]{3}{*}{ Milestones: } & $\begin{array}{l}\text { Potential membrane processes with associated pretreatment technologies } \\
\text { identified }\end{array}$ & & & & & & \\
\hline & Preliminary process and cost models for alternatives developed & & & & & & \\
\hline & Range of cost estimates for low-TDS water recovery completed & & & & & & \\
\hline \multicolumn{8}{|c|}{\begin{tabular}{|c|} 
Decision Point: \\
$\begin{array}{l}\text { Go/no-go decision on Low-TDS frac water recovery feasibility (based on } \\
\text { performance/cost assumptions) }\end{array}$ \\
Task 4: Evaluate key Pretreatment \& Membrane Processes in bench-scale experiments
\end{tabular}} \\
\hline \multicolumn{8}{|c|}{ Task 4: Evaluate key Pretreatment \& Membrane Processes in bench-scale experiments } \\
\hline \multirow[t]{3}{*}{ Milestones: } & $\begin{array}{l}\text { Pretreatment: test setup, validation and testing with field flowback water } \\
\text { samples }\end{array}$ & & & & & & \\
\hline & $\begin{array}{l}\text { Membrane: test setup, validation and initial testing with field flowback water } \\
\text { samples }\end{array}$ & & & & & & \\
\hline & $\begin{array}{l}\text { Key known membrane foulants in frac flowback water identified and } \\
\text { successfully removed }\end{array}$ & & & & & & \\
\hline Decision Point: & $\begin{array}{l}\text { Go/no-go decision based on preliminary cost estimates of effective } \\
\text { pretreatment process }\end{array}$ & & & & & & \\
\hline \multicolumn{8}{|c|}{ Task 5: Obtain bench-scale experimental data suitable for process modeling } \\
\hline Milestone: & $\begin{array}{l}\text { Experimental data for key pretreatment and membrane processes with field } \\
\text { frac flowback water }\end{array}$ & & & & & & $\mathbf{\Delta}$ \\
\hline \multicolumn{2}{|c|}{ Task 6: Develop system performance and cost models } & ᄃ & & & & & \\
\hline \multirow[t]{4}{*}{ Milestones: } & $\begin{array}{l}\text { Detailed process configuration modeling for low-TDS water recovery based on } \\
\text { bench-scale experimental data. }\end{array}$ & & & & & & \\
\hline & $\begin{array}{l}\text { Technical feasibility of low-TDS frac flowback recovery process to produce } \\
\text { water for frac re-use }\end{array}$ & & & & & & \\
\hline & $\begin{array}{l}\text { Cost modeling for mobile unit with technically feasible process for low-TDS flow } \\
\text { back water recovery }\end{array}$ & & & & & & \\
\hline & $\begin{array}{l}\text { Determination of "cut-off" point for low-TDS water recovery process for } \\
\text { commercial shale-gas drilling operations. }\end{array}$ & & & & & & \\
\hline Deliverable: & $\begin{array}{l}\text { Technical report summarizing downselected low-TDS frac water recovery } \\
\text { system configuration and cost estimate including supporting bench-scale } \\
\text { experimental data }\end{array}$ & & & & & & O \\
\hline Decision Point: & $\begin{array}{l}\text { Go/no-go decision on final process configuration to meet performance and cost } \\
\text { targets }\end{array}$ & & & & & & \\
\hline
\end{tabular}

Legend: $O$ Deliverable $\quad$ Milestoneal Path Milestone

Figure 3. Schedule and milestones for the program. 
Task2 -Obtain flowback attributes and define Feed \& Product Specs for water reuse

- Frac flowback water profiles from 1 or 2 shale-gas sites

- Specifications for recovered water for reuse as frac water

- Field water samples for bench-scale testing

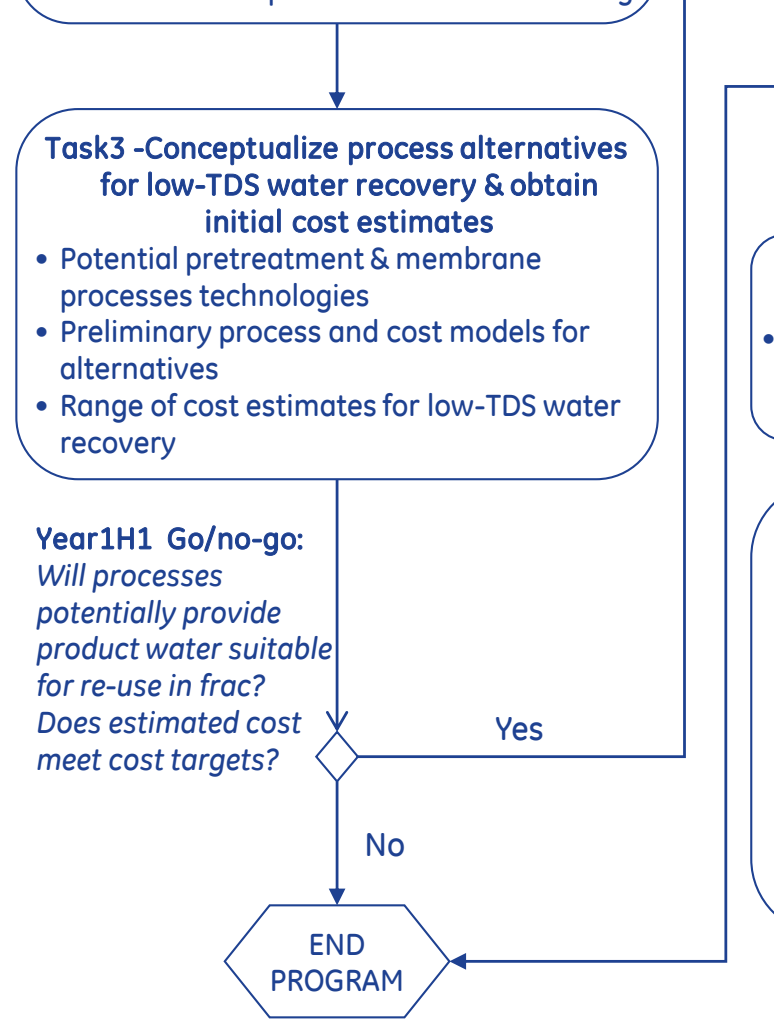

Task4 -Evaluate downselected pretreatment \& membrane processes in bench-scale experiments

- Pretreatment: test setup and testing with field flowback water

- Membrane: test setup and testing with field

flowback water

- Key known membrane foulants identified and successfully removed

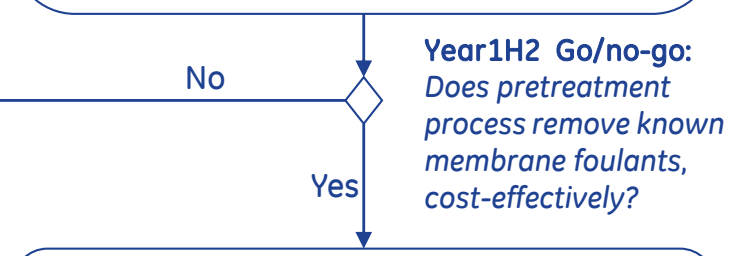

Task5 -Obtain bench-scale experimental data suitable for process modeling

- Experimental data for key pretreatment and membrane processes with field frac flowback water

Task6 -Develop system performance and cost models of low-TDS frac flowback recovery process for re-use in frac

- Detailed process modeling based on benchscale experimental data

- Technical feasibility analysis

- Cost model for mobile unit with technically feasible process

- Determination of "cut-off" point for low-TDS water recovery process for commercial shalegas drilling operations

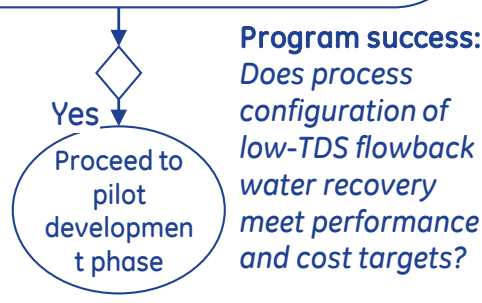

Figure 4. Task interrelationships and Go/No-go decisions. 


\section{Results and Discussions}

\subsection{Task 1: Project management}

This program delivered 5 technical progress reports, one at the end of each quarter of this project. A Technology Status Assessment analyzing the most advanced examples of the proposed technology was completed and a report was issued. In addition, at the end of budget period (BP) 1 an annual report on project accomplishments for continuation of funding was submitted. The team presented work done for the project at the 2010 Ground Water Protection Council Annual Meeting, Pittsburgh, PA, Sep 26-281 and the Canadian Society of Unconventional Gas Water Workshop, April 20, 20112. Additionally, presentations were made to potential customers to educate and highlight potential solutions to frac flowback and produced water recovery.

\subsection{Task 2: Obtain Flowback Attributes and Define Specifications for Water Re-use}

\subsubsection{Objectives and Approach}

The specific objectives of this task were to:

- Understand frac flowback operations and estimate the amount of flowback that qualifies as "low-TDS" water suitable for recovery via membrane processes

- Define performance and cost specifications, and develop the verification of success criteria for assessing the water recovery processes considered in this project.

The key activities were to:

- Obtain frac flowback water attributes (composition and flow rate profiles over time)

- Obtain specifications for "product" water that would be re-used for hydrofracturing.

We reviewed information published in open literature, discussed with frac operators, and visited a frac flowback site to get a better understanding of the actual operation logistics.

There have been several barriers to obtaining reliable information on the water chemistry used for hydrofracturing, flowback attributes, and specifications for the re-use water, including:

- The water chemistry used for hydrofracturing depends on the geology of the shale formation and the technology bias/experience of the operator. Thus, there could be variation in the water chemistry between different shales, within different sites within the same shale and between different services companies operating in the same shale. Moreover, the methods used for hydrofracturing are being continuously updated as the industry tries to optimize operations to maximize gas recovery while minimizing energy and especially, fresh water usage ${ }^{3}$. For example, current research 
on new slicking agents (friction reducers) may allow the use of higher salinity in the feed water compared to present operations.

- Information on frac flowback attributes (flow rate vs. time and corresponding water analysis) is not readily available, as frac operators tend to keep their data proprietary and confidential. There is very limited published data on the flowback attributes for the various shales.

- Opinions vary widely on the water quality that may be used for hydro-fracturing. For instance, some of the operators insist on using very low-TDS source water to avoid scaling issues in the downhole piping, while others, such as Range Resources, have reported some success in using a 26,000 ppm Chlorides water feed in the Marcellus shale ${ }^{4}$. Some experts feel that water salinity equivalent to seawater, namely $\sim 35,000$ ppm TDS may be usable for hydrofracturing ${ }^{5}$. Some operators are considering the use of even salinity as high as 120,000 ppm TDS with low hardness and scale-causing contaminants ${ }^{6}$. As a practical matter, the relative costs for drilling and hydrofracturing a well are in the neighborhood of $\$ 1$ million each, while water costs for 100,000 bbls, when available, are in the neighborhood of $\$ 25,000$. The risks associated with scaling and well-plugging due to "unclean" water used for hydrofracturing may not be tolerable to many operators. Hence, it appears that the move towards higher TDS water used to stimulate gas wells is being driven by state and regional water availability, the logistics of flowback water transportation and disposal costs, and also the desire to mitigate negative public perception about water use for hydrofracturing and groundwater pollution.

- Regulations are being considered by various federal and state agencies on the disclosure of chemistry used for the hydrofracturing process, discharge of flowback water, and the re-use of flowback water for hydrofracturing. Until the regulations are finalized, there will be uncertainty on the specifications for the treated water and discharge water. This affects the determination of how much of the flowback water would qualify as "low-TDS" suitable for membrane treatment, the choices of technology options useful to treat the frac flowback water to meet the technical specifications, and the overall system cost.

The conclusion from our survey was that the specification for acceptable re-use is subject to change in the short-term depending on technology advances that are continuously occurring, operator experience and confidence, and upcoming regulations regarding discharge and re-use.

Nevertheless, we were able to find relevant information on the flowback and produced waters in the Marcellus, Haynesville, Barnett, Fayetteville and Woodford shales. Some of this data was acquired under non-disclosure agreements and will only be summarized as appropriate in the following sections. 


\subsubsection{Water usage in shale gas exploration}

The main uses for water in deep shale exploration are:

- Drilling, where a mixture of clay and water is used to carry rock cuttings to the surface, as well as to cool and lubricate the drill bit.

- Hydrofracturing (or "frac"), where a mixture of water and sand is injected into the deep shale at a high pressure to create small cracks in the rock and allow gas to freely flow to the surface.

Typical average usage of water for drilling and frac operations for the Barnett, Fayetteville, Haynesville and Marcellus shales, as estimated by Chesapeake Energy Company ${ }^{7}$ are shown in Table 1.

Table 1. Water usage (average) per well and water requirements for the various shale plays las estimated by Chesapeake Energy ${ }^{7}$ )

\begin{tabular}{|c|c|c|c|c|c|}
\hline & \multicolumn{3}{|c|}{ Water used (average), bbls/well } & \multirow{2}{*}{ Wells/year } & \multirow{2}{*}{$\begin{array}{c}\text { Water } \\
\text { MM bbls/year }\end{array}$} \\
\hline & Drilling & Fracturing & Total & & \\
\hline Barnett & 10,000 & 70,000 & 80,000 & 600 & 48 \\
\hline Fayetteville & 1,500 & 70,000 & 71,500 & 250 & 18 \\
\hline Haynesville & 25,000 & 65,000 & 90,000 & 200 & 18 \\
\hline Marcellus & 2,000 & 90,000 & 92,000 & 600 & 55 \\
\hline
\end{tabular}

According to Chesapeake Energy, a deep shale gas well will produce between 2 and 6.5 Bcf (billion cubic feet) over its lifetime. Thus, the amount of water used to produce the gas equates to about 0.8 to 1.7 gallons/MMBTU or 19 to 40 bbls water/MMcf of gas lassuming $1,000 \mathrm{scf}$ of gas is equivalent to 1 MMBTU of energy) 8 .

\subsubsection{Definitions of various fluids used in shale gas exploration - Fracturing, Flowback/ Produced waters}

The fluid that is used to stimulate the shale gas formation during hydrofracturing is generally referred to as "Fracturing Fluid" or "Completion Fluid". The fluid that flows back after a hydrofracturing operation is referred to either as "flowback" water or "produced" water. There is some confusion on the strict definitions and differences between the two terms. In conventional oil \& natural gas fields and in coal bed methane reservoirs, there is an excess of water in the formation that comes up to the surface during oil and gas production. This water has traditionally been referred to as "produced water". In fact, during oil production, it is estimated that approximately 7 bbls of water are produced for every bbl of oil ${ }^{9}$. However, in shale gas exploration, typically, most of the water that flows back is the water that was fed during the hydrofracturing operation.

According to Horn ${ }^{10}$, when the flowback volume reaches $100 \%$ of the fracturing fluid volume, it is then subsequently referred to as "produced water". However, our survey ${ }^{11}$ of gas pro- 
ducers appears to indicate that the rationale for referring to the water as "flowback" or "produced" could be any of the following:

1. Financial: Water produced during the well completion stage is defined as flowback and the associated costs are part of the well completion budget. When the well is considered to be under "gas production" the water is called "produced", and the associated costs are part of the "operating" budget.

2. Time: Some companies use a time factor, for example 30 days as the demarcation between "flowback" and "produced". Typically, the flow rate has dropped off significantly during this period.

3. Volume: Some producers differentiate based on how much they get back as a percent of fracturing fluid put down into the well. It may be $100 \%$ as per the definition provided by Horn ${ }^{10}$ or less, as per the operator's choice. However, in shale gas wells, the overall water flowback could be $<50 \%$ of the fracturing fluid used, typically only $25-35 \%$ in the first 30 days.

It appears that the financial reason appears to be the most commonly used definition to differentiate between "flowback" and "produced" waters.

In any case, for shale gas wells, from a flow rate perspective, the flow rates during the "flowback" phase are significantly larger (by 10-100x) than in the "produced" phase. From a chemical perspective, the produced water has higher concentrations of the various minerals because of the greater residence downhole, whereas the flowback water may contain higher amounts of suspended solids, oils, fuels and chemicals associated with the drilling and hydrofracturing operations. However, for some shales, the chemical characteristics during the flowback phase may have already approached those at the produced phase of the operation (depending on the definition chosen by the operator).

In this report we do not differentiate between the two definitions and refer to all returning water after a hydrofracturing event as "flowback" for evaluation of our recovery process options.

\subsubsection{Water Chemistry of the fracturing fluids used for shale gas exploration}

It is important to know the composition of the fluid used for drilling and hydrofracturing since

the flowback water may contain some or all of these chemicals besides the contaminants from the soil and shale layers.

Drilling fluids:

The composition of the drilling fluids used depends on the geology of the shale formation and the technology bias/experience of the operator. Most of the information is held proprietary and confidential. However, a good summary of the various components is provided at the 
DOE NETL website ${ }^{12}$. Relevant information for this project is summarized in Appendix A. From the flowback water treatment perspective, the key components that could be considered as contaminants during recovery are:

- "oil" in the oil-based muds. These are most likely diesel. In fact, the Day-1 sample of flowback water obtained by the team has a diesel-like odor. Apparently, at some locations, after drilling, the equipment are cleaned with diesel, although this practice may be discontinued in the future ${ }^{13}$.

- olefins, esters, linear alpha-olefins, poly alpha-olefins, linear paraffins, etc. in the synthetic-based muds, if used.

Frac fluids:

Fracturing fluids used for fracturing gas shales include a variety of additive components, each with an engineered purpose to facilitate fractures and the production of gas ${ }^{3}$ (see Appendix for details). Currently, the trends in shale wells are to use water based or mixed slickwater-fracturing fluids. These are water-based fluids mixed with friction reducing additives ${ }^{14}$, which allows a fracturing fluid and proppant to be pumped to the target zone at a higher rate and reduced pressure than by using water alone. In addition, other additives including biocides are utilized to prevent micro-organism growth and to reduce bio-fouling of fractures. Of particular concern are the sulfate reducing bacteria (SRB) as they reduce sulfate ions to hydrogen sulfide; H2S causes corrosion in the downhole pipeline and at higher concentrations (> 4 ppmv) may cause sourness issues with the sales gas. Oxygen scavengers and other stabilizers which prevent corrosion of metal pipes and acids which are used to remove drilling mud damage near the wellbore area are also common either in fracturing fluids or as part of fracture treatments.

Details of the various components in the hydrofracturing fluid are provided in Appendix. From the flowback water treatment perspective, although it is expected that some or all of these additives may be expected in the flowback, no literature reports confirming the presence and concentrations of these additives could be found. It is likely that these compounds may get chemically, physically or microbiologically altered or destroyed during the hydrofracturing process or become lost in the shale formation. Although some of these additives, such as guar gel, polyacrylamides, and petroleum distillates, may affect membrane performance, the actual impact would have to be experimentally determined with flowback water samples.

\subsubsection{Flowback Attributes}

Information on frac flowback attributes (flow rate vs. time and corresponding water analysis) is not readily available, as frac operators tend to keep their data proprietary and confidential. There is very limited published data on the flowback attributes for the various shales. Nevertheless, we were able to find relevant information on the flowback \& produced water attributes for the Marcellus, Haynesville, Barnett, Fayetteville and Woodford shales. Most of this 
data was acquired under non-disclosure agreements and will only be summarized, as appropriate in the following sections.

\section{Flowback Flow rates}

For the Marcellus shale, Gaudlip 4 has reported flowback volumes over a period of 14 days for a few wells, as reproduced in Figure 5.



Figure 5. Flowback from a few wells in the Marcellus shale (Gaudlip et al).

We make the following observations:

- The \% recovery, i.e. the volume of water that flows back as a $\%$ of the fracturing fluid fed during the hydrofracturing process is between $19 \%$ to $29 \%$ at the 14 -day mark. A general rule of thumb is that $\sim 25 \%$ recovery is the expected norm in the Marcellus shale during the initial phase of the flowback, generally regarded as the first 30 days ${ }^{11}$.

- The flowback rate is highest initially and then decreases. This is illustrated in Figure 6. For the first few days, the flow rates could be in the high range of 2,500 to 6,000 bbls/day (or $\sim 100 \mathrm{bbls} / \mathrm{hr}$ to $250 \mathrm{bbls} / \mathrm{hr}$ ). There is a significant drop off in the flow rate at or near the 10 day mark to $\sim 1000 \mathrm{bbl} /$ day (or $\sim 40 \mathrm{bbl} / \mathrm{hr}$ ), and another significant drop at the 30 day mark to $\sim 100-150 \mathrm{bbl} /$ day (or 4 to $6 \mathrm{bbl} / \mathrm{hr}$ ). Beyond the 50 day mark, the flow rates are between 5 to $100 \mathrm{bbl} /$ day but mostly $10 \mathrm{bbl} /$ day (or 0.4 $\mathrm{bbl} / \mathrm{hr})$. 




Figure 6 Flow rates vs. Flowback time for a few wells in the Marcellus shale (Gaudlip ${ }^{4}$ ). Blue points refer to "Flowback" and the red points refer to "Produced".

Horn ${ }^{10}$ has reported flowback attributes for a Woodford shale site. Their flow rate data is replotted in Figure 7. We again observe that the flow rate was $\sim 150 \mathrm{bbl} / \mathrm{hr}$ for the first 3 days and then decreased with time. At the 10-day mark, the flow rate was $\sim 50 \mathrm{bbl} / \mathrm{hr}$. In this case, at the 14-day mark, only $\sim 34 \%$ of the $\sim 95,000$ barrels used for hydrofracturing had been recovered.

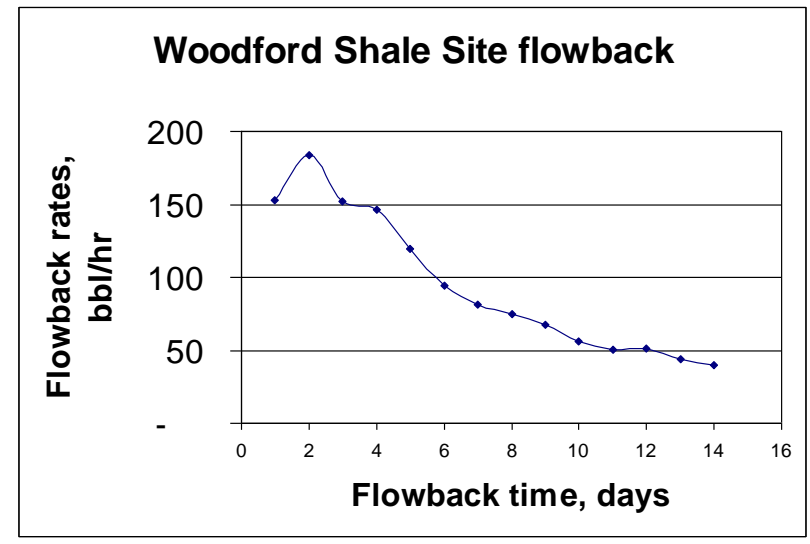

Figure 7. Flowback rate vs. time for a Woodford shale (re-plotted from the data shown in Horn ${ }^{10}$ ). 
In Figure 8, typical flowrates for the Woodford that were shared by a customer are shown. We see that the flowrate profiles for two of the wells are similar as in Figure 7 while the flowrate decreases rapidly for one of the wells.

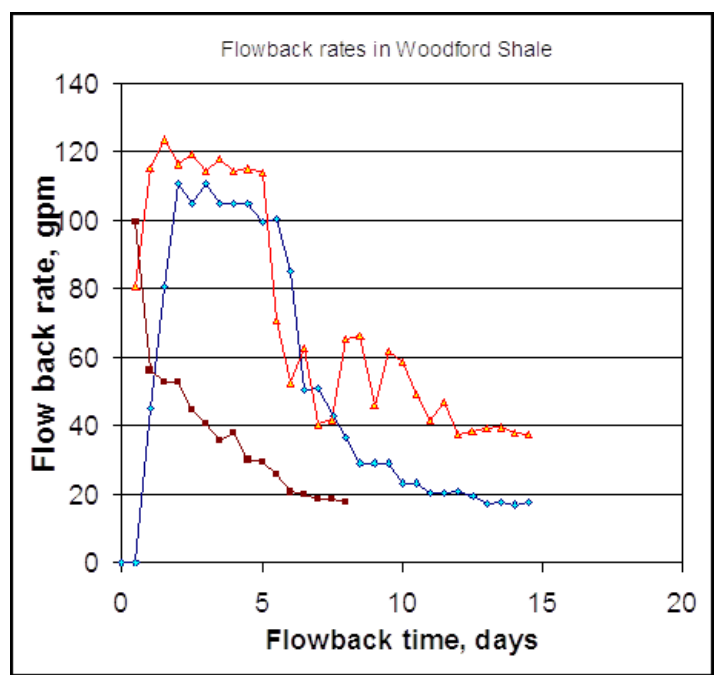

Figure 8. Flowrate profiles for frac flowback from three Woodford shales.

Flowback Composition

For the Marcellus shale, the flowback compositions for a few sites have been reported by Gaudlip ${ }^{4}$. The composition of a flowback sample from a Marcellus shale site is reproduced in Figure 9.

\begin{tabular}{|c|c|}
\hline Catlons & $\mathrm{mg} / \mathrm{L}$ \\
\hline Calcium $\left(\mathrm{Ca}^{2+}\right)$ & 20,463 \\
\hline Magnesium $\left(\mathrm{Mg}^{2+}\right)$ & 1,987 \\
\hline Sodium $\left(\mathrm{Na}^{+}\right)$ & 37,063 \\
\hline Iron $\left(\mathrm{Fe}^{2+}\right)$ & 143 \\
\hline Potassium $\left(\mathrm{K}^{+}\right)$ & 296 \\
\hline Barium $\left(\mathrm{Ba}^{2+}\right)$ & 203 \\
\hline Strontium $\left(\mathrm{Sr}^{2+}\right)$ & 2,243 \\
\hline Manganese $\left(\mathrm{Mn}^{2+}\right)$ & 43 \\
\hline Anlons & $\mathrm{mg} / \mathrm{L}$ \\
\hline Bicarbonate $\left(\mathrm{HCO}_{3}{ }^{-}\right)$ & 100 \\
\hline Sulfate $\left(\mathrm{SO}_{4}{ }^{-}\right)$ & 8 \\
\hline Chloride $\left(\mathrm{Cl}^{-}\right)$ & 97,084 \\
\hline & $\mathrm{mg} / \mathrm{L}$ \\
\hline TDS & 159,541 \\
\hline Gases & $\mathrm{mg} / \mathrm{l}$ \\
\hline Carbon Dioxide $\left(\mathrm{CO}_{2}\right)$ & 481 \\
\hline Hydrogen Sulfide $\left(\mathrm{H}_{2} \mathrm{~S}\right)$ & 2 \\
\hline
\end{tabular}

Figure 9. Composition of a flowback sample from a Marcellus shale site (reproduced from Gaudlip 4 . 
Although the TDS of $\sim 160 \mathrm{~K} \mathrm{ppm}$ of this particular sample is too high for any reverse-osmosis membrane based recovery processes, there are some interesting observations to be made, as described below.

- The chlorides concentration at $~ 97 \mathrm{~K} \mathrm{ppm} \mathrm{make} \mathrm{up} 60.6 \mathrm{wt} \%$ of the TDS. Interestingly, this value is remarkably close to the value of $60.8 \mathrm{wt} \%$ that we would obtain if we assume that the TDS were entirely due to $\mathrm{NaCl}$ (based on the ratio of molecular weights, $\mathrm{Mcl} / \mathrm{M}_{\mathrm{NaCl}}=35.5 / 58.5=0.608$ ). However, note that the $\mathrm{Na}$ content in Figure 4 corresponds to only $23.2 \mathrm{wt} \%$ in the flowback sample vs. $39.2 \mathrm{wt} \%$ in pure $\mathrm{NaCl}$.

- The concentration of the "hardness" ions (divalents - $\mathrm{Ca}, \mathrm{Mg}, \mathrm{Ba}, \mathrm{Sr}$ ) correspond to $\sim 56 \mathrm{~K}$ ppm when reported on a $\mathrm{CaCO} 3$ basis. The ratio of Hardness (CaCO3 ba$\mathrm{sis} / / \mathrm{TDS}=56 \mathrm{~K} / 160 \mathrm{~K} \sim 0.35$. This value is in close agreement with several other data that we have examined for the Marcellus shale. This ratio varies amongst different shales with values ranging from 0.2 to 0.35 depending on downhole soil conditions and the composition of the water used for hydrofracturing.

- The source of potassium is perhaps from $\mathrm{KCl}$ added to the fracturing fluid during hydrofracturing. So, it may be desirable to retain it in the product water for frac re-use.

- The Sulfates concentration is low at $~ 8 \mathrm{ppm}$. This is not surprising since the Ba and Sr concentrations are so high at 203 and 2243 ppm, respectively. This also implies that most of the divalents and trivalent ions are present in the form of chlorides that have higher solubilities in water in relation to $\mathrm{NaCl}$.

- The Fe content of 143 ppm may be too high for re-use, especially since it is in the Fe ${ }^{2+}$ state, which may potentially get oxidized and form undesired precipitates that could cause scaling.

Gaudlip 4 has also reported on the variation of chloride concentration in the flowback as a function of flowback time, as reproduced in Figure 10. From our general observation noted earlier of the relationship between $\mathrm{Cl}$ and TDS in flowback waters, we may obtain a rough estimate of the TDS by dividing the $\mathrm{Cl}$ values by 0.61 . From Figure 10, we note that in the Marcellus shale, the $\mathrm{Cl}$ values rise quickly, as follows:

$\begin{array}{llr} & \text { Cl, ppm } & \text { Estimated TDS, ppm } \\ \text { Day 5: } & \text { 20K to } 70 \mathrm{~K} & 33 \mathrm{~K} \text { to } 115 \mathrm{~K} \\ \text { Day 10: } & 40 \mathrm{~K} \text { to } 90 \mathrm{~K} & 66 \mathrm{~K} \text { to } 148 \mathrm{~K} \\ \text { Day 15: } & 55 \mathrm{~K} \text { to } 110 \mathrm{~K} & 90 \mathrm{~K} \text { to } 180 \mathrm{~K}\end{array}$

From the above data, we observe that the "low-TDS" water recovery processes $<45,000 \mathrm{ppm}$ TDS in flowback) may have limited applications in the Marcellus shale play. However, we observe from composition data obtained from elsewhere in the Marcellus shale play from con- 
fidential sources, that $10-20 \%$ of the flowback may be amenable at certain locations with appropriate water management to isolate the first $<3 \sim 5$ days of flowback water.



Figure 10. Variation of flowback composition with time for a Marcellus shale site (reproduced from Gaudlip)

For a Haynesville shale site, Kaufman et al ${ }^{15}$ have described the flowback composition. The data for the sulfates and $\mathrm{Ba} / \mathrm{Sr}$ compositions plotted as a function of the cumulative flowback volume are reproduced in Figure 11. We observe a sharp transition at $\sim 11,000$ bbls when the $\mathrm{Ba} / \mathrm{Sr}$ concentrations increase to cause a precipitous drop in Sulfate concentrations.

\section{Sulfates and Barium/Strontium}



Figure 11. Variation of Sulfates and Ba/Sr concentrations as a function of flowback volume for a Haynesville shale 
For the Woodford shale, Total Dissolved Solids (TDS) concentration profiles for a few wells are shown in Figure 12. We observe that the concentrations increase from nearly zero initially to between 15,000 ppm to 35,000 ppm over the next 15 days.

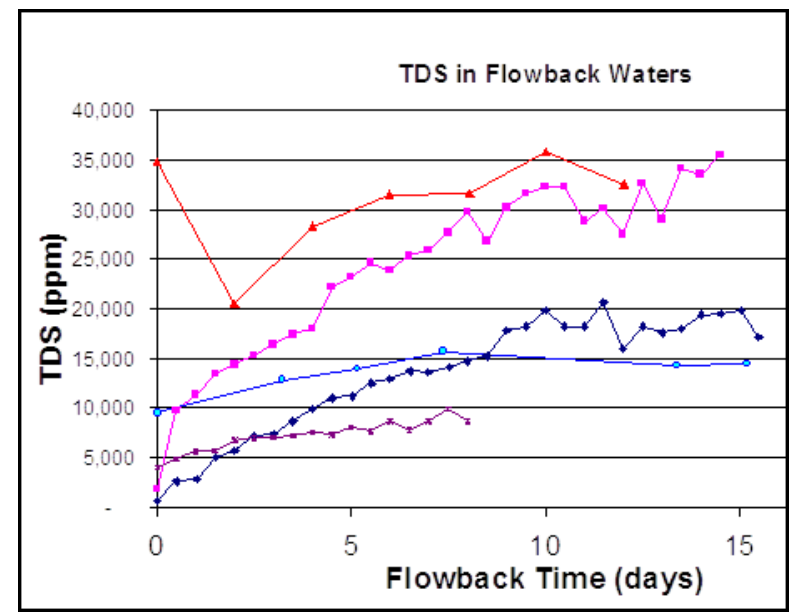

Figure 12. Total Dissolved Solids (TDS) concentration profiles for flowback waters from a few Woodford shale wells

\subsubsection{Summary of the flowback attributes}

Flowback water is not a uniform "raw material" from a process development perspective. The physical and chemical properties of flowback water vary considerably depending on the geographic location of the shale play, the geological formation, and the chemicals introduced during the drilling and fracturing operations. Flowback volume and water properties vary throughout the lifetime of the well.

\subsubsection{Flowback volumes amenable to "Low-TDS" membrane-recovery}

Flowback waters with composition in the $<45,000$ ppm range are highly amenable for economic recovery using $R O$-based membrane recovery systems.

The initial flowback typically has low enough salinity to qualify for recovery via the methods that were investigated in this project. However, as noted earlier, the TDS levels increase with flowback volume, and the rate of increase depends on the shale formation, the TDS of the water used for hydrofracturing, etc. Based on our survey of available literature information, the salinity ranges of the flowback waters from the various shales are shown in Table 2 . The average values represent a combined mean for flowback from a well while the maximum could be an instantaneous value. Note that the actual values will vary widely from the numbers given here depending on the well location, chemistry, etc. 
Table 2. Salinity of the flowback waters from various shales expressed in terms of Total Dissolved Solids (TDS).

\begin{tabular}{|c|c|c|}
\hline Shale & Average TDS, ppm & Maximum TDS, ppm \\
\hline Fayetteville & $13 \mathrm{~K}$ & $20 \mathrm{~K}$ \\
\hline Woodford & $30 \mathrm{~K}$ & $40 \mathrm{~K}$ \\
\hline Barnett & $80 \mathrm{~K}$ & $>150 \mathrm{~K}$ \\
\hline Marcellus & $120 \mathrm{~K}$ & $>280 \mathrm{~K}$ \\
\hline Haynesville & $110 \mathrm{~K}$ & $>200 \mathrm{~K}$ \\
\hline
\end{tabular}

The extent of applicability of our low-TDS recovery approach for the various shales would be $\sim 100 \%$ of the flowback from the Fayetteville and Woodford shales. In the Barnett shale, by selectively directing the flowback from the first 5 days, $30-40 \%$ of the flowback may be amenable to the Low-TDS recovery (note, however, that this recovery process may not be considered at all since deep well disposal is easily available and so cheap - unless water availability may be an issue due to drought conditions). In the Marcellus shale, overall, only a small fraction $(<10 \%)$ of the flowback may be amenable to Low-TDS recovery; however, 10$20 \%$ of the flowback may be amenable at certain locations with appropriate water management to isolate the first 3 5 days of flowback water. In the Haynesville shale, due to the high TDS salinity and the availability of saline water disposal sites in East Texas, there is limited scope for membrane-based frac flowback recovery.

\subsubsection{Flow volumes \& flow rates}

The amount of frac fluid used depends on the type of well, the geographical location and operator bias/experience:

$\begin{array}{lcl}\text { Well type } & \frac{\text { Range }}{\text { Vertical }} & \text { Mean } \\ \text { Horizontal } & 11,000-90,000 \text { bbls } & 40,000 \text { bbls } \\ 70,000-190,000 \text { bbls } & 100,000 \text { bbls }\end{array}$

Flow rates during flowback typically show the following characteristics as a function of flowback time:

\begin{tabular}{|c|c|c|}
\hline Time & Flowback rate & Flowback recovery, \% frac fluid \\
\hline 1-5 days: & $100-150 \mathrm{bbl} / \mathrm{hr}$ & $10 \sim 25 \%$ \\
\hline 5-15 days: & $20-60 \mathrm{bbl} / \mathrm{hr}$ & $8 \sim 12 \%$ \\
\hline $15-30$ days & $5-10 \mathrm{bbl} / \mathrm{hr}$ & $1 \sim 5 \%$ \\
\hline 30 - 90 days: & $10 \mathrm{bbl} / \mathrm{day}$ & $1 \sim 2 \%$ \\
\hline
\end{tabular}

However, it is important to note that there is considerable variation in the flow rate profiles during flowback, and the water recovery cleanup system needs to be robust to these flow fluctuations. 


\subsubsection{Frac site visit}

We visited a frac site in the Barnett shale in Fort Worth, TX area to get a first-hand understanding of the flowback operations and the water-handling logistics. Due to safety concerns, we could not visit this site during the hydrofracturing process but our visit happened immediately after the "frac-job" and while the well services crew was managing the flowback. We also visited a saline water deep well injection site in the Cleburn, TX area. In Figure 13, the photograph shows a saline water disposal (SWD) well co-located with three hydrofractured wells producing gas. At this site, the saline water was being disposed into the Ellenburger formation that was below the shale-gas formation layer. One of the remarkable impressions of these site visits was the general cleanliness of the operational sites once the flows were established.

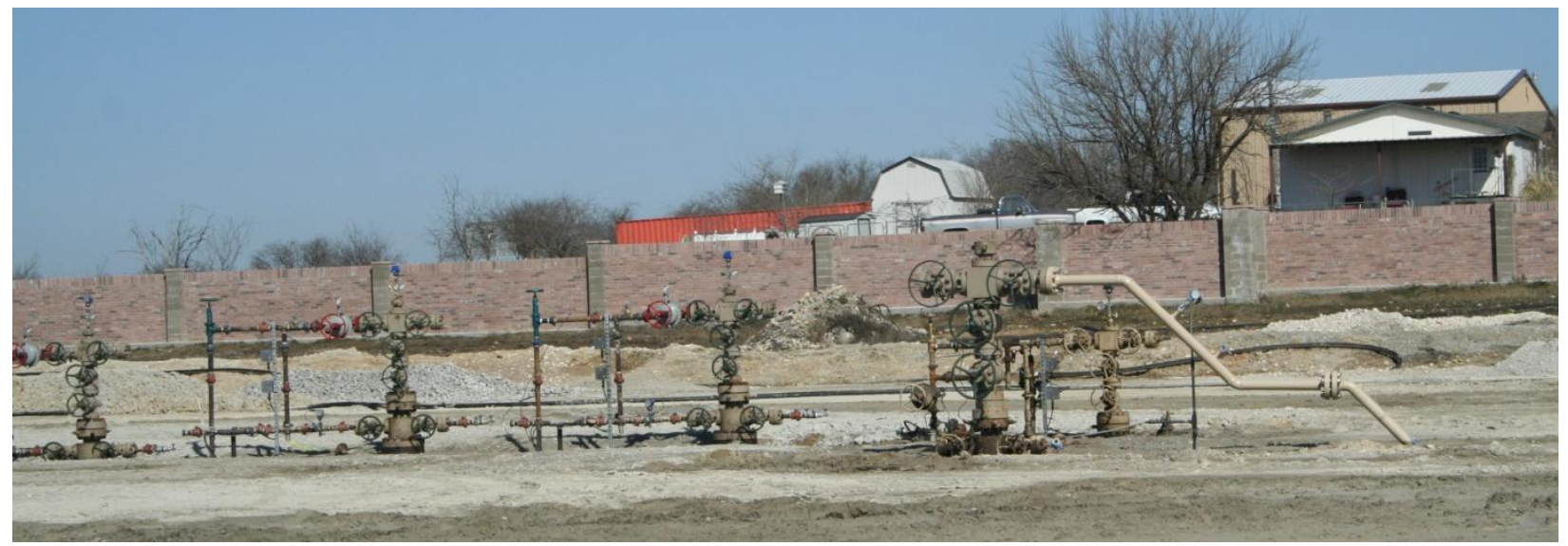

Figure 13. Photograph shows a saline water disposal (SWD) well co-located with three hydrofractured wells At this site, the saline water was being injected into the Ellenburger formation that is below the shale-gas formation layer.

\subsubsection{Flowback samples}

It had been challenging to obtain water samples from frac flowback, as frac operators prefer to keep the information proprietary and confidential. After several months of trying, we were fortunate to obtain flowback samples from two wells in the Woodford shale in Oklahoma. The well was hydrofractured in mid-March, 2010. For client confidentiality reasons, the customer and sites will not be identified in this report. The sample collections from the sites were as follows:

- Site-1: We coordinated with the customer to collect water samples during the initial flowback.

- Daily 1-liter samples were collected from Day-1 through Day-14

- One 55-gal drum from Day-1. This is referred to as "Site-1 Day-1" sample.

- One 55-gal drum containing a composite of several daily samples. This is referred to as "Site-1 Composite" sample. 
- Site-2: One 55-gal drum of sample was collected on the Day-26 after flowback had started. This is referred to as "Site-2 Day-26" sample.

In the sections below, the variation of frac flowback flow rate and the concentrations of the various components/contaminations in the above mentioned flowback waters are discussed.

\subsubsection{Flowback rate profile}

The profile for the flowback rate for Days 1-14 at Site-1 is shown in Figure 14. We observe the highly varying nature of the flowrate profile on an hourly basis. Over the first 11 days, the flowrate is approximately constant at about $120+/-15 \mathrm{bbl} / \mathrm{hr}$. Beyond Day-12, the flowrate appears to decrease with time. Interestingly, the flowrate profile at this Site-1 is different from the profiles shown in Figures 7 and 8, also for wells in the Woodford shale, wherein the flow rate drops steeply over the first 10 days of flowback from $\sim 150 \mathrm{bbl} / \mathrm{hr}$ initially to $\sim 50$ $\mathrm{bbl} / \mathrm{hr}$. This illustrates one of the key issues with frac flowback water treatment, especially for



Flowback time, days

Figure 14. Profiles of the flowback water rate and water temperature are plotted vs. flowback time for the Site-1 in Woodford shale.

an on-site mobile rig that will have to be robust to such varying flow profiles not only at the same frac sites but also that anticipated across different frac sites, although in the same shale geology.

\subsubsection{Flowback Temperature:}

In Figure 14, the temperature profile for the flowback water from Site-1 is also plotted. We note that the temperature is about $150^{\circ} \mathrm{F}$. The flowback water temperature varies across frac sites and with time. Water from deeper wells tends to have higher temperatures. Also, the temperature is higher initially when the flowback rates are highest and gradually decreases with time. This relationship is apparent in the flow rate and temperature profiles in Figure 14. This aspect of the flowback has implications on the choice of process technologies and design of on-site mobile rigs to make them robust to varying temperatures; alternatively, 
we may need to install adequate heat exchange equipment if the chosen treatment processes have limited temperature operating ranges.

\subsubsection{Flowback Water Composition}

The water samples were analyzed at the GE Water Analysis Lab, Woodlands, TX, employing standard techniques used routinely for analysis of frac flowback and produced waters. The compositional data for the various components of interest are shown below in Figures 15-23.

Total Dissolved Solids (TDS)

The TDS values for Woodford Sites 1 and 2 are plotted in Figure 15. The TDS profile for Site-1 Days 1-14 was surprising. The Day-1 sample had 38,000 ppm TDS and the value climbed up to $\sim 85,000$ ppm TDS on Day-14. This is in contrast to all the other data we had seen from customers in the Woodford shale, wherein the general trend showed that the TDS after Day14 was between 10,000 and 38,000 ppm, as seen in Figure 12. Interestingly, the Day-26 sample from Site-2 had $\sim 35,000$ ppm TDS, which is in agreement with the general trend. Horn ${ }^{10}$ has reported a value of $\sim 13,800$ ppm TDS for a Woodford shale site flowback water. It is not known why the Site-1 flowback shows such elevated levels of TDS.



Figure 15. Concentration profiles for Total Dissolved Solids (TDS) for the two Woodford frac sites.

\section{$\underline{\text { Total Suspended Solids (TSS) }}$}

These are fine particulates of inorganic, metallic or organic materials, typically $<5 \mu \mathrm{m}$ in size. They can also be colloidal in nature. The TSS measurement is conducted by passing the water sample through a 1.0 micron filter and weighing the residue material after drying. Turbidity, measured and reported in NTU units, refers to the transmission (or lack of) of light 
through a water samples. Turbidity may be influenced by the suspended solids and also color of the sample.

In Figure 16, the TSS and Turbidity profiles for the Woodford Sites 1 and 2 are plotted. We note that the TSS generally decreases as a function of flowback time for Site- 1 flowback from as high as $\sim 825 \mathrm{mg} / \mathrm{l}$ on Day-1 to below detection. Interestingly, the Site-2 Day-26 sample also had low TSS values. Many of the produced waters (late flowback) obtained from other shales also typically show very low TSS values.

The Turbidity values, however, show a changing profile as a function of flowback time for the Site-1 flowback. This observed change in Turbidity (NTU) measurements may be influenced by the sample color. The Day-26 sample from Site-2 shows a value of $~ 300$ NTU, which is in the range of the values measured for the Site-1 Days 1-14 flowback.

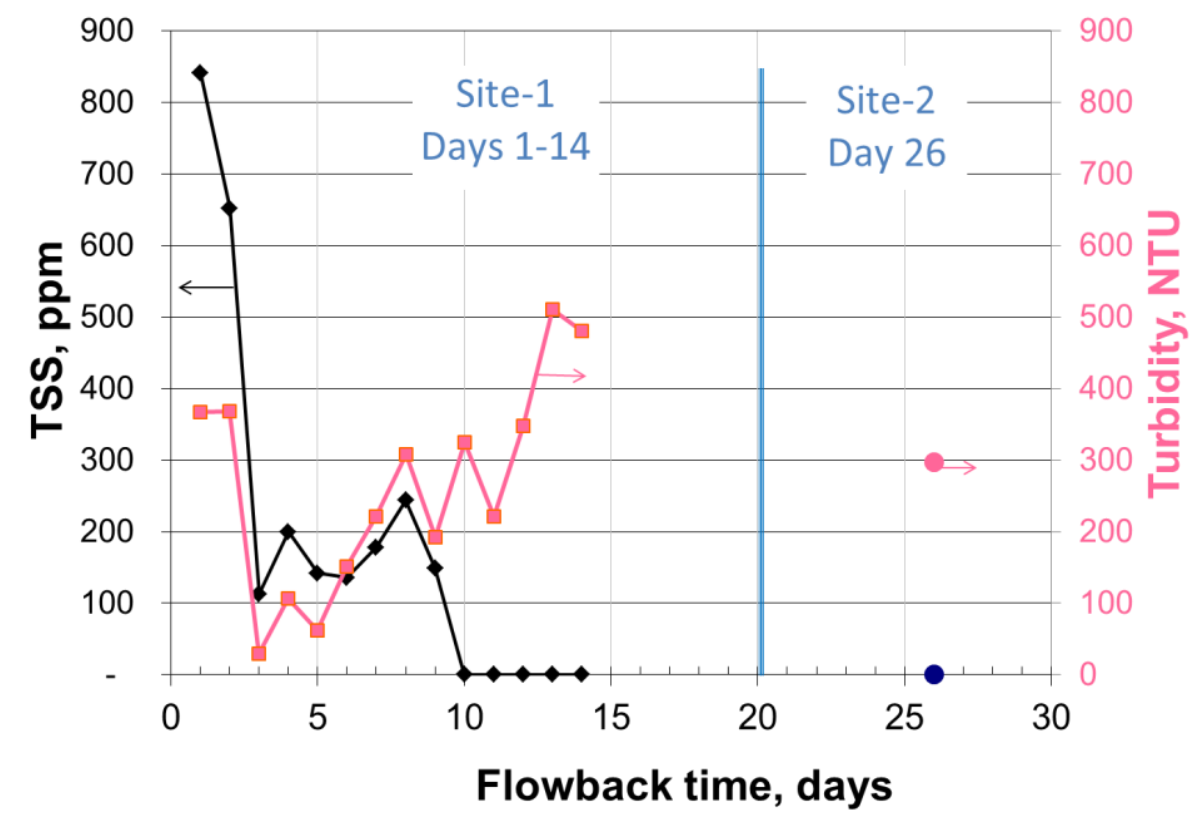

Figure 16. Concentration profiles for Total Suspended Solids (TSS) and Turbidity for the two Woodford frac sites.

Organics:

The organic content of the flowback waters was measured by two techniques, namely via "hexane extraction" and by Total Organic Carbon (TOC). The "Hexane Extractables" method gives a measure of the components that are hexane soluble and is a good indicator of the free Oil \& Grease content of the frac flowback water. The TOC measures the amount of combustible organic carbon present in the frac flowback water and is an indicator of dissolved and undissolved organics, including non-volatile and volatile compounds. Chemical Oxygen Demand (COD) is typically also mentioned in such water analyses; however, the presence of high amounts of chlorides interferes with this test and gives inaccurate results, and hence is not reported here. 
The profiles for the Hexane Extractables and TOC for the flowback waters for the Woodford Sites $1 \& 2$ are plotted in Figure 17. For the Site-1 flowback over Days 1-14, we observe high initial values for Hexane Extractables followed by a sharp decrease over the next few days. The values are below detection beyond Day-10 for Site-1 which also corresponds to negligible value for the Day-26 sample from Site-2. The TOC profile for the Site-1 Days 1-14 samples also shows a high initial value of $\sim 180 \mathrm{mg} / \mathrm{l}$ for Days $1 \& 2$ followed by a sharp decrease over Days $3 \& 4$, but then increases to a value of $~ 30 \mathrm{mg} / \mathrm{l}$ over the next few days. The value for the Day-26 sample from Site-2 is $\sim 18 \mathrm{mg} / \mathrm{l}$. It is likely that the Site-2 flowback may have gone through a similarly varying profile before settling to a steady value.

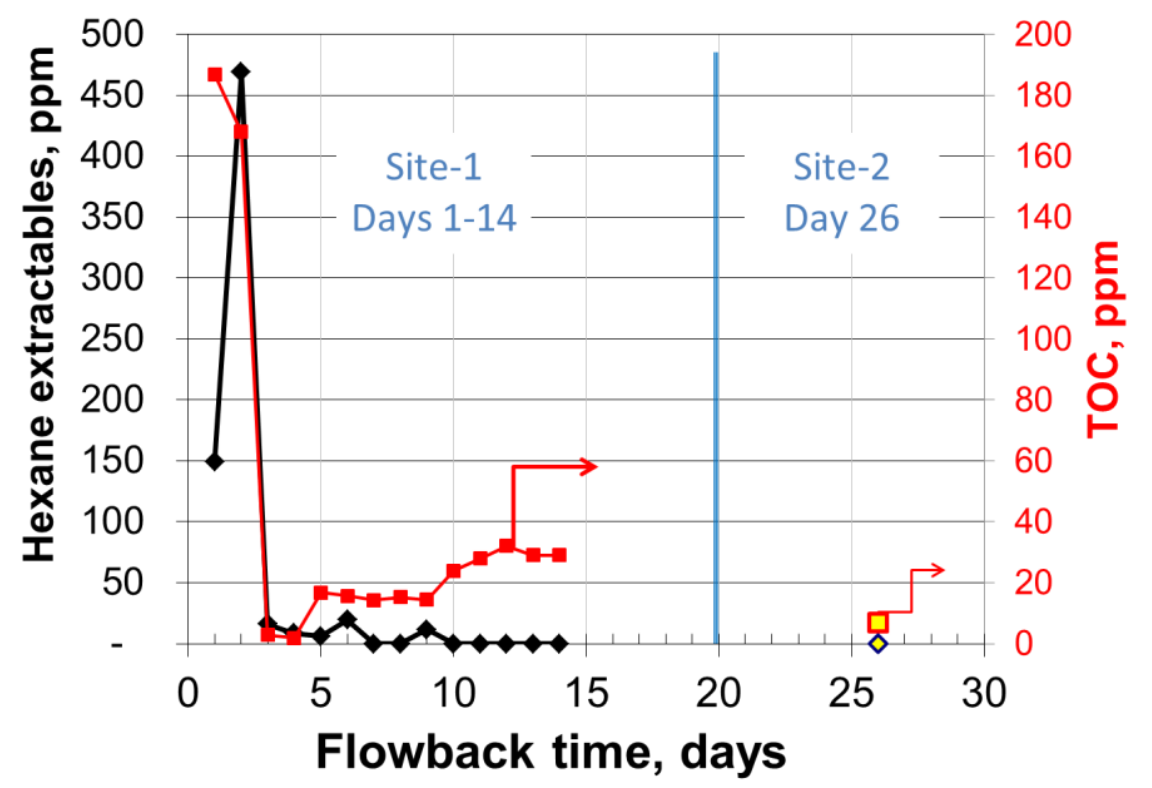

Figure 17. Concentration profiles for Hexane Extractables and Total Organic Carbon for the two Woodford frac sites.

It is likely that the nature of the organic compounds changes over the flowback period. The data for the initial flowback may be reflective of the compressor oils, diesels and frac chemicals present immediately after a frac operation, while the data for the subsequent flowback may be reflective of more natively present organics ("connate") or organic species that are more water soluble.

\section{Hardness:}

Potential scale-forming ions, such as divalent and trivalent cations, such as $\mathrm{Ca}, \mathrm{Mg}, \mathrm{Al}, \mathrm{Ba}, \mathrm{Fe}$, $\mathrm{Mn}$, and $\mathrm{Sr}$, and divalent anions, such as sulfates and carbonates, need to be measured \& monitored.

The Total Hardness estimated from the concentrations of the individual potential scaleforming ions and reported in terms of ppm $\mathrm{CaCO} 3$ is shown in Figure 18. We observe that for the Site-1 Days 1-14 flowback, the values climb from an initial $~ 4,000 \mathrm{mg} / \mathrm{CaCO}$ to 
$14,000 \mathrm{mg} / \mathrm{C}$ CaCO3 by Day-14. By contrast, the Day-26 sample from Site-2 shows a significantly lower value of $~ 2,000 \mathrm{mg} / \mathrm{l} \mathrm{CaCO3}$.

In Figure 19, the Total Hardness is plotted as a function of the TDS in the water samples for the two Woodford frac sites. Interestingly, we observe the Total Hardness showing an almost linear relationship to the TDS. Horn ${ }^{10}$ has reported a value of 1163 ppm Total Hardness for a Woodford shale site flowback water containing 13,800 ppm TDS.

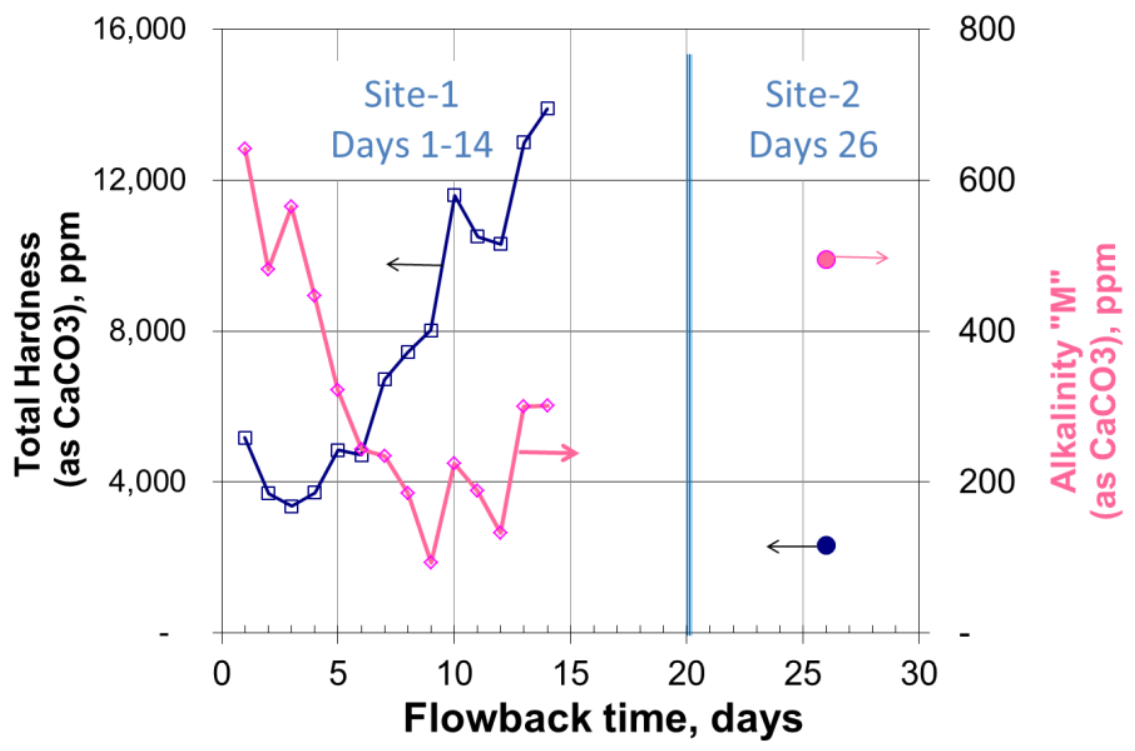

Figure 18. Concentration profiles for Total Hardness and Alkalinity for the two Woodford frac sites.

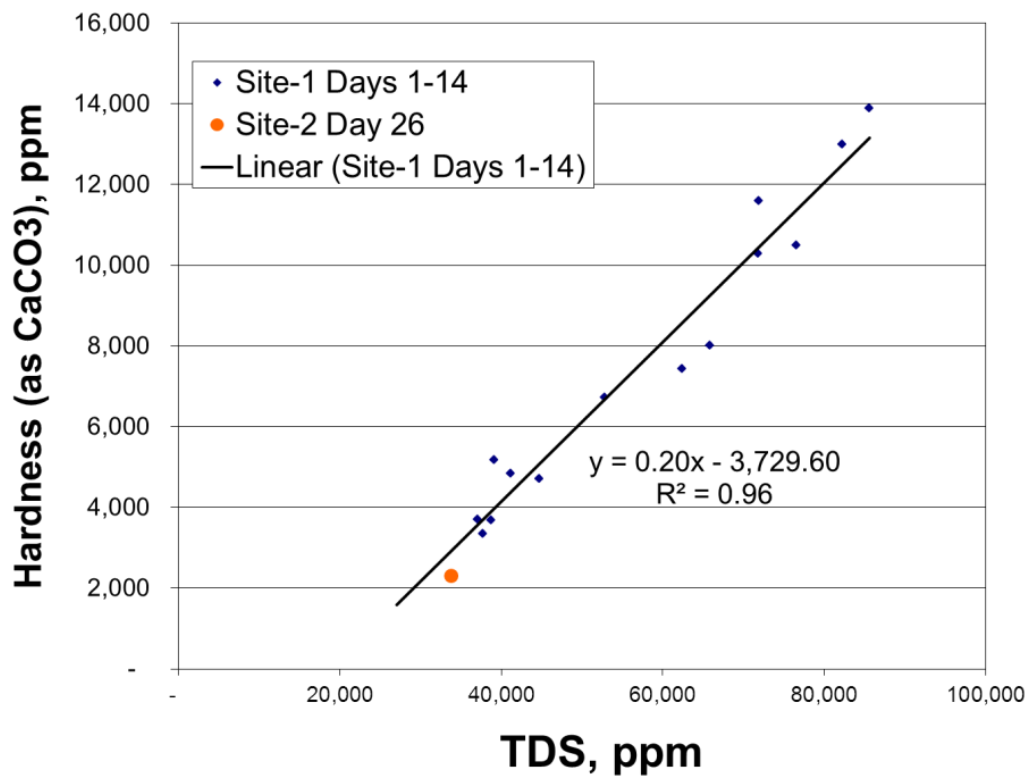

Figure 19. Plot of Total Hardness (mg/l CaCO3) vs. Total Dissolved Solids (TDS) for the various frac flowback water samples collected from the two Woodford frac sites. 
In Figure 20, the contributions of $\mathrm{Ca}$ and $\mathrm{Mg}$ to the Total Hardness are further elucidated for the flowback waters from the Woodford shale sites. We observe that for the Site-1 Days 1-14 flowback, nearly $98 \%$ of the hardness of the initial flowback is due to $\mathrm{Ca} \& \mathrm{Mg}$, while this value decreases to 95\% for later days. For the Day-26 sample from the Site-2 flowback, Ca \& Mg contribute to only $91 \%$ of the Total Hardness.



Figure 20. Profiles for the contributions of Calcium, Magnesium and Others ( $\mathrm{Fe}, \mathrm{Sr}, \mathrm{Ba})$ in terms of $\mathrm{mg} / \mathrm{l} \mathrm{CaCO}$ for the two Woodford frac sites.

Interestingly, when the Chloride levels are plotted against the TDS, as shown below, we observe a linear correlation with slope of 0.618 , which is remarkably close to the value of the value of 0.608 that we would obtain if we assume that the TDS were entirely due to $\mathrm{NaCl}$ (based on the ratio of molecular weights, $\mathrm{MCl} / \mathrm{MNaCl}$ $=35.5 / 58.5=0.608$ ). However, note that the flowback samples contain varying amounts of the other cationic species besides $\mathrm{Na}$. Such an observation was made earlier with regard to Figure 9 for

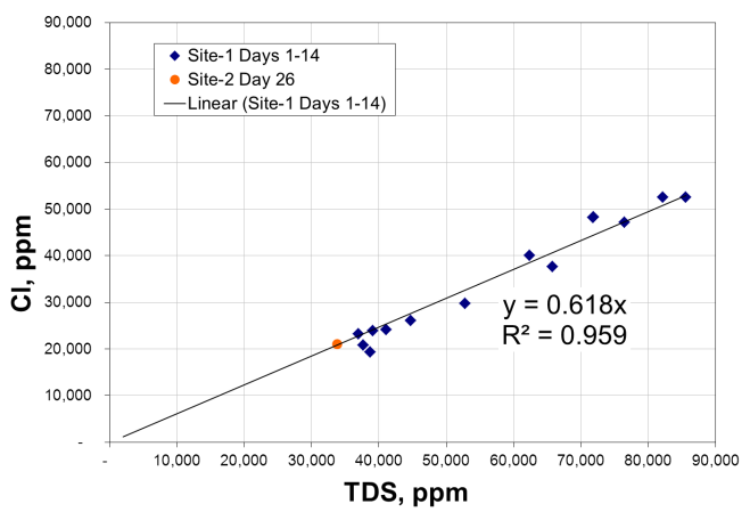
data from the Marcellus shale. 


\section{Barium, Strontium and Sulfates:}

Ba as a contaminant is a concern as in many plays the Ba levels are too high for frac reuse due to scaling concerns. Since BaSO4 has very low solubility, when Ba++ concentration is high, SO4- concentration is low, and vice-versa. This is apparent in the profiles for $\mathrm{Ba}, \mathrm{Sr}$ and SO4 for the two Woodford frac sites seen in Figure 21. We also observe that the Ba concentrations increase from $\sim 3$ ppm initially to 68 ppm on Day-14 for the Site-1 Days 1-14 flowback while the Site-2 Day-26 flowback sample has only $30 \mathrm{mg} / \mathrm{l}$. Horn ${ }^{10}$ has reported a value of $\sim 38 \mathrm{mg} / \mathrm{l}$ Ba for a Woodford shale site flowback water. By contrast, some areas in the Marcellus shale may have even as high as $6,000 \mathrm{mg} / \mathrm{l} \mathrm{Ba}$.

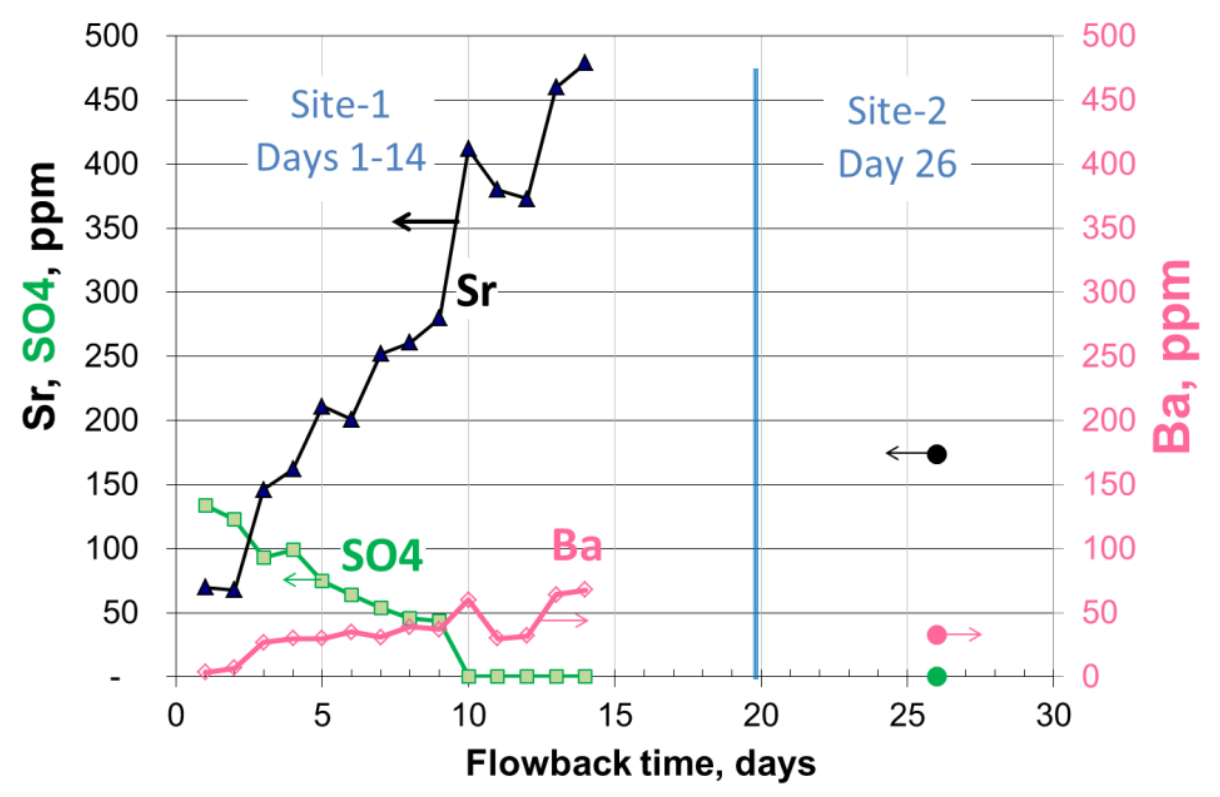

Figure 21. Concentration profiles for Barium, Strontium and Sulfate for the two Woodford frac sites.

The Strontium concentration increases from $\sim 70 \mathrm{ppm}$ initially to $\sim 480 \mathrm{ppm}$ on Day-14 for the Site-1 Days 1-14 flowback while the Site-2 Day-26 flowback sample has only $174 \mathrm{mg} / \mathrm{l}$.

The Sulfate concentrations decrease from $100 \mathrm{mg} / \mathrm{l}$ initially to below detection beyond Day10 for the Site-1 Days 1-14 flowback, while the Site-2 Day-26 flowback sample has negligible concentration.

Iron, Manganese and Boron:

$\mathrm{Fe}^{2+}$ is a concern as it may oxidize to form $\mathrm{Fe}^{3+}$, which may readily form precipitates with various anions. Similarly, Mn may oxidize to form precipitates. The concentration profiles for Fe, $\mathrm{Mn}$ and $\mathrm{B}$ are plotted in Figure 22 for the two Woodford frac sites. 
We observe that the Fe concentration for the Site-1 Days 1-14 flowback is initially 30 mg/l but decreases to $\sim 10 \mathrm{mg} / \mathrm{l}$ over the next few days before rising to $\sim 40 \mathrm{mg} / \mathrm{l}$ by Day- 14 . The Site-2 Day-26 flowback water contains $\sim 72 \mathrm{mg} / \mathrm{l} \mathrm{Fe}$. This is important since the product specifications for frac re-use water require $<10 \mathrm{mg} / \mathrm{l} \mathrm{Fe}$, as discussed later.

We observe that the Manganese concentration for the Site-1 Days 1-14 flowback is $~ 1 \mathrm{mg} / \mathrm{l}$ similar to the Site-2 Day-26 flowback.

We observe that the Boron concentration for the Site-2 Days 1-14 flowback is initially 10 $\mathrm{mg} / \mathrm{l}$ and increases to $18 \mathrm{mg} / \mathrm{l}$ by Day-14, while the Site-1 Day-26 flowback water contains $\sim 28 \mathrm{mg} / \mathrm{l}$. Boron removal may be a concern if the product water is surface discharged but may not be an issue for frac re-use in slickwater hydrofracturing (however, B levels are tightly controlled in gel-based hydrofracturing).

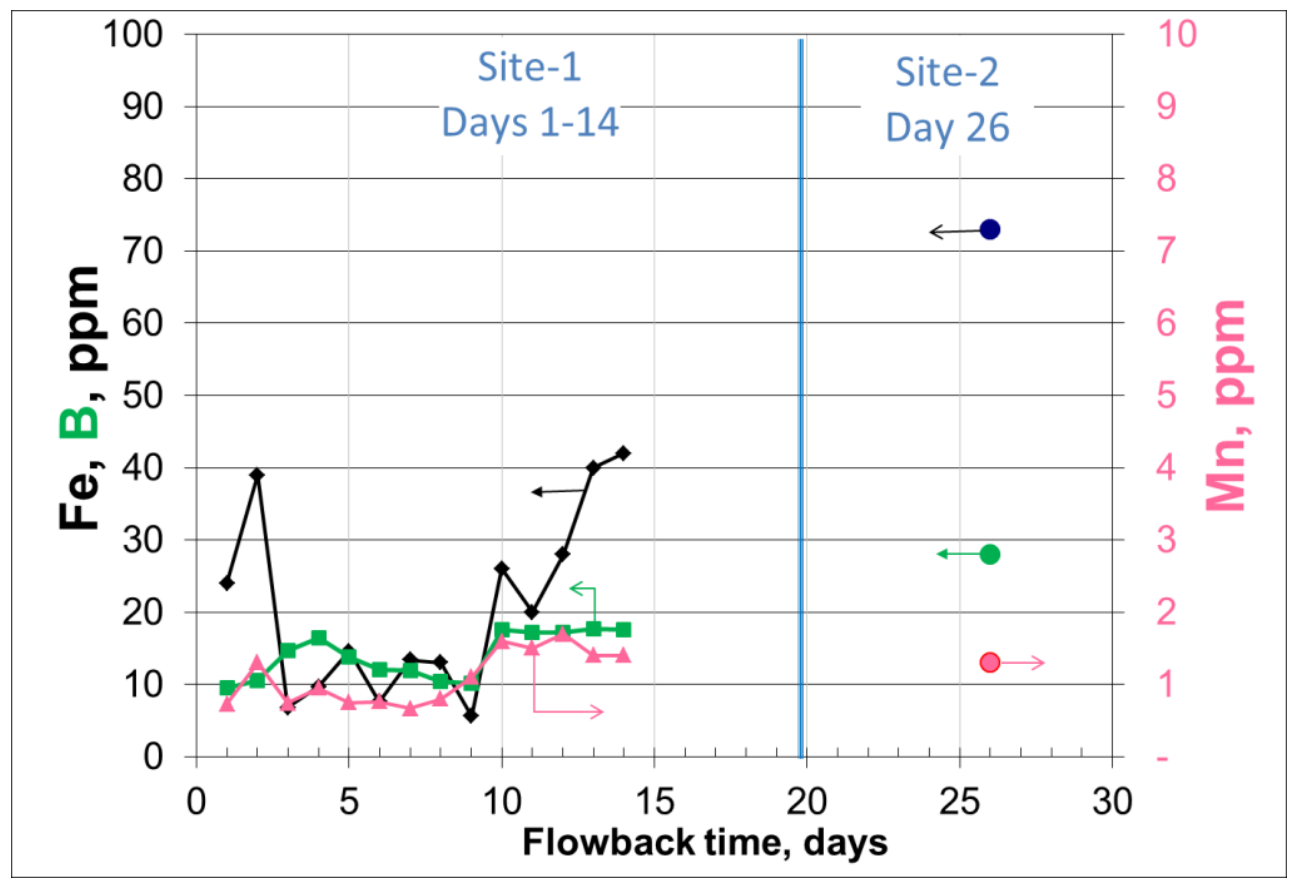

Figure 22. Concentration profiles for Iron, Manganese and Boron for the two Woodford frac sites.

Silica:

Silica may be present in the flowback water either as colloidal silica or reactive silica; the latter is of concern as a potential foulant for desalination membranes. In Figure 23, the concentration profiles for both of these species are plotted as a function of flowback time for the two Woodford frac sites. We observe that there is some variation in both measurements of silica for the Site-1 Days 1-14 flowback with the values between 20 and $70 \mathrm{mg} / \mathrm{l}$ : the silica concentration for the Site-1 Days 1-14 flowback is initially $\sim 60 \mathrm{mg} / \mathrm{l}$ but decreases to $\sim 20 \mathrm{mg} / \mathrm{l}$ over the next few days before rising to $\sim 70 \mathrm{mg} / \mathrm{l}$ total silica and $\sim 55 \mathrm{mg} / \mathrm{l}$ reactive silica by Day- 14 . The Site-2 Day-26 flowback water contains $\sim 120 \mathrm{mg} / \mathrm{l}$ total silica and $\sim 60 \mathrm{mg} / \mathrm{l}$ reactive sili- 
ca. Removal of colloidal silica may occur during removal of suspended solids but removal of reactive silica is important to prevent RO/NF membrane fouling.



Figure 23. Concentration profiles for Total and Reactive Silica for the two Woodford frac sites.

NORM:

Normally Occuring Radioactive Material (NORM) levels were not measured for these samples. Examination of some of the low-TDS waters from the Woodford shale reveal NORM values in the range from $<20$ to $500 \mathrm{pCi} / \mathrm{L}$. These are very low compared to values in the Marcellus shale (reported at $\sim 10,000 \mathrm{pCi} / \mathrm{L}$ ). The treatment of NORM containing waters is being specifically addressed by GE Global Research under contract with Research Partnership to Secure Energy for America (RPSEA) (RPSEA 08122-36, principal investigator, Dr. James Silva). The results from that project, when available, will be incorporated into this project.

\section{Composition analysis for the drum samples.}

The compositions of the three 55-gal drums obtained from the Woodford shale sites are listed in Table 3. Photographs of vials containing these samples are shown in Figure 24.

The 33,800 ppm TDS of the Site-2 Day-26 sample was in the desired range for the evaluation of RO-type membrane processes for desalination and was used for membrane fouling studies in Task 4 and 5. Although the TDS values of the water samples obtained from Site- 1 were too high for the consideration of RO-type membrane processes for desalination, the samples were useful for the bench-mark evaluation of pretreatment processes for the removal of other undesired components in Task 4. 
Table 3. Compositions of the three 55-gal drums obtained from the Woodford shale that were used for bench-mark testing in Tasks 4 and 5 .

\begin{tabular}{|l|r|r|r|}
\hline \multicolumn{1}{|c|}{ Components } & $\begin{array}{c}\text { Site-2 } \\
\text { Day 1 }\end{array}$ & $\begin{array}{c}\text { Site-2 } \\
\text { "Composite" }\end{array}$ & $\begin{array}{l}\text { Site-1 } \\
\text { Day 26 }\end{array}$ \\
\hline Specific Conductance, at 25 ${ }^{\circ} \mathrm{C}, \mu \mathrm{mhos}$ & 51,100 & 71,125 & 54,200 \\
\hline Alkalinity, "M" as CaCO3, ppm & 641 & 381 & 495 \\
\hline Sulfate, as SO4, ppm & 134 & 104 & 35 \\
\hline Chloride, as Cl, ppm & 23,900 & & 21,000 \\
\hline Hardness, Total, as CaCO3, ppm & 5,170 & 5,838 & 2,310 \\
\hline Calcium Hardness, as CaCO3, ppm & 3,910 & 4,260 & 1,240 \\
\hline Magnesium Hardness, as CaCO3, ppm & 1,180 & 1,348 & 855 \\
\hline Barium, Total, as Ba, ppm & 3 & 30 & 33 \\
\hline Strontium, Total, as Sr, ppm & 70 & 186 & 174 \\
\hline Iron, Total, as Fe, ppm & 24 & 22 & 73 \\
\hline Sodium, as Na, ppm & 14,100 & 14,600 & 19,100 \\
\hline Potassium, as K, ppm & 301 & 436 & 340 \\
\hline Manganese, Total, as Mn, ppm & 0.7 & 1.3 & 1.3 \\
\hline Phosphate,Total, as PO4, ppm & 12 & & 12 \\
\hline Silica, Total, as SiO2, ppm & 67 & 47 & 120 \\
\hline Silica, Reactive, as SiO2, ppm & 63 & 44 & 59 \\
\hline Solids, Total Suspended mg/l & 841 & 277 & $\mathrm{n} / \mathrm{a}$ \\
\hline Solids, Total Dissolved, mg/l & 39,100 & 59,475 & 33,800 \\
\hline Boron, as B, ppm & 10 & 13 & 28 \\
\hline Carbon, Total Organic, as C, ppm & 187 & 42 & 17 \\
\hline Turbidity, NTU & 367 & 143 & 297 \\
\hline Hexane Extractable Material, mg/l & 149 & 14 & \\
\hline
\end{tabular}

\section{Frac Flowback Water Sampling}

Woodford shale Site1 Days 1-14

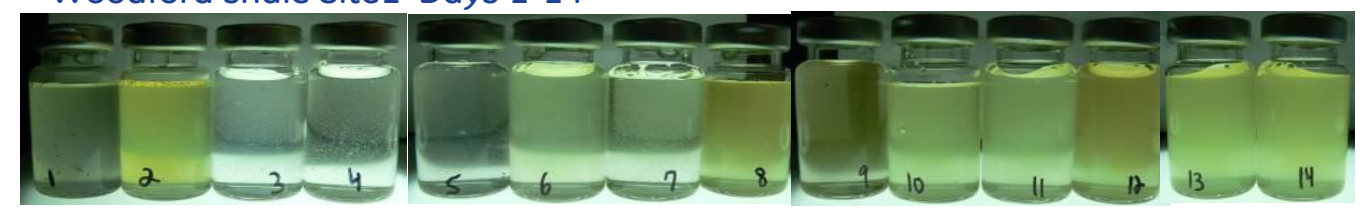

Woodford shale

Site2 Day 26

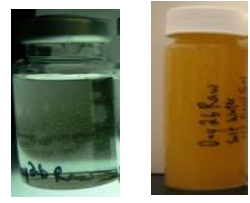

typical

"bottom" of barrel

Figure 24. Photographs of vials containing frac flowback samples from Woodford shale Site-1 Days1-14 and Site-2 Day-26. 


\subsubsection{Specifications for the frac flowback water recovery process}

\subsubsection{Conventional Frac Flowback process}

The frac flowback water handling process, although quite complex in terms of the safety and operational logistics, is shown simplified for our purposes in Figure 25. The flowback water is directed to a separator to separate the water from the gas and the solid proppants. The flowback water is stored in interim storage tanks. The water is trucked to water disposal sites.

\section{Conventional Flowback Water Disposal Process}

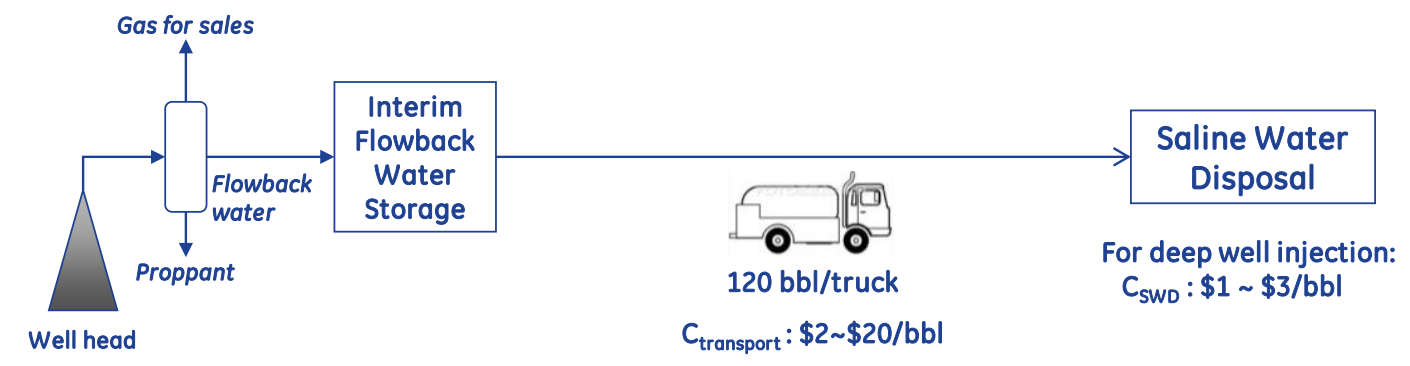

$\mathrm{C}_{\text {Disposal }}=\mathrm{C}_{\text {Transport }}+\mathrm{C}_{\text {SWD }} \quad(\$ /$ bbl water $)$

Figure 25. Simplified frac flowback water handling and disposal operation at a shale gas well site.

\subsubsection{Conventional water disposal}

Flowback water may be disposed of by various means including:

- Deep well injection: Disposal in Class II saline water injection sites has been the most common and sometimes the only means of disposal of the high-TDS flowback and produced waters. This has been especially true in the Barnett shale where such disposal sites are available locally and the cost of disposal is relatively cheap at $\$ 1$ $\$ 3 / \mathrm{bbl}$. However, such deep well injection sites are few in the Marcellus shale (West Virginia, Pennsylvania, New York), and hence there is a need to transport the flowback waters to sites in Ohio and Indiana. The costs of such long distance hauling by trucks are in the range of $\$ 4-\$ 19 / \mathrm{bbl}$. An independent operator in the PA area indicated that his disposal costs were $\sim \$ 8 / \mathrm{bbl}$. In the Fayetteville shale (Arkansas) it can cost upwards of $\$ 6$ per barrel to transport and dispose of water in an independently owned disposal well ${ }^{3}$. For the Woodford shale (Oklahoma), the trucking costs are estimated at $\$ 3.71 / \mathrm{bbl}$ and disposal between $\$ 1-2 / \mathrm{bbl}^{10}$.

- Surface water discharge: Until recently, this mode of disposal was used in the Marcellus shale in the PA area. PA DEP 25 regulations enacted in August 2010 limit surface discharge from Oil \& Gas operations to less than 500 ppm TDS lamong other specific constituents such as Chlorides, Sulfates, Barium and Strontium).

- Land farm use: This was used until recently in the Fayetteville shale in Arkansas, but there are restrictions to such use ${ }^{3}$. Waters cannot be land applied when the ground is saturated, frozen, or if precipitation is imminent. In order for water to be applied to the surface under land application permits, it must have a chloride concentration of 
less than 5,000 parts per million (ppm) and comply with a Sodium Adsorption Ration (SAR) specifications. If chloride content is less than 1,500 ppm, water can also be utilized on roads for dust suppression. If chloride concentrations exceed 5,000 ppm, disposal in approved disposal wells is required.

\subsubsection{Frac Flowback Recovery Process}

A conceptual process for recovering all or part of the flowback water for re-use in hydrofracturing operations is shown in Figure 26. The flowback water recovery process (FWRP) is preferably located physically close to the well operations to minimize water hauling costs. It includes a mobile unit equipped with the necessary treatment operations to provide a "product" water that meets specifications for re-use in hydrofracturing. Only a portion of the flowback water may be recovered as product, while the rest may have to be disposed of either in conventional saline water disposal Class II wells or via further recovery by methods suitable for desalination of high-TDS waters (> 70,000ppm), such as thermal processes.

\section{Flowback Water Recovery Process for Frac Re-use}

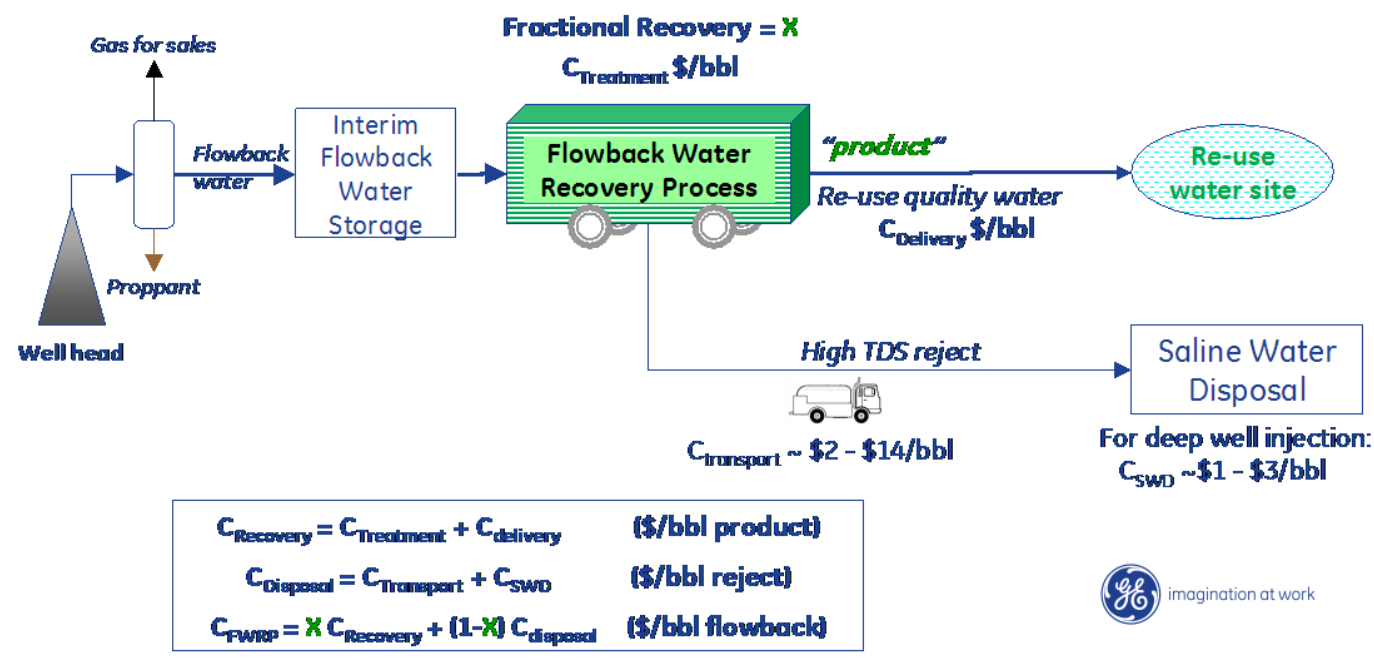

Figure 26. Conceptual Flowback Water Recovery Process (FWRP) for re-use in hydrofracturing. The overall cost will depend on the extent of water recovery, $x$, in the FWRP.

\subsubsection{Technical specifications for recovery for frac re-use}

\section{Product composition:}

The contaminants of interest in the frac flowback water for mitigation and their impact on water re-use for hydrofracturing are shown in Figure 27. 


\section{Frac Flowback: Key Contaminants}

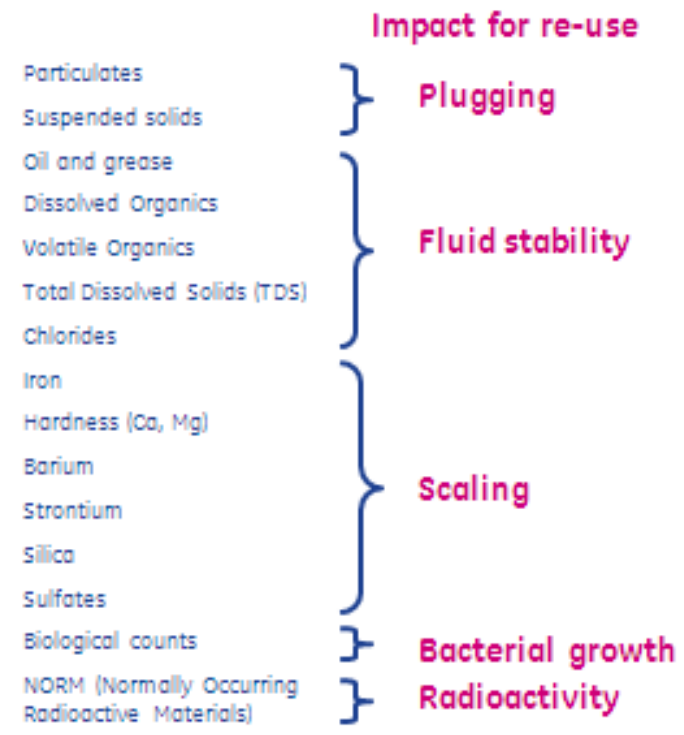

Figure 27. Key contaminants in frac flowback water and their impact on re-use in hydrofracturing.

Opinions vary widely on the water quality that may be used for hydrofracturing. For instance, most of the operators currently insist on using very low-TDS source water to avoid scaling issues in the downhole piping. Some well operators, such as Range Resources, have reported success in using up to 26,000 ppm Chlorides in the Marcellus shale ${ }^{16}$. In fact, Range Resources and Chesapeake reported at the 2010 GWPC Conference, Pittsburgh, PA that they presently re-use $\sim 100 \%$ of early flowback water in the Marcellus shale by blending with fresh water (TDS $<500 \mathrm{ppm}$ ) in subsequent hydrofracturing operations. Some experts feel that water salinity equivalent to seawater, namely $\sim 35,000$ ppm TDS may be usable for hydrofracturing 5 . Some operators are reportedly even considering the re-use of waters with salinity as high as 120,000 ppm TDS with low hardness and scale-causing contaminants ${ }^{17}$, but we consider these to be highly speculative at the present moment as these may be applicable to specific situations where blending with a majority of very low-TDS source water may be anticipated before frac use.

To develop specifications for frac re-use water, we evaluated the limited information available in literature and spoke to frac operators. The data provided by Range Resources ${ }^{4}$ gives one benchmark for re-use specifications. This is reproduced in Figure 28 and provides a good understanding of a practical application. Apparently, the frac flowback waters from a Marcellus shale well site were blended with fresh water to create a frac fluid with the reported characteristics, which was successfully used for hydrofracturing at another site. 


\begin{tabular}{|l|c|c|c|}
\hline Parameter & Conventional Limits & Blended Marcellus Water & Considerations \\
\hline $\mathrm{pH}$ & 6.0 to 8.0 & 8.1 & Fluid Stability, Scaling \\
\hline Chlorides & $<20,000 \mathrm{mg} / \mathrm{L}$ & $26,000 \mathrm{mg} / \mathrm{L}$ & Fluid Stability \\
\hline Iron & $<20 \mathrm{mg} / \mathrm{L}$ & $14.5 \mathrm{mg} / \mathrm{L}$ & Fluid Stability \\
\hline $\mathrm{Ca}, \mathrm{Mg}, \mathrm{Ba}, \mathrm{SO}_{4}, \mathrm{CO}_{3}, \ldots$ & $f(\mathrm{P}, \mathrm{T}, \mathrm{pH})(+/-350 \mathrm{mg} / \mathrm{L})$ & $\begin{array}{c}\mathrm{Ca}-4,200 \mathrm{mg} / \mathrm{L}, \mathrm{Mg}-488 \mathrm{mg} / \mathrm{L}, \\
\mathrm{Ba}-39 \mathrm{mg} / \mathrm{L}, \mathrm{SO}-124 \mathrm{mg} / \mathrm{L}\end{array}$ & Scaling \\
\hline Bacteria Count & $<100 / 100 \mathrm{~mL}$ & $1 \mathrm{million} / 100 \mathrm{~mL}$ & Bacteria Growth \\
\hline Suspended Solids & $<50 \mathrm{mg} / \mathrm{L}$ & $1,500 \mathrm{mg} / \mathrm{L}$ & Skin \\
\hline Oil \& Soluble Organics & $<25 \mathrm{mg} / \mathrm{L}$ & $4.6 \mathrm{mg} / \mathrm{L}$ & Fluid Stability \\
\hline
\end{tabular}

Figure 28. Summary of chemical characteristics of the waters used in conventional and blended Marcellus waters used for hydrofracturing by the Range Resources Company 4 .

A specification for re-use frac water apparently developed with data supplied by Halliburton and XTO Energy are provided in Table 4.

Table 4. The following specifications for re-use frac water in the Marcellus shale were apparently developed ${ }^{18}$ with data supplied by Halliburton and XTO Energy

\begin{tabular}{|l|l|}
\hline \multicolumn{1}{|c|}{ Parameter } & \multicolumn{1}{c|}{ Range } \\
\hline maximum scale formers & $2,500 \mathrm{mg} / \mathrm{l}$ as CaCO3 \\
\hline maximum dissolved solids & $50,000 \mathrm{mg} / \mathrm{l}$ \\
\hline maximum iron & $3.5 \mathrm{mg} / \mathrm{l}$ \\
\hline maximum calcium & $250 \mathrm{mg} / \mathrm{l}$ \\
\hline pH range & 6.5 to 7.5 \\
\hline
\end{tabular}

* scale formers are generally considered to be aluminum, barium, calcium, iron, manganese, and strontium

Moreover, the methods used for hydrofracturing are being continuously updated as the industry is trying to maximize gas recovery while minimizing energy and especially, fresh water usage. For example, current research on new slicking agents (friction reducers) may allow the use of higher salinity in the feed water compared to present operations. Regulations are being considered by various state and federal agencies on the disclosure of water chemistry used for hydrofracturing, discharge of flowback water, and the re-use of flowback water for hydrofracturing. Until the frac industry has honed in on their requirements, there will be uncertainty on the specifications for the treated water and discharge water. This affects the determination of how much of the flowback water would be treatable, the choices of technology options applicable and the overall system cost. The conclusion from our survey was that the specifications for acceptable re-use are subject to change in the short-term.

Based on the feedback from hydrofracturing operators, it was realized that the team needed to update the product water scope from the one product with 20,000 ppm TDS originally proposed to potentially four alternative products with varying levels of purification: 
1. Product-1: Clarified only (removal of suspended matter, free oil \& grease, Fe, and microbiological contaminants),

2. Product-2: Softened and Clarified (removal of hardness ions, namely $\mathrm{Ba}, \mathrm{Sr}, \mathrm{Ca}, \mathrm{Mg}$ besides the purity specs for Product-1),

3. Product-3: Partially desalinated to $<20,000$ ppm TDS (besides the purity specs for Product-2), and

4. Product-4: Substantially desalinated to < 500ppm TDS (besides the purity specs for Product-2).

These product options and the associated target contaminants for removal are shown in Figure 29.

\section{Frac Flowback Recovery: Product Options}

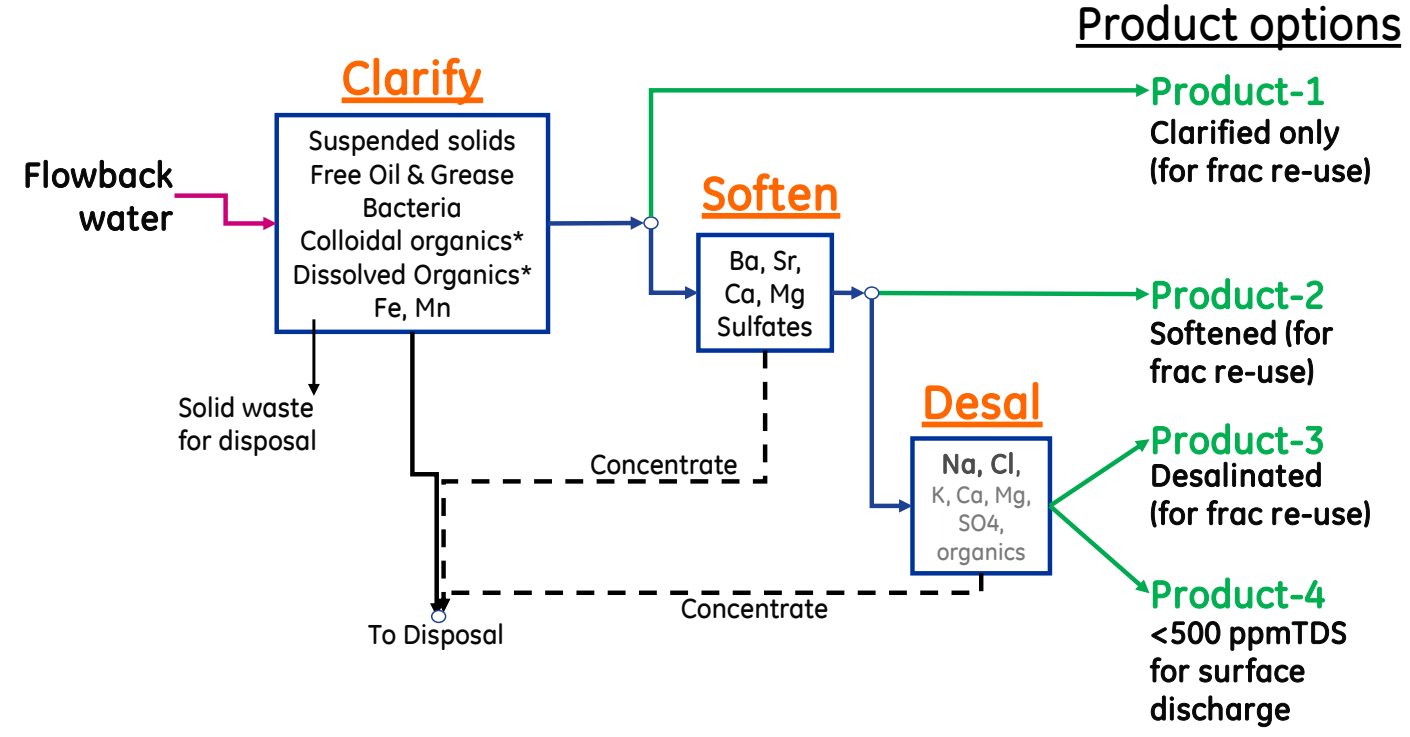

Figure 29. . Product Options for frac flowback water recovery. The target contaminants are listed for each process step in the respective boxes. The target contaminants to be removed in each process step are indicated inside the boxes.

The specifications for the products under consideration are shown in Figure 30. It should be noted that as the shale gas industry is continually evolving in terms of the water quality used for hydrofracturing, the specifications are based on currently best available information from operators and published literature. The first three product waters would be suitable for reuse in hydrofracturing while Product-4 would also be suitable for surface discharge. It should be noted that the product quality requirements increase as we consider Product-1 through Product-4, both in terms of the number of target contaminants as well as the extent of their removal. For example, dissolved organic contaminants at levels $<50 \mathrm{ppm}$ may not be as much of an issue with Product-1 and Product-2, namely Clarified-only and Softened-only, respectively; however, these contaminants at levels $>10$ ppm may be foulants for the desalination membranes that would be used to produce Product- 3 and Product- 4 . 


\section{Requirements for the "product" waters}

\begin{tabular}{|l|c|c|c|}
\hline \multicolumn{1}{|c|}{ Parameter } & Units & $\begin{array}{c}\text { Conventional } \\
\text { "fresh" source } \\
\text { water before } \\
\text { additive } \\
\text { blending }\end{array}$ & $\begin{array}{c}\text { Conventional } \\
\text { frac fluid } \\
\text { after additive } \\
\text { blending }\end{array}$ \\
\hline Total Dissolved Solids & $\mathrm{mg} / \mathrm{L}$ & $<500$ & $<1000$ \\
\hline Total alkalinity & $\mathrm{mg} / \mathrm{L}$ & $\sim 50$ & $\sim 50$ \\
\hline Hardness as CaCO3 & $\mathrm{mg} / \mathrm{L}$ & $<150$ & $<150$ \\
\hline Total suspended solids & $\mathrm{mg} / \mathrm{L}$ & $<2 \sim 10$ & $<50$ \\
\hline Turbidity & $\mathrm{NTU}$ & $<4$ & $<250$ \\
\hline Chloride & $\mathrm{mg} / \mathrm{L}$ & $<50$ & $<100$ \\
\hline Iron & $\mathrm{mg} / \mathrm{L}$ & $<4$ & $<10$ \\
\hline Oil \& soluble organics & $\mathrm{mg} / \mathrm{L}$ & $<10$ & $<400$ \\
\hline Sulfate & $\mathrm{mg} / \mathrm{L}$ & $<25$ & $<25$ \\
\hline Total Phosphorus & $\mathrm{mg} / \mathrm{L}$ & $\sim 0.1$ & $0.1 \sim 5$ \\
\hline Bacteria Count & $\# / 100 \mathrm{~mL}$ & $<100$ & $<100$ \\
\hline pH & & $6.7-7.4$ & $5.2-8.9$ \\
\hline SAR & & \multicolumn{3}{|l}{} \\
\hline Temperature & $\mathrm{C}$ & \multicolumn{3}{|l|}{} \\
\hline
\end{tabular}

\begin{tabular}{|c|c|c|c|}
\hline $\begin{array}{c}\text { * "Clarified } \\
\text { product" for re- } \\
\text { use }\end{array}$ & $\begin{array}{c}\text { * "Softened } \\
\text { product" for re- } \\
\text { use }\end{array}$ & $\begin{array}{c}\text { * "Desal } \\
\text { water" } \\
\text { product for } \\
\text { frac re-use }\end{array}$ & $\begin{array}{c}\text { *"Desal water" } \\
\text { product for } \\
\text { agricultural } \\
\text { discharge }\end{array}$ \\
\hline $\mathrm{NR}$ & $\mathrm{NR}$ & $<20,000$ & $<500$ \\
\hline$<600$ & $<600$ & $<600$ & $\sim 50$ \\
\hline $\mathrm{NR}$ & $<2000$ & $<2000$ & See SAR \\
\hline$<50$ & $<50$ & $<50$ & $<2 \sim 10$ \\
\hline$<100$ & $<100$ & $<100$ & $<4$ \\
\hline $\mathrm{NR}$ & $\mathrm{NR}$ & $<12,500$ & $<50$ \\
\hline$<10$ & $<10$ & $<10$ & $<4$ \\
\hline$<50$ & $<50$ & $<50$ & $<29$ \\
\hline$<125$ & $<25$ & $<25$ & $<25$ \\
\hline $\mathrm{NR}$ & $\mathrm{NR}$ & $\mathrm{NR}$ & $<5$ \\
\hline$<100$ & $<100$ & $<100$ & $<100$ \\
\hline $6.5-8.5$ & $6.5-8.5$ & $6.5-8.5$ & $6.7-7.4$ \\
\hline $\mathrm{NR}$ & $\mathrm{NR}$ & $\mathrm{NR}$ & $<12$ \\
\hline $\mathrm{NR}$ & $\mathrm{NR}$ & $\mathrm{NR}$ & $\mathrm{ambient}$ \\
\hline
\end{tabular}

* Best available specifications from few operators and published literature. Actual values may vary depending on shale formation, local regulations and operator preferences.

Figure 30. Specifications for the various Product Options described in Figure 29.

Note that due to addition of the various chemicals for friction reduction, etc. Isee Appendix for details), there is a net increase in the TDS and other components in the frac fluid relative to the source water, as seen in Figure 30 for the compositions of the frac fluid before and after additives blending for a conventional "fresh" water source. Also, the specifications for Product-3 appear to be roughly half of the Chlorides and TDS reported by Range Resources in Figure 28. We felt that it was prudent to take a conservative approach.

\section{Extent of product recovery}

The extent of recovery of the product water (fit for frac re-use), $x$, is defined as:

$$
x=\frac{\text { Volume recovered water }}{\text { Volume flowback water }}
$$

For Product-1 and Product- 2 in Figure 29 that involve only processes such as filters, clarifiers, sorbents, and precipitation equipment, the water recovery is typically $>90 \%$ or higher depending on the efficiency of the sludge handling methods employed.

However, the extent of product permeate recovery in membrane desalination processes is limited by the feed water composition (including salts, hardness ions, silica, organics, etc.), the pressure limitations of the pumping equipment used and the membrane area available. As water permeates through the selective membrane inside the permeator module, the concentration of salts and other non-permeable components, such as silica, organics, etc., increase in the retentate. This results in the need for a greater pressure drop across the membrane for reasonable permeate production rates, and also increases the potential for precipitation of insoluble salts, such as $\mathrm{CaCO} 3, \mathrm{CaSO} 4, \mathrm{BaSO}_{4}, \mathrm{SrSO} 4$, etc. and fouling of the membrane by reactive silica and other contaminants. Typically, for economically viable sea water desalination, the upper limit on the concentration of the retentate in RO processes is about 70,000 
ppm - the actual value will depend on the concentrations of the other ions, silica and other components.

In Figure 31, the extent of recovery, $x$, is plotted as a function of the flowback TDS concentration for different values of the permeate product TDS concentrations, namely 250 ppm, $10,000 \mathrm{ppm}$ and $20,000 \mathrm{ppm}$. The value of $250 \mathrm{ppm}$ TDS corresponds to a very low-TDS product that is suitable for potable water or surface discharge (Product-4), and the value of 20,000 ppm TDS corresponds to our proposed "frac re-use" (Product-3) specifications shown in Figures $29 \& 30$. The condition for typical seawater desalination to produce potable water (<250 ppm TDS) is also shown in Figure 31.

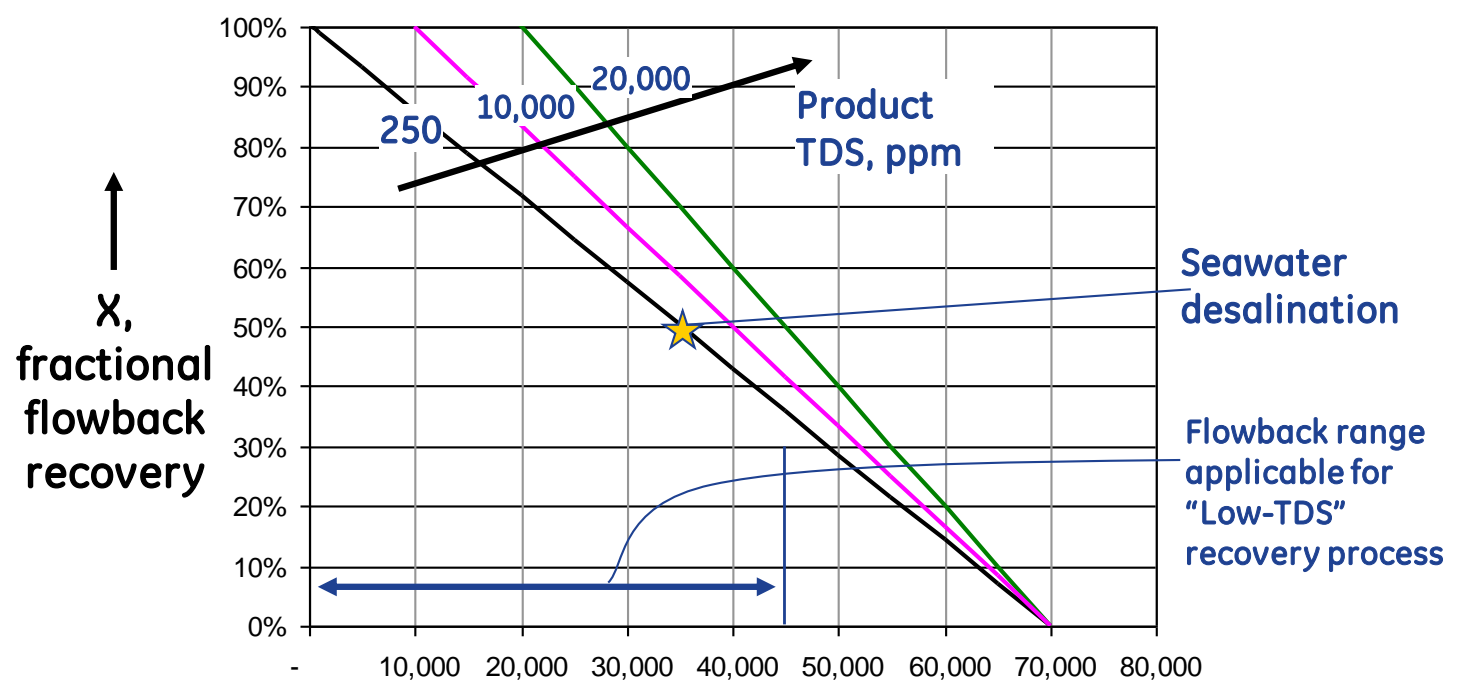

TDS in Flowback, ppm

Figure 31. Plot of extent of product recovery, $x$ as a function of the flowback water concentration and desired permeate product water concentrations when retentate concentration is limited to 70,000 ppm TDS.

The applicable range of flowback water composition for "Low-TDS" recovery processes is expected to be in the range of 15,000 to 45,000 ppm TDS depending on the shale play under consideration (see Table 2 for expected TDS ranges for different shales). For flowback water concentrations in the range of 30,000 to $45,000 \mathrm{ppm}$, the expected extents of recoveries are $50-80 \%$ for Product-3 (20,000 ppm TDS product) and 35-55\% for Product-4 (500ppm TDS product).

\section{Cost criteria:}

\section{Value Assessment of Flowback Water Recovery Process}

The value of the Flowback Water Recovery Process (FWRP) would depend on the specifics of the shale site. The factors to consider are (a) the salinity and other contaminants in the flowback water that would limit the recovery $(x)$, (b) the cost of conventional disposal options, (c) 
any regulations (penalties) related to disposal of the flowback waters or use (benefits/incentives) of the product water for frac re-use, (d) the availability (or lack) of water for frac use, and (e) the cost and logistics of the infrastructure available to bring in a mobile unit at the frac flowback site.

The acceptable cost target of the recovery process would consequently be dependent on the specifics of the shale site under consideration. Of course, the preferred option is the "cheapest" process that meets the technical specifications at the "highest" recovery.

When we consider the cost of a FWRP, we need to consider the following:

- Cost of recovery process to produce a product fit for frac re-use.

- Delivery of the product to the re-use site

- Value benefit of the fresh water avoided during the subsequent frac operation.

- Disposal of the unrecovered product via deep well saline water injection or some other recovery method (e.g. thermal recovery) including transportation.

These are represented below:

$$
\begin{aligned}
& C_{\text {FWRP }}=C_{\text {Recovery }}+C_{\text {Concentrate disposal }} \quad(\$ / \text { bbl feed }) \\
& C_{\text {Recovery }}=C_{\text {Treatment }}+C_{\text {Product Delivery }}-\left(C_{\text {Fresh Water }}+C_{\text {Penalties_Avoid }}\right)(\$ / \text { bbl product })
\end{aligned}
$$

where the cost for the product recovery $C_{\text {Recovery }}$ includes the cost of the treatment processes and the cost for delivery of the product water to the re-use site. Additionally, credits could be taken for the value of the fresh water avoided during the next fracturing job, and any avoidance of penalties from existing or pending regulations.

The volume and cost of water being withdrawn, and consequently not available for public consumption, is a significant public perception issue, especially during water-constrained situations (drought, etc.). But in most shale plays when water availability is not a concern, fresh water from river water and municipalities typically costs $\sim \$ 0.05 / \mathrm{bbl}$ plus delivery, which may result in a net cost of $\sim \$ 0.22 / \mathrm{bbl}$. This cost is small compared to typical saline water Class II disposal costs of $\$ 1-3 / \mathrm{bbl}$. The value of the penalties avoided, $C_{\text {Penalties_avoid }}$ is unknown at the moment. Hence, although inclusion of $C_{\text {Fresh water }}$ and $C_{\text {Penalties_Avoid }}$ offers a more economically attractive condition, a more conservative approach would be to ignore them, as in eqn. (3):

$$
\mathrm{C}_{\text {Recovery }} \cong \mathrm{C}_{\text {Treatment }}+\mathrm{C}_{\text {Product_Delivery }} \quad \text { (\$/bbl product) }
$$

The cost of delivery, CProduct_Delivery will again vary depending on the distance between the reuse site and flowback site, and the mode of product water transfer. The cheapest option will be to pump into a local pond dedicated to hold this product until re-use. The most expensive 
option will be trucking over long distances. A reasonable estimate would be C $_{\text {Product_Delivery }}<$ $\$ 0.1 \sim 0.5 / \mathrm{bbl}$.

For the Flowback Water Recovery Process to be economically attractive, the minimum requirement is:

\section{$\mathrm{C}_{\text {FWRP }}<\mathrm{C}_{\text {Conventional Disposal }}$}

From our earlier discussions, we noted that the typical conventional disposal costs, including transportation, could vary depending on the individual shale plays and the availability of disposal sites. These values range from as low as $\$ 2-\$ 4 / \mathrm{bbl}$ in Barnett to as high as $\$ 4-\$ 19 / \mathrm{bbl}$ in Marcellus, while it is $\$ 6 / \mathrm{bbl}$ in Fayetteville 3 and $\$ 3.71 / \mathrm{bb}$ for transportation and $\sim \$ 1-2 / \mathrm{bbl}$ for disposal in Woodford ${ }^{10}$. (Although, interestingly, during the Pennsylvania Chap 95 regulation analysis review, it was reported that even at costs anticipated for proper treatment and disposal at as high as $\sim \$ 10 / \mathrm{bbl}$, the annual costs would comprise a mere $0.4 \%$ of the estimated annual revenue ${ }^{19}$.).

From these values and feedback from a few well operators, as well as paring down the contributions of product handling $\&$ delivery costs and rig operating labor, the treatment cost criterion for this project was set as:

\section{$\mathrm{C}_{\text {Treatment }}<\$ 2 / \mathrm{bbl}$ feed}

Where $\mathrm{C}_{\text {Treatment }}=\mathrm{C}_{\text {Setup }}+\mathrm{C}_{\text {Process }}$

$C_{\text {setup: }}$ Cost of mobile rig transportation and setup at the frac site.

Cprocess: Cost associated with the capital and operating expenses related to the process steps including process equipment, chemicals, waste disposal and maintenance.

This is the treatment cost on-site and does not include the cost of product- and concentratedisposal. The labor costs associated with setting up the mobile rig are included in $\mathrm{C}_{\text {setup }}$ and thus in the $\mathrm{C}_{\text {Treatment }}$ value. However, the rig operating labor for treating flowback water has not been included since these costs may be accounted differently by different producers as the rig may be run by operators handling multiple responsibilities at the frac site.

\subsubsection{Summary of the verification of success criteria}

The verification of success criteria are summarized in Figure 32. 


\section{Verification of success criteria:}

$\checkmark$ Performance:

\begin{tabular}{|l|c|c|c|}
\hline \multicolumn{1}{|c|}{ Parameter } & Units & $\begin{array}{c}\text { Conventional } \\
\text { "fresh" source } \\
\text { water before } \\
\text { additive } \\
\text { blending }\end{array}$ & $\begin{array}{c}\text { Conventional } \\
\text { frac fluid } \\
\text { after additive } \\
\text { blending }\end{array}$ \\
\hline Total Dissolved Solids & $\mathrm{mg} / \mathrm{L}$ & $<500$ & $<1000$ \\
\hline Total alkalinity & $\mathrm{mg} / \mathrm{L}$ & $\sim 50$ & $\sim 50$ \\
\hline Hardness as CaCO3 & $\mathrm{mg} / \mathrm{L}$ & $<150$ & $<150$ \\
\hline Total suspended solids & $\mathrm{mg} / \mathrm{L}$ & $<2 \sim 10$ & $<50$ \\
\hline Turbidity & $\mathrm{NTU}$ & $<4$ & $<250$ \\
\hline Chloride & $\mathrm{mg} / \mathrm{L}$ & $<50$ & $<100$ \\
\hline Iron & $\mathrm{mg} / \mathrm{L}$ & $<4$ & $<10$ \\
\hline Oil \& soluble organics & $\mathrm{mg} / \mathrm{L}$ & $<10$ & $<400$ \\
\hline Sulfate & $\mathrm{mg} / \mathrm{L}$ & $<25$ & $<25$ \\
\hline Total Phosphorus & $\mathrm{mg} / \mathrm{L}$ & $\sim 0.1$ & $0.1 \sim 5$ \\
\hline Bacteria Count & $\# / 100 \mathrm{~mL}$ & $<100$ & $<100$ \\
\hline pH & & $6.7-7.4$ & $5.2-8.9$ \\
\hline SAR & & & \\
\hline Temperature & $\mathrm{C}$ & & \\
\hline
\end{tabular}

Product recovery:
Requirements for the "product" waters

\begin{tabular}{|c|c|c|c|}
\hline $\begin{array}{c}\text { *Clarified } \\
\text { product" for re- } \\
\text { use }\end{array}$ & $\begin{array}{c}\text { * "Softened } \\
\text { product" for re- } \\
\text { use }\end{array}$ & $\begin{array}{c}\text { * "Desal } \\
\text { water" } \\
\text { product for } \\
\text { frac re-use }\end{array}$ & $\begin{array}{c}\text { *"Desal water" } \\
\text { product for } \\
\text { agricultural } \\
\text { discharge }\end{array}$ \\
\hline NR & NR & $<20,000$ & $<500$ \\
\hline$<600$ & $<600$ & $<600$ & $\sim 50$ \\
\hline NR & $<2000$ & $<2000$ & See SAR \\
\hline$<50$ & $<50$ & $<50$ & $<2 \sim 10$ \\
\hline$<100$ & $<100$ & $<100$ & $<4$ \\
\hline NR & NR & $<12,500$ & $<50$ \\
\hline$<10$ & $<10$ & $<10$ & $<4$ \\
\hline$<50$ & $<50$ & $<50$ & $<29$ \\
\hline$<125$ & $<25$ & $<25$ & $<25$ \\
\hline NR & NR & NR & $<5$ \\
\hline$<100$ & $<100$ & $<100$ & $<100$ \\
\hline $6.5-8.5$ & $6.5-8.5$ & $6.5-8.5$ & $6.7-7.4$ \\
\hline NR & NR & NR & $<12$ \\
\hline NR & NR & NR & ambient \\
\hline & & &
\end{tabular}

$>95 \%>90 \% \quad>50 \% \quad>40 \%$

Cost of FWRP < Cost of Conventional Disposal

Treatment cost $<\$ 2 /$ bbl feed

Mobile rig configuration feasibility
* Best available specifications from few operators and published literature. Actual values may vary depending on shale formation, local regulations and operator preferences.

Figure 32. Verification of success criteria for the Low-TDS frac flowback recovery process 


\subsection{Task 3: Define conceptual process alternatives for frac water recovery for re-use}

The specific objective was to:

- Evaluate possible frac water recovery flow schemes and obtain preliminary costs.

The key activities were to:

- Identify potential treatment technologies for the various contaminants identified in Task 2.

- Generate preliminary process schemes with these various technology options and evaluate potential feasibility and risks to meet the technical product requirements, cost targets and mobility requirements.

We reviewed available technology options to remove the various contaminants of interest in frac flowback water. Additionally, we, at GEGR, worked closely with various groups within GE Water \& Process Technologies (GEWPT) to leverage their knowledge in treating various industrial waste waters. Specifically, GEWPT Water Chemicals division offers a wide product portfolio of chemicals used for membrane-water pretreatment and corrosion prevention, GEWPT Membranes division offers a wide product portfolio on microfiltration, ultrafiltration, nanofiltration, reverse osmosis, and membrane bioreactors for treating various municipal and industrial waste waters. GE WPT Mobile Services offers the world's largest fleet of mobile water treatment systems, providing rapid response for a full range of reverse osmosis, filtration, demineralization, softening, and deoxygenation treatment on demand.

\subsubsection{Frac Flowback Water Recovery Process Options}

A conceptual Frac Flowback Recovery Process (FWRP) scheme for treating the frac flowback water to provide product water fit for frac re-use is shown in Figure 33. 


\section{Frac Flowback Recovery Process}

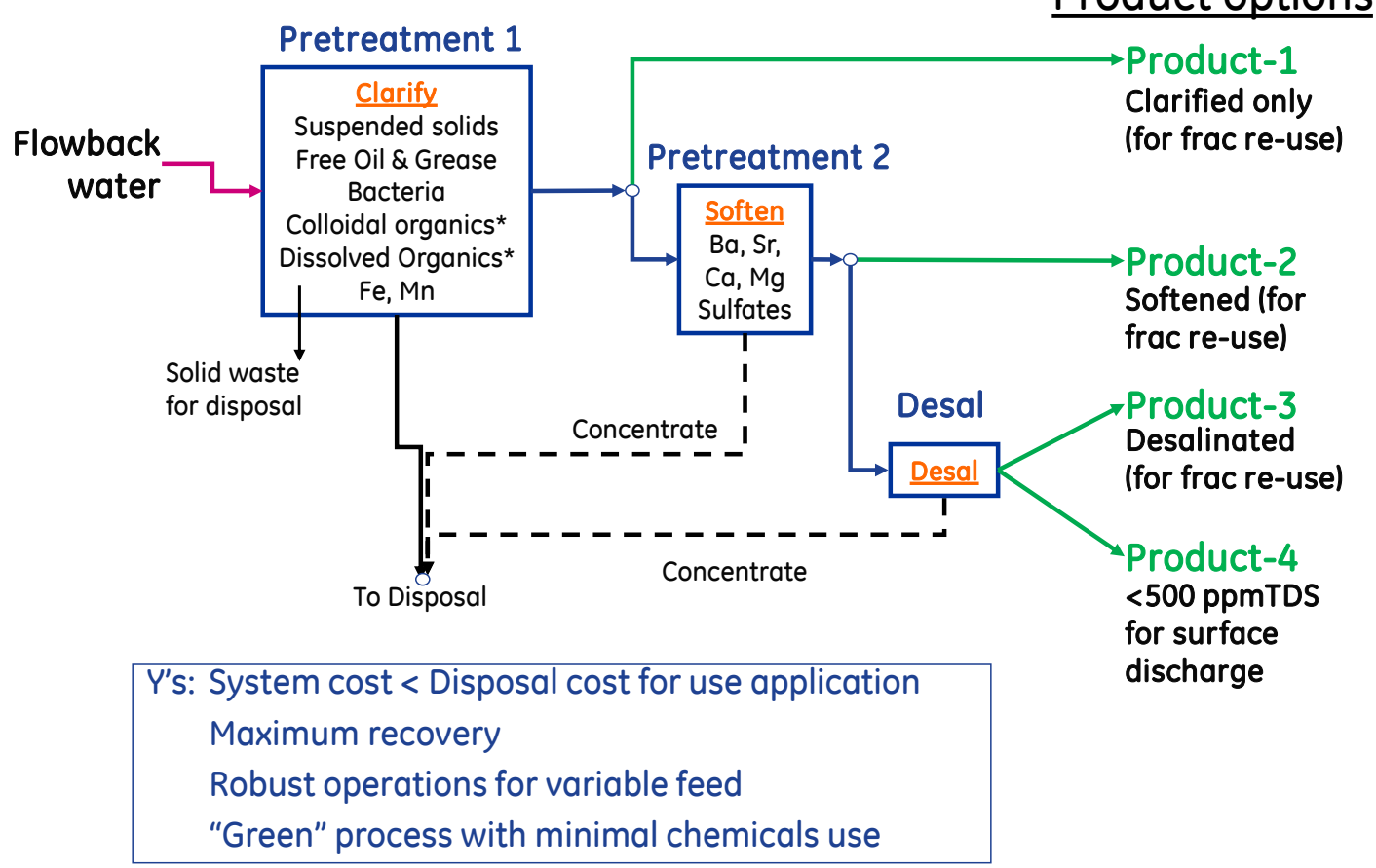

Figure 33. Conceptual representation of a frac flowback recovery process to treat the frac flowback waters to provide the product options in Figure 30. The target contaminants to be removed in each process step are indicated inside the boxes.

The flowback water is first treated to remove the various contaminants shown in the Pretreatment-1 box in Figure 33. The key contaminants to be removed are suspended solids, free oil \& grease, bacteria, colloidal organic and inorganic material. Dissolved ions are not removed. The outputs from this process are: (a) a clarified "product" stream that will meet the Product-1 requirements specified in Figure 30, and (b) a small solids-rich waste stream produced from the precipitation and filtration steps for disposal.

For Product-2, the output from Pretreatment-1 may be further treated to remove hardnesscausing ions, mainly divalent and trivalent ions, in the step shown as Pretreatment- 2 in Figure 33. It is possible, as shown later, to combine the processes in the Pretreatment-1 and -2 steps. The outputs from this process are: (a) a softened "product" stream that will meet the Product-2 requirements specified in Figure 30, and (b) a solids-rich waste stream that needs to be disposed of, preferably as a non-hazardous waste disposed of in a land-fill, or a liquid waste stream that is concentrated in the divalent and trivalent ions that is disposed of in an underground saline water injection facility. The solids-rich waste stream would be generated when precipitation methods such as "lime softening" are used, followed by settling and filtration. A liquid-rich waste stream would be generated when a nanofiltration membrane process that selectively rejects di- and tri-valent ions is employed. The extent of water recovery is definitely higher for the solids-precipitation method but it requires handling of solids. 
To meet the Product- 3 and Product- 4 requirements, the output from Pretreatment 2 would require the use of desalination membranes that selectively exclude the permeation of monovalent ions, such as $\mathrm{Na}, \mathrm{K}$, and $\mathrm{Cl}$ besides any residual divalent and trivalent ions. The extent of salt removal is influenced by the choice of desalination membranes employed. The extent of removal could be least when nanofiltration (NF) membranes that remove the divalents and some of the monovalents are employed and most when high-selectivity reverse osmosis (RO) membranes are employed. The NF membranes have the highest permeate flux and would require the lowest membrane area and lowest operating pressure ( 100 psig range), while the high-selectivity RO membranes typically have the lowest flux and would require the largest membrane area and highest operating pressure (800-1200 psig), and thus the highest electrical power consumption (kW/m3 of permeate). Membranes with intermediate ranges of flux and selectivity may also be considered for an optimal flux/area/power requirement for the desired product TDS quality.

The retentate or concentrate stream from the membrane desalination process would be sent to disposal in deep well injection wells, or as feed to thermal desalination systems that can recover more useful water for reuse and further concentrate the saline stream to reduce the volumes for deep well injection. An ideal situation would be in a zero liquids discharge (ZLD) facility wherein all the water is recovered and the residue is a valuable by-product salt useful as an industrial raw material or as road-salt.

\subsubsection{Key contaminants in frac flowback of concern for reuse}

The contaminants in the frac flowback water were discussed in Section 3.2.10.3 and their impact on water reuse for hydrofracturing were illustrated in Figure 27 . The salient aspects of these contaminants for evaluating process technology options for cleanup are described below:

- Particulates: These could be precipitated solids, sand and silt, carbonates, clays, proppant, corrosion products, and other solids derived from the producing formation and from well bore operations. Quantities can range from insignificant amounts to high enough to yield a solids slurry. In theory, these should be amenable to removal via filtration or other mechanical means.

- Suspended solids: These are finer particulates of inorganic, metallic or organic materials. They can also be colloidal in nature. Reported values are typically $~ 200$ ppm but could be much higher depending on the particular operating conditions of the flowback. There could be significant variability in the values during the flowback.

- Free oil and grease (FOG): These could be from the oils and diesels from compressors and other drilling equipment or native from the producing formation. There is a lot of fluctuation in the reported values even in the same shale. There could be significant variability in the values during the flowback. 
- Dissolved Organics: These could be small amounts of low molecular weight hydrocarbons, polymers used as friction reducers (see Appendix), or other organics from the formation. Reported values range from 10 - 150 ppm.

- Volatile Organics: Some of the dissolved and undissolved organics could be considered as volatile under normal operating conditions and as such may present concerns with emissions or fire/explosion hazards if the concentrations are too high. Condensates present in the shale gas that contaminate the flowback water, especially benzene, toluene and xylenes, need to be explored as they are of public concern. Most literature values indicate $<10$ ppm for such compounds.

- Hardness: These include divalent ions, with the ions of most concern being Ca and Mg. The concentrations of these ions are high in certain shales, such as Marcellus while low in shales such as Woodford and Fayetteville. They could range from 100 ppm to 10,000 ppm depending on the shale and vary as a function of flowback time (typically increase almost linearly with TDS).

- Barium: Ba as a contaminant is a concern as in many plays the Ba levels are very high. Since BaSO4 has very low solubility, when $\mathrm{Ba}^{++}$concentration is high, $\mathrm{SO}^{-}$ concentration is low, and vice-versa (see Figure 11 for the Haynesville shale data). Reported Ba values range from <100 ppm in Woodford to as high as 6,000 ppm in certain areas of Marcellus. Even in Marcellus, there is significant variation as one travels from WV via PA to NY.

- Strontium: Reported values range from <50 ppm in Woodford to >2,000 ppm in Marcellus.

- Iron: Reported values range from 20-200 ppm. Fe $\mathrm{Fe}^{++}$is a concern as it may oxidize and form precipitates with various anions.

- Silica: Reported values range from 10 - 120 ppm. This could be colloidal silica or reactive silica; the latter is of concern as a potential foulant for desalination membranes.

- NORM: NORM originates in geological formations and can be brought to the surface with the flowback water. The NORM values for some of the low-TDS waters from the Woodford shale appear to range from $<20$ to $500 \mathrm{pCi} / \mathrm{L}$. These low values do not pose any concerns for treated water or any waste residues produced during recovery of the saline waters considered in this project.

\subsubsection{Considerations for evaluating technology \& process options}

A review of available technology options to remove the various contaminants of interest in frac flowback water was conducted. Process flow schemes with these technology options were created. The technology options were rated for the following:

- Technical Performance: Will the technology option remove the contaminant to the desired specification? Can it be integrated with the other process technologies to yield a technically workable process solution?

- Cost Performance: Will the technology be cost-effective? Will the overall process cost incorporating this technology be cost-effective? 
- Mobility Performance: Does this technology have a low enough footprint that makes it amenable to incorporation into a mobile rig? Will the overall process using this technology be usable in a mobile rig?

The following rating scale was used:

- Green: The risks are low with this technology option for this contaminant. Also, overall process integration with this technology carries low risks

- Yellow: There are some low-med level risks with this technology option that would need to be retired either using pretreatment or post-treatment. For example, polyamide membranes typically used for desalination will get fouled at high concentrations of reactive silica or precipitating salts, such as $\mathrm{CaCO} 3, \mathrm{CaSO} 4$, etc. Therefore, there is need to pre-treat the feed to this membrane unit to remove the potential foulants or add anti-scaling agents.

- Red: The technology option has some substantial risks that need to be retired by either pretreatment or post-treatment.

The results of the analysis are shown in Figure 34. The conclusions from the analyses are discussed in the next section. 




Figure 34. Technology options evaluated in the preliminary screening in Task 3 for removal of the various contaminants in frac flowback water. Each of the options was evaluated for potential risks with performance individually and upon integration into a process. Costs risks were based on overall process satisfying the $\$ 2 / \mathrm{bbl}$ feed treatment cost criterion. Mobility risks were for incorporating the technology and the integrated process 


\subsection{Task 4: Evaluate key Pretreatment and Membrane Processes in bench- scale experiments}

\subsubsection{Objectives and Approach}

The specific objectives were:

- Evaluate pretreatment methods and RO/NF membranes for treating frac flowback water via bench-scale experiments

- Make a go/no-go decision based on whether pretreatment methods for effective removal of the contaminants are technically feasible and cost-effective.

\subsubsection{Bench-scale experimental approach}

The extent of removal of contaminants and water recovery will depend on the flowback concentration and the desired product concentrations for the Product options 1-4 described in Figure 30. The various mechanical, chemical and membrane technologies that were identified to be 'Green' in Task 3 were evaluated via bench-scale laboratory experiments. The experiments were conducted initially with simulated frac water (pure water mixed with known concentrations of one or more target contaminants) and later with the frac flowback water samples obtained from the Woodford shale.

The bench-scale experiments involved the evaluation of various additives, such as coagulants, flocculants, softening chemicals, sorbents, etc., various operating conditions, such as $\mathrm{pH}$, concentrations, mixing times, settling times, temperatures, flow rates, etc. various separation equipment, such as filters, mixed-media deep filtration beds, cross-flow filtration, microfiltration, ultrafiltration, nanofiltration, reverse osmosis, etc.

Essentially, the key process steps for treating the frac flowback waters can be categorized as follows:-

- Clarification: Removal of suspended solids, oil \& grease, microbiologicals, and dissolved organics (in some cases). Removal of Fe++ may be included here since oxidation to Fe+++ occurs readily in the presence of oxygen and Fe+++ can cause precipitation and fouling in downstream applications either during re-use as Product- 1 or in the desalination membrane modules used for producing Product-3 or Product-4..

- Softening; Removal of "hardness" ions, such as $\mathrm{Ca}, \mathrm{Mg}, \mathrm{Ba}$ and $\mathrm{Sr}$, which may cause precipitation and plugging in downhole applications during re-use as Product-2 or in the desalination membrane modules used for producing Product-3 or Product-4.

- Desalination: Removal of dissolved salt ions, mainly $\mathrm{NaCl}$ using membranes used to produce product waters suitable for re-use as Product-3 or surface discharge as Product-4.

In the sections below, the approach for treating the flowback waters and the associated bench-scale experiments and results are described for the key process steps. 


\subsubsection{Process Step: "Clarify"}

The purpose of this step is to remove contaminants in the flowback water to satisfy the downstream applications, either as Product-1 (cf. Figure 33) or as feed to membrane desalination processes. Note that the specifications for the membrane applications may be more stringent than for frac re-use with Product-1.

Various coagulants were evaluated at different operating conditions. Some of these benchscale experiments with certain coagulants for the "composite" Days 1-14 water from Site-1 are shown for illustration in Figure 35. We observe that coagulation is effective at significantly reducing turbidity, TOC, Fe and Mn, as required for Product-1.

\section{Clarify: Evaluation of coagulants}

\section{Sample: Site-1 "composite" Days 1-14 water}

Procedure:
- Rapid mix coagulant for
2 mins
- Mix Polymer Flocculant
(10 ppm) for 1 min
- Slow mix for 5 mins
- Settling 20 mins

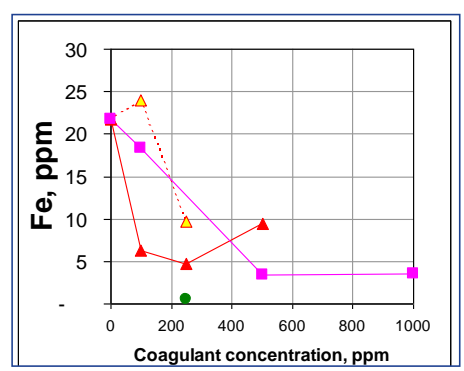

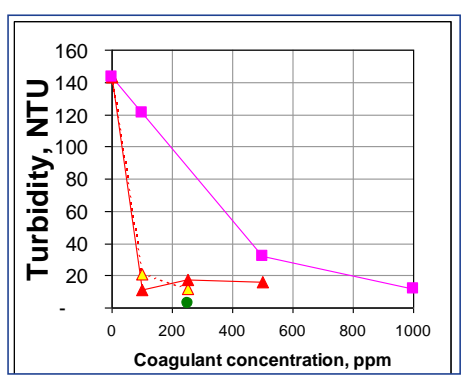
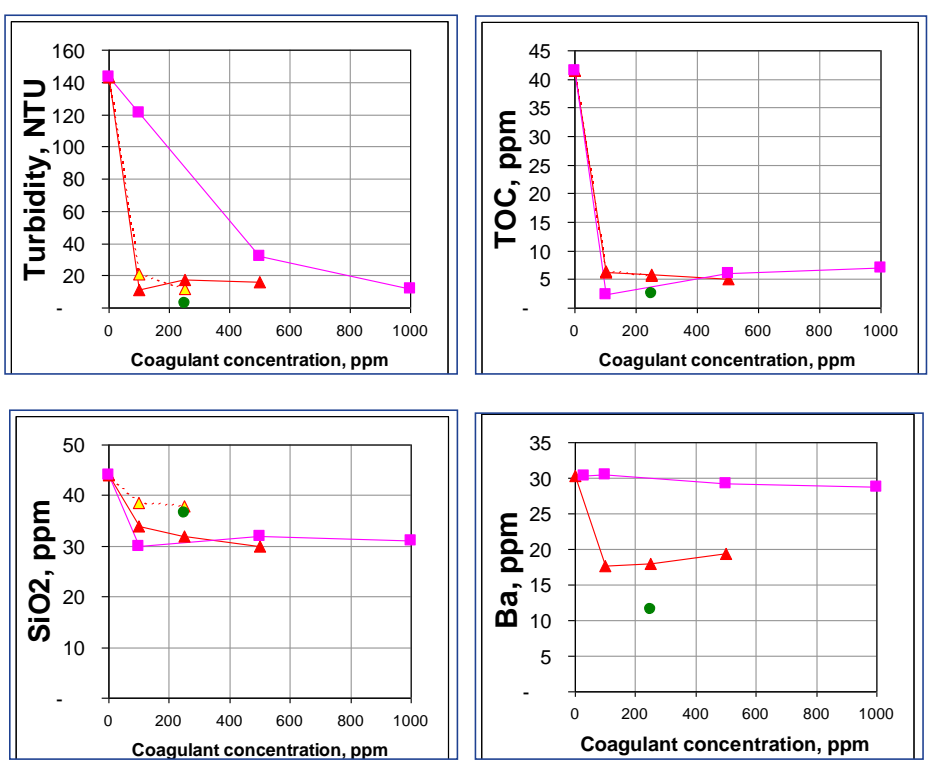

\section{Coagulants effectively remove target contaminants}

Figure 35. Clarification of frac flowback waters. Results of bench-scale experiments with the "composite" Days 1-14 Woodford Site-1 sample.

In Figure 36, the results of coagulation experiments with the Site-2 Day-26 sample are shown. For this experiment, the sample from the bottom of the 55-gal drum which had significant solids content was deliberately chosen to illustrate the effectiveness of the coagulation conditions. We observe that even this worst portion of the flowback water was effectively treated by these conditions. 


\section{Clarify: Evaluation of coagulants}
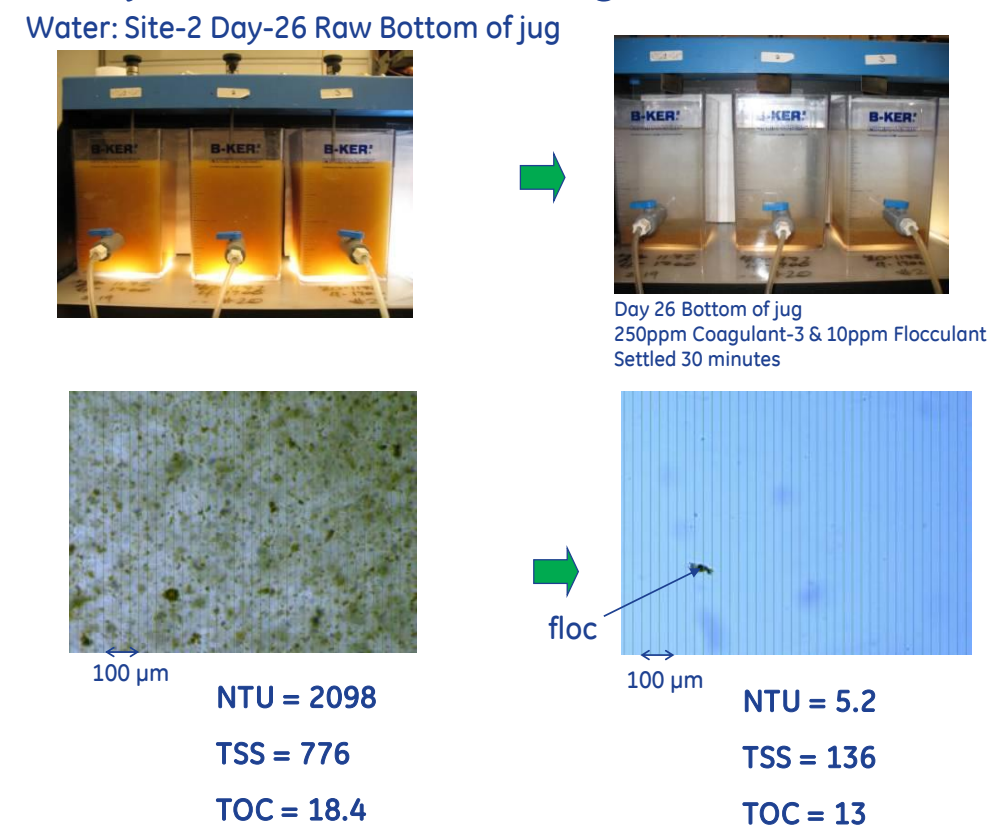

Figure 36. Clarification of frac flowback waters. Results of bench-scale experiments with the Day26 Woodford Site-1 sample.

In Figure 37, the results of coagulation experiments with the Site-1 Day-1 sample are shown. As seen in Figures 16 and 17, the Day-1 sample had the highest total suspended solids (TSS) and very high total organic carbon (TOC) values relative to the "composite" Days 1-14 from Site-1 or the Day-26 sample from Site-2. We observe in Figure 37 that the coagulation conditions that were successful previously with the "composite" Site-1 Days 1-14 sample in Figure 35 and Day-26 Site-1 sample in Figure 36 were not as successful with this Site-1 Day-1 sample.

\section{Clarify: Evaluation of coagulants}

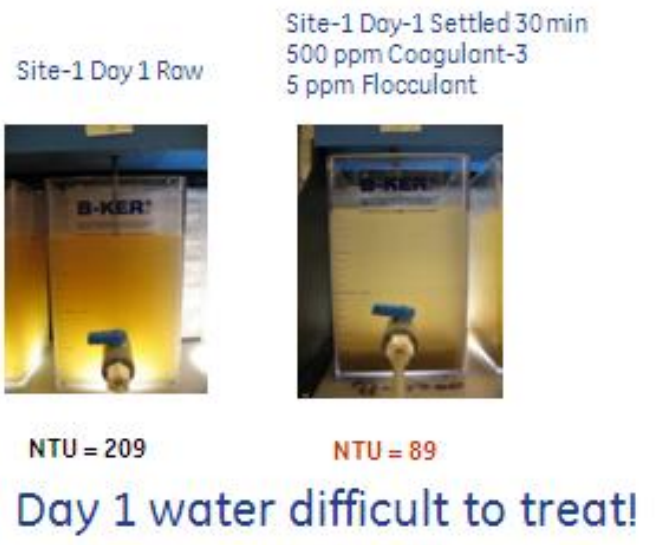

Figure 37. Clarification of frac flowback waters. Results of bench-scale experiments with the Day1 Woodford Site-1 sample. 
However, when the supernatant liquid after flocculation and settling was passed through a novel GE-ultrafiltration membrane, the desired clarification was obtained, as shown in Figure 38. The technique was also effective for the Day-26 sample from Site-2, although such extra clarification may not be necessary in this case.

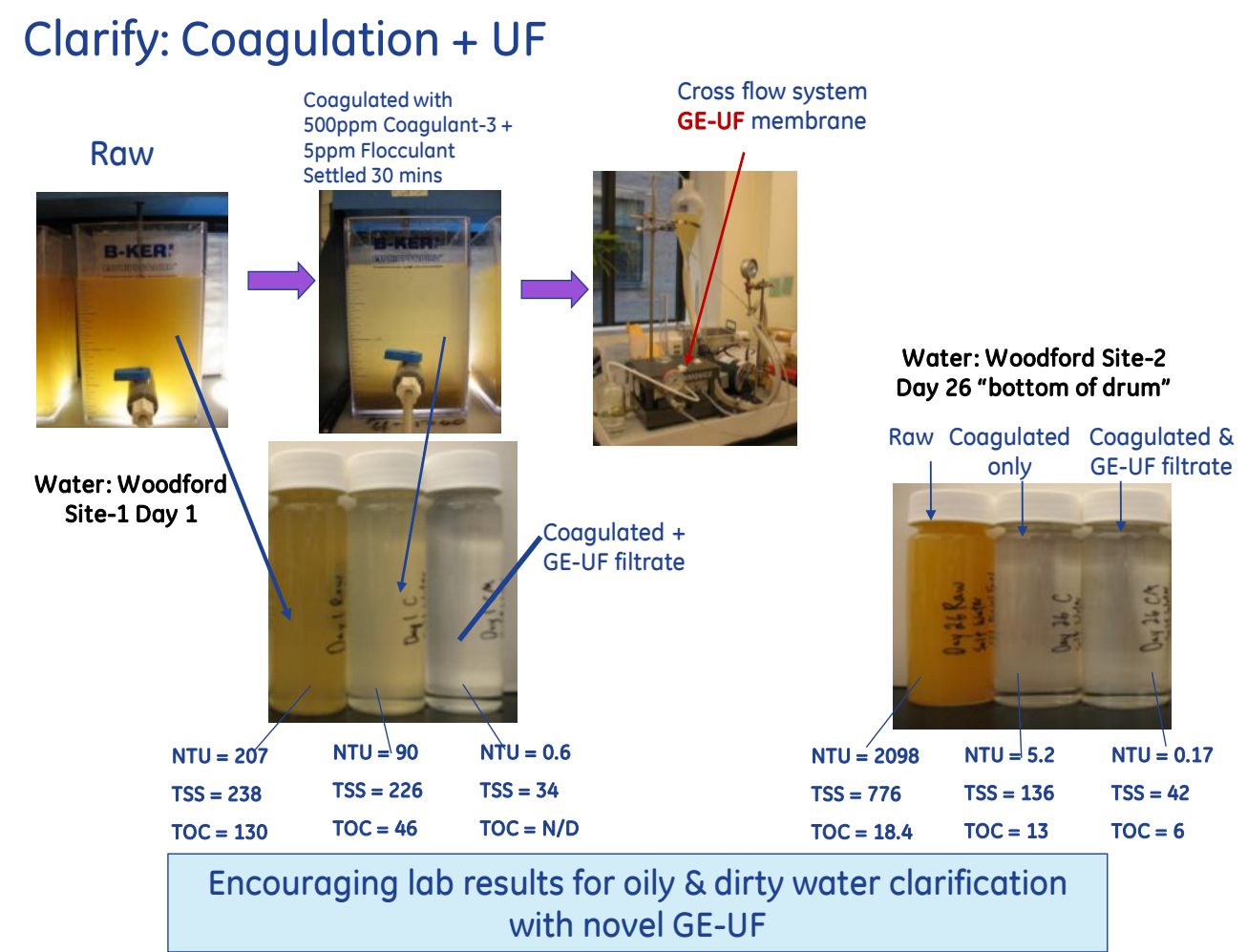

Figure 38. Clarification of frac flowback waters with coagulation and ultrafiltration. Results of bench-scale experiments with the Site-1 Day-1 and Site-2 Day-26 Woodford samples.

\subsubsection{Removal of Organics}

The sources of organic compounds in the frac flowback water were described in Section 3.3.2 and were broadly classified as Free Oil \& Grease, Dissolved Organics and Volatile Organics. In the data shown in Figures 35-38, we observed that it is relatively difficult to reduce the TOC for the Site-1 Day-1 water compared to the Site-2 Day-26 and Site-1 "composite" waters. It is very likely that the nature of the organics for the Site-1 Day-1 water is significantly different compared to the other later flowback samples, perhaps more contaminated by the Free Oil \& Grease components.

For better understanding, various sorbents were evaluated. In Figure 39, the sorbent performance from isotherm experiments are plotted for similar experiments conducted with the Site-1 Day-1 sample and Site-1 "Composite" Days 1-14 sample. Interestingly, with the Day-1 sample, we observe two distinct regions in terms of efficacy of organics removal: (a) "easy" to remove organics from $\sim 180 \mathrm{ppm}$ to $\sim 30 \mathrm{ppm}$ TOC, and (b) "difficult" to remover organics down from $\sim 30 \mathrm{ppm}$ TOC. This suggests to possibly different natures of the two sets of organ- 
ics in the flowback sample. Moreover, we observe a similar behavior with the "Composite" Days 1-14 water sample, with an "easy" to remove group down to 20 30 ppm TOC and a more "difficult" to remove group down from 20 ppm TOC. Very interestingly, the slopes for the "easy" regions of the adsorption isotherms for the two samples shown in Figure 39 are same, which indicates that the "composite" sample may be considered to be a diluted version of the Day-1 sample in this regard.

\section{Organics removal with sorbents: Lab-scale experiments}

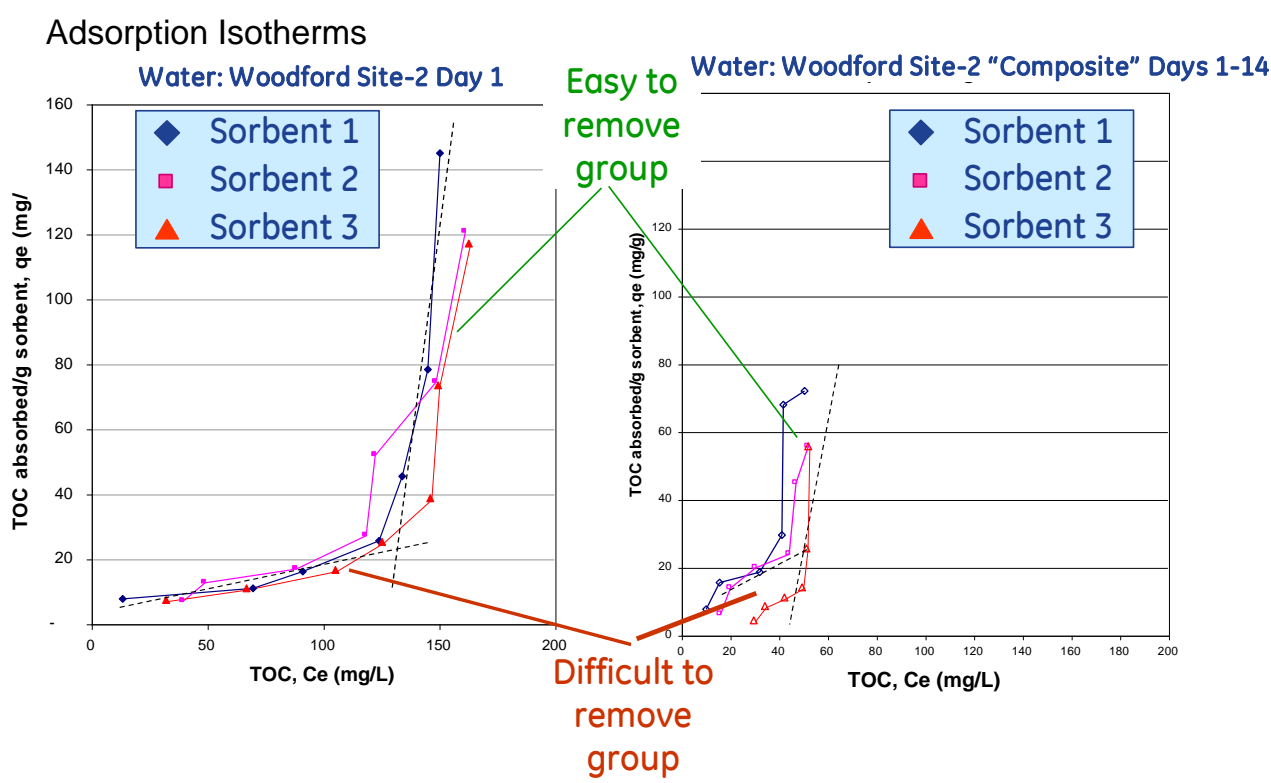

Two "oil" groups - easy vs difficult to remove with sorbents!

Figure 39. Removal of organics from Woodford shale flowback samples. Comparison of adsorption isotherms of three sorbents for the Site-1 Day-1 sample and "Composite" Days 1-14 sample.

\subsubsection{Nature of the organics in frac flowback waters - novel analytical technique}

The organic content of the flowback waters were initially measured by two techniques, namely via "hexane extraction" and by Total Organic Carbon (TOC), as reported in Figure 17. The "Hexane Extractables" method gives a measure of the components that are hexane soluble and is a good indicator of the free Oil \& Grease content of the frac flowback water. The TOC measures the amount of combustible organic carbon present in the frac flowback water and is an indicator of dissolved and undissolved organics, including non-volatile and volatile compounds.

The "hexane extractables" and TOC methods are used routinely for estimating the organic content in waste waters. However, to understand the nature of these organic contaminants, we have used another technique developed by Hans Grade at GE Global Research that uses a 2-column gas chromatography (GC) method for separation of the components based on polarity and boiling point, followed by analysis with a Time of Flight Mass Spectrometer. In 
this technique, $100 \mathrm{ml}$ of the water of interest is mixed intimately with $20 \mathrm{ml}$ of methylene chloride to allow extraction of the organic contaminants into the methylene chloride phase. After separation of the two layers, the organic contaminants are analyzed by the GCxGC MS method. A pure methylene chloride with $10 \mathrm{ppb}$ methyl eiosonoate was used as the Control sample for comparison.

In Figure 40, the GCxGC MS plots for the Day-26 raw frac sample and the Control sample are shown in the 2-dimensional format of Polarity $\times$ Boiling Point. We notice the location of different hydrocarbons on the plot for Site-2 Day-26 water.
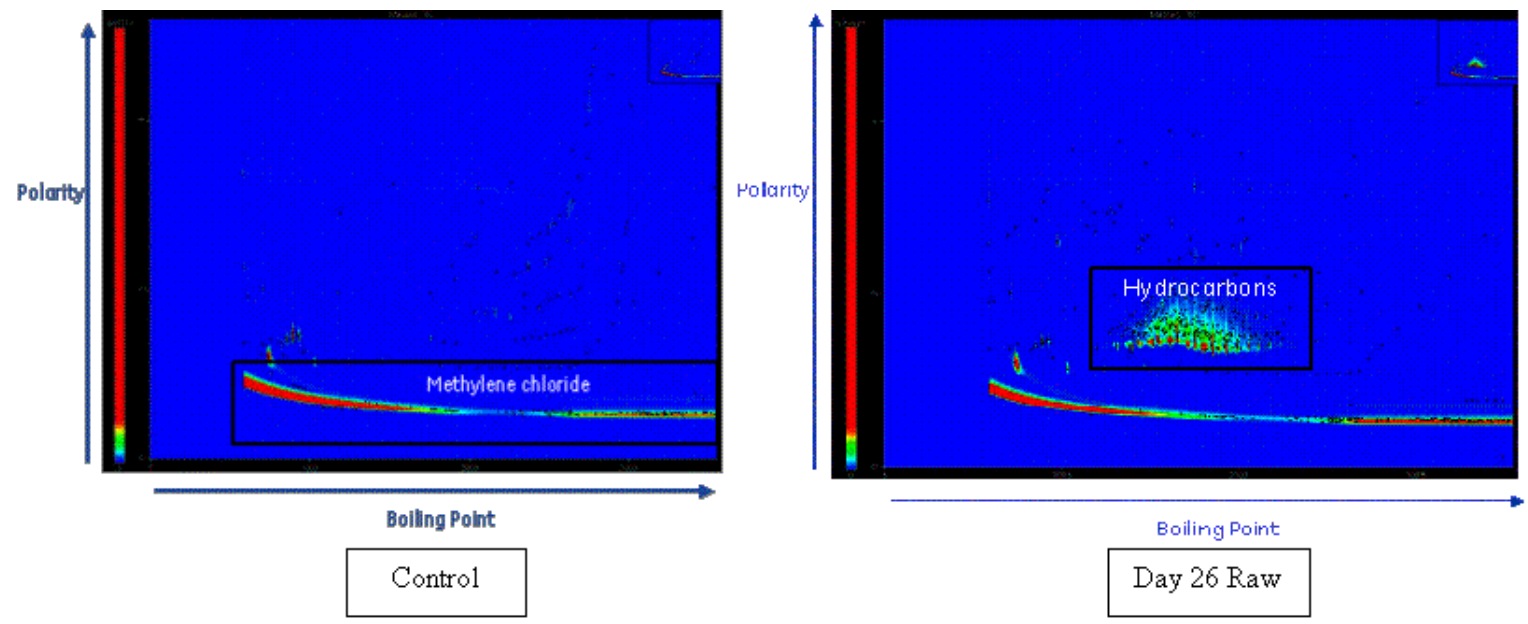

Figure 40. GCXGC-MS 2-D plots for the Control and Day-26 (frac) raw water. Note the presence of hydrocarbons of various polarities and boiling points (molecular weight) in the Site-2 Day-26 sample.

The GCxGC-MS data may also be plotted in a 3-D format to indicate the magnitude of the response, as shown in Figure 41 for the Control sample. It should be noted that although the magnitude could be an indicator of the concentration of the organic contaminant lor fragment), it may be influenced by a variety of others factors. Hence, these 3-D plots are best used as qualitative indicators. 


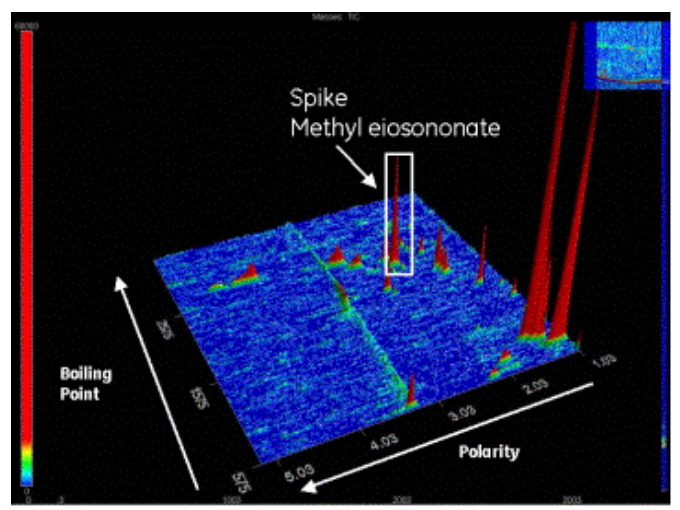

Figure 41. GCXGC-MS 3-D plot for the Control methylene chloride (with $10 \mathrm{ppb}$ methyl eiosonoate).

Similarly, GCxGC-MS 3-D plots for the Site-2 Day-26 and Site-1 Day-1 frac water field samples are shown in Figure 42. The corresponding data for the hexane-extractables and TOC methods shown in Figure 17 are also reproduced in Figure 42. We observe that the Site-1 Day-1 sample has more polar hydrocarbon compounds and also higher intensities. This corresponds to higher total organic carbon in the Site-1 Day-1 raw water compared to Site-2 Day26 sample.

\section{Hydrocarbon removal analysis}

\section{Novel sample analysis based on GC $\times$ GC + ToFMS technique (Instrument: LECO Pegasus 4D )}

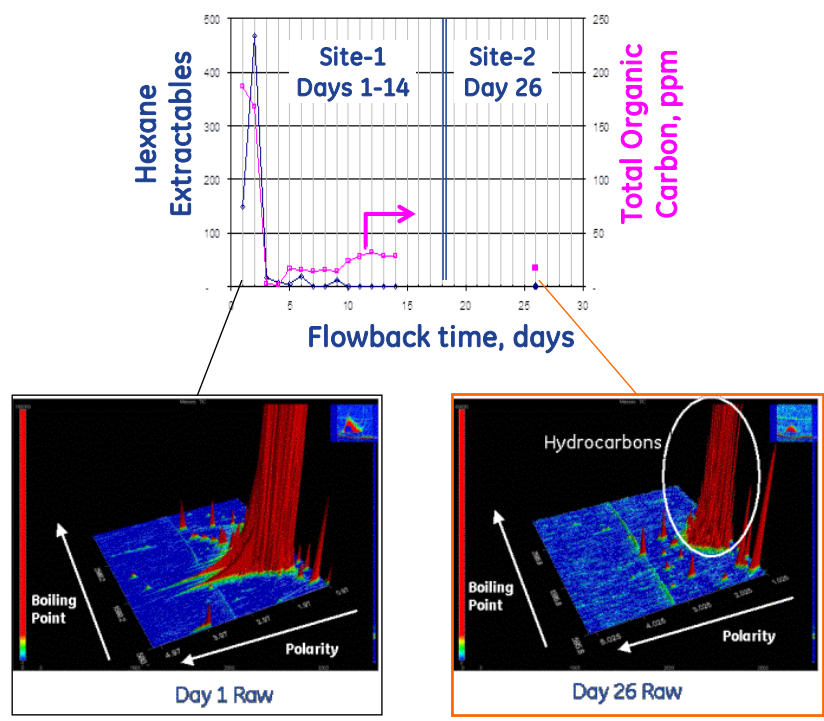

Hans Grade, GE GRC

Figure 42. GCxGC-MS 3-D plot for the Day-26 and Day-1 frac water field samples. Day-1 sample has more polar hydrocarbons and in general, higher intensities corresponding to the overall higher TOC content. 
Evaluation of various treatment methods for removing organics in frac flowback waters

A series of 1-liter jar experiments were conducted with the frac flowback field samples using a variety of coagulants, flocculants, adsorbents, and oxidants and for various operating conditions (time, mixing conditions). Samples were collected during these experiments and analyzed by the above mentioned GCXGC-MS method to evaluate the effect of the treatment method on appearance or disappearance of organic species. For example, in Figure 43, the GCXGC-MS plot for the water sample after Treatment 1 is compared to the original raw Site-2 Day-26 water sample. We observe that the Treatment 1 introduced certain species that were shown to correspond to surfactant molecules.



Day 26

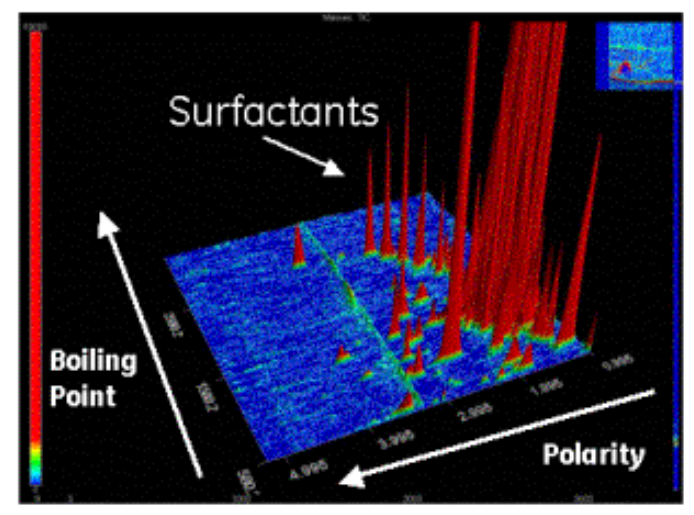

Treatment 1

Figure 43. Effect of Treatment\#1 on the organic contaminant levels of the Day-26 frac flowback water sample. Observe the appearance of peaks associated with surfactant molecules.

Similarly, Treatment method 5 and Treatment method 13 are compared in 2-D GCxGC-MS plots in Figure 44. We observe that Treatment 5 has effectively removed a portion of the hydrocarbons found in the original Day-26 raw water, while Treatment 13 has significantly diminished the intensities of the hydrocarbon peaks relative to raw and after Treatment 5.

The effect of operating time for Treatment \#13 on the level of organic contaminants in the frac flowback water is illustrated in Figure 45. We observe that the intensities of the peaks corresponding to organic contaminants diminishes significantly for longer operating times.

From the above results it is clear that the novel GCXGC + ToFMS analytical technique provides a powerful means to evaluate the effect of various treatment methods on the presence and disappearance of various organic species. However, it should be noted that the nature of this research is still in its infancy. More work is required to quantitatively link the effectiveness of any treatment method on the removal of particular organic species that are undesirable for product quality specifications for frac re-use or impact on desalination membrane fouling. 


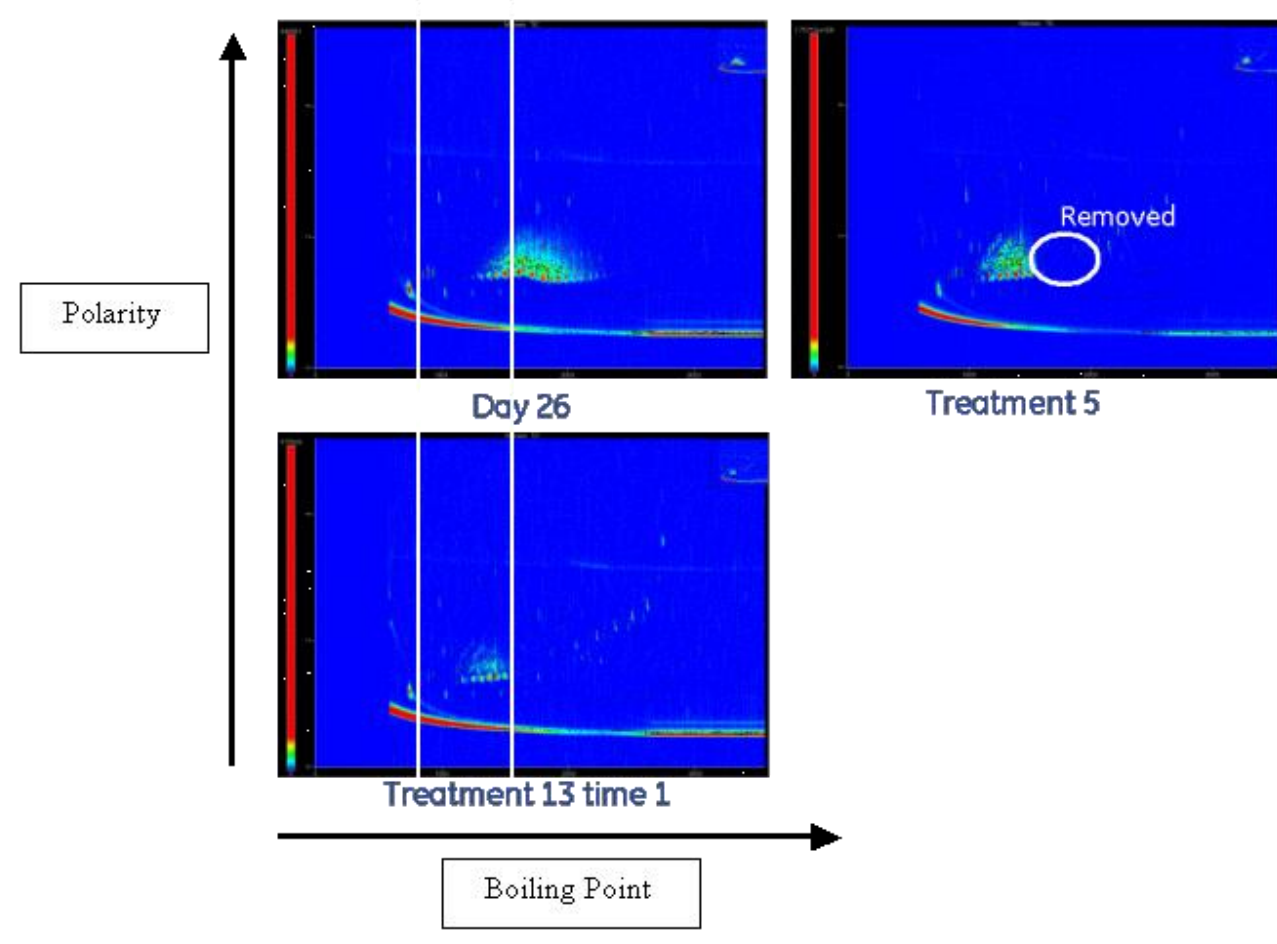

Figure 44. Comparison of GCxGC-MS 2-D plots for Day-26 raw water and after Treatment\#5 and Treatment\#13.

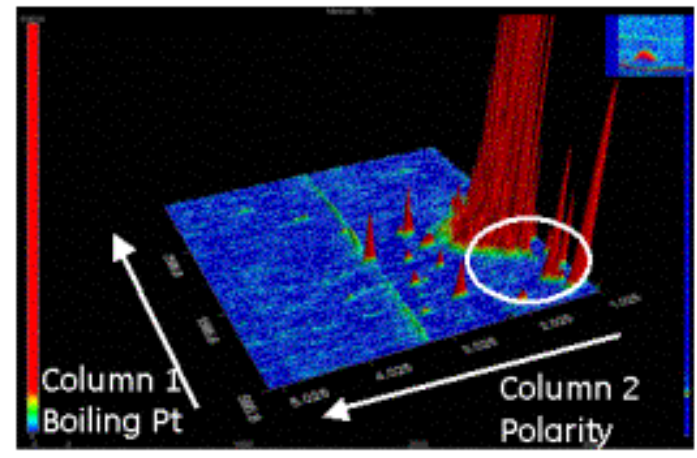

Dav 26

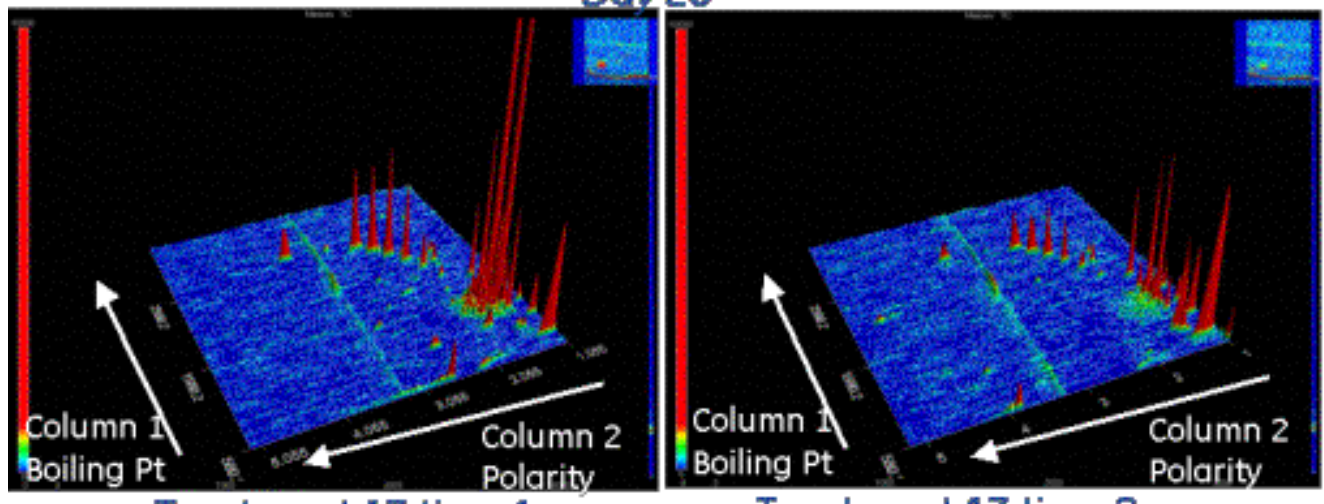

Treatment 13 time 1

Treatment 13 time 2

Figure 45. Comparison of GCxGC-MS 3-D plots for Day-26 raw water and after Treatment\#13 for two different times.

GE Global Research 


\subsubsection{Process Step: "Soften"}

The removal of "hardness" ions, such as $\mathrm{Ca}, \mathrm{Mg}, \mathrm{Ba}$ and $\mathrm{Sr}$, may be accomplished by precipitation methods, such as lime softening or membrane methods, such as nanofiltration that selectively reject the divalent and trivalent ions. The lime-softening process, if properly designed would provide water recoveries in the range of $>95 \%$, which satisfies the requirements in Figure 30. We evaluated nanofiltration via modeling with the GE Winflows membrane system design and simulation software 20 using technical performance data for GE's nanofiltration membranes. For the frac feed water sample analyses reported in Table 3, although the removal of hardness was $>80 \%$, the water recoveries were in the range of $50 \sim 80 \%$, which is much lower than the product specifications in Figure 30. Hence, we have focused our efforts on evaluating only lime-softening for softening frac flowback waters.

Lime softening has been industrially used for more than a hundred years. It may be operated in the "cold" mode or "hot" mode. Although the "hot" mode requires less chemicals, choossing the "cold" mode will provide robustness to our conceptual process in handling frac flowback waters from a variety of frac sites.

The principles and process of lime softening are best explained on the GE Water website ${ }^{21}$. Hence, only a summary is provided below.

When hydrated lime, $\mathrm{Ca}(\mathrm{OH}) 2$, is added to the water being treated, the $\mathrm{Mg}++$ ions are precipitated as $\mathrm{Mg}(\mathrm{OH}) 2$. Noncarbonate or permanent calcium hardness, if present, is not affected by treatment with lime alone. The frac flowback water sample analyses shown in Table 3 indicate a high level of noncarbonate hardness - the total hardness/" $M$ " alkalinity ratio is 45 for the three samples under consideration. In such cases, soda ash $\left(\mathrm{NaCO}_{3}\right)$ is added to precipitate the $\mathrm{Ca}++$ as $\mathrm{CaCO} 3$.

Bench-scale experiments were conducted by addition of $\mathrm{Ca}(\mathrm{OH}) 2$ and $\mathrm{Na} 2 \mathrm{CO} 3$ to 1-liter jars containing the frac flowback sample. The results for the Site-1 Day-1 and Site-1 "Composite" Days 1-14 samples are shown in Figure 46. Similar data was obtained for the Site-2 Day-26 sample (reported later in Table 5). We observe that lime softening conditions are able to significantly reduce the hardness levels to meet the specifications for Product- 2 and the pretreatment levels required for desalination membrane processes.

The process equipment required for precipitation softening are vessels with mixing equipment to contact the feed water with the lime initially and then with soda ash. After sufficient contacting, the precipitate is allowed to settle and the clear liquid is filtered. The settled solids or sludge needs to be compacted to reduce the water content and lower the waste handling and disposal costs. A combination of sludge compaction and filtration is used typically to obtain wastes containing $\sim 30 \%$ solids. Further reduction of the water content may require some means of evaporation. The relative costs of locating such sludge drying processes onsite versus the waste disposal costs need to be weighed on an individual frac flowback site basis. 


\section{Clarify + Soften: Lab-scale experiements}

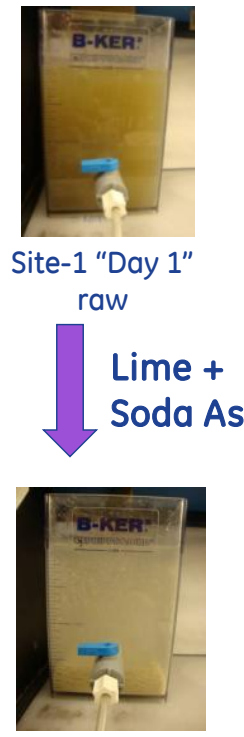

$25 \min$ settling
Site-1 Day 1 water
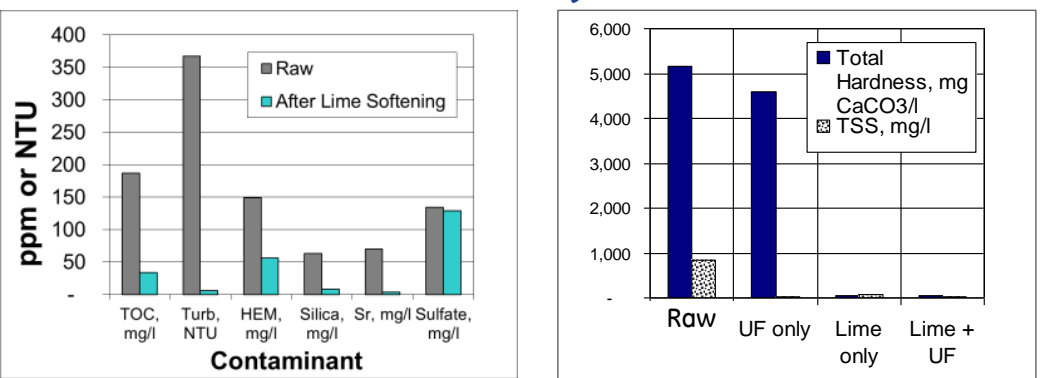

Site-1 "Composite" water
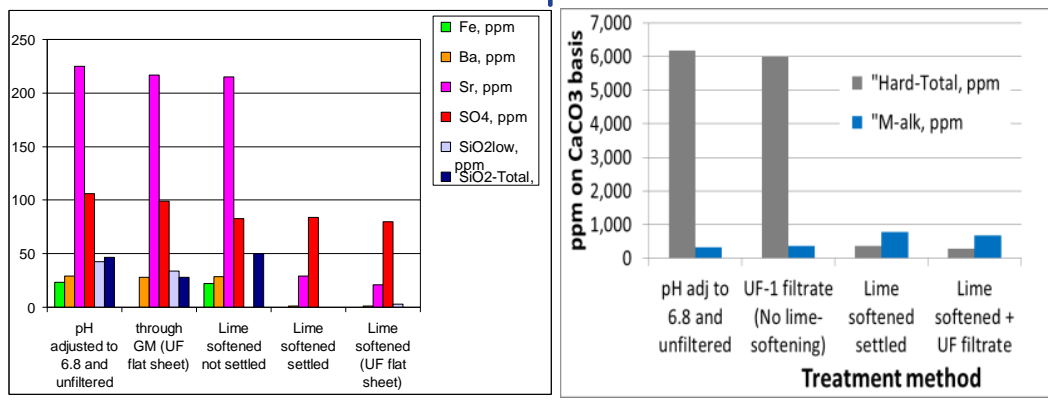

Softening feasible for Woodford frac flowback water samples

Figure 46. Clarification of frac flowback waters with coagulation and ultrafiltration. Results of bench-scale experiments with the Site-1 Day-1 and Site-2 Day-26 Woodford samples.

The expected water recovery after such a lime-softening process is expected to be $>95 \%$.

Mass balances were conducted for a 50-gpm frac flowback water treatment system to determine the amounts of lime $\&$ soda ash required and the amount of waste stream generated.

For the Site-2 Day-26 stream shown in Table 3, the amounts of $\mathrm{Ca}(\mathrm{OH}) 2$ and Soda Ash required per bbl of feed water would be $0.38 \mathrm{lbs}$ and $0.56 \mathrm{lbs}$, respectively on a dry basis. The amount of sludge (30\% solids) produced would be $3.68 \mathrm{lbs} / \mathrm{bbl}$ feed processed, i.e. 3.2 short tons/day. Assuming disposal costs of $\$ 70 /$ ton at a non-hazardous disposal site located within 50 miles and transportation costs of $\$ 5 /$ mile, the waste disposal costs are estimated to be in the range of $\$ 0.15 / \mathrm{bbl}$ of feed.

For the Site-1 Composite Days1-14 sample, which contains a higher level of hardness, the amounts of $\mathrm{Ca}(\mathrm{OH}) 2$ and Soda Ash required per bbl of feed water would be $0.50 \mathrm{lbs}$ and 1.91 lbs, respectively on a dry basis. The amount of waste generated would be $7.84 \mathrm{lbs} / \mathrm{bbl}$ water processed, i.e. 6.7 short tons/day. The waste transportation and disposal is estimated in the range of $\$ 0.30 / \mathrm{bbl}$ of feed. 


\subsubsection{Desalination Membrane performance}

For Product-3 and Product-4, that require desalination to TDS levels $<20,000 \mathrm{ppm}$ and $<500$ ppm, respectively, the performance of membrane desalination was evaluated via modeling using the GE Winflows membrane system design and simulation package ${ }^{20}$. Various membrane materials and system design configurations were considered to increase water product recovery. The methodology is illustrated in Figure 47 for a feed solution with composition similar to that obtained after pretreating (lime softened and filtered) Site-2 Day-26 sample. This feed rate was $50 \mathrm{gpm}$ and contained $35 \mathrm{~K} \mathrm{ppm} \mathrm{TDS}$, while the desired product has TDS $<500 \mathrm{ppm}$, i.e. meeting Product-4 quality requirements (cf. Figure 30). We observe that by appropriate choice of membrane system designs, it is possible to increase the recovery from $49 \%$ using the standard seawater-desalination design to as high as $61.5 \%$. The retentate concentration correspondingly increased from $68 \mathrm{~K} \mathrm{ppm}$ to $90 \mathrm{~K} \mathrm{ppm} \mathrm{TDS} \mathrm{for} \mathrm{these} \mathrm{conditions.}$ This has implications on overall system recovery and costs of the overall flowback water recovery process, as will be discussed under Task 6 . The increase in the number of stages and process complexity increases capital equipment costs in terms of pumps, membrane modules, interconnected piping and control equipment. Hence, trade-offs of higher recovery vs. higher equipment costs needs to be considered.

\section{Desalination: Increasing water recovery by Multi-staging}

\section{Modeling with GE Winflows membrane simulation package}

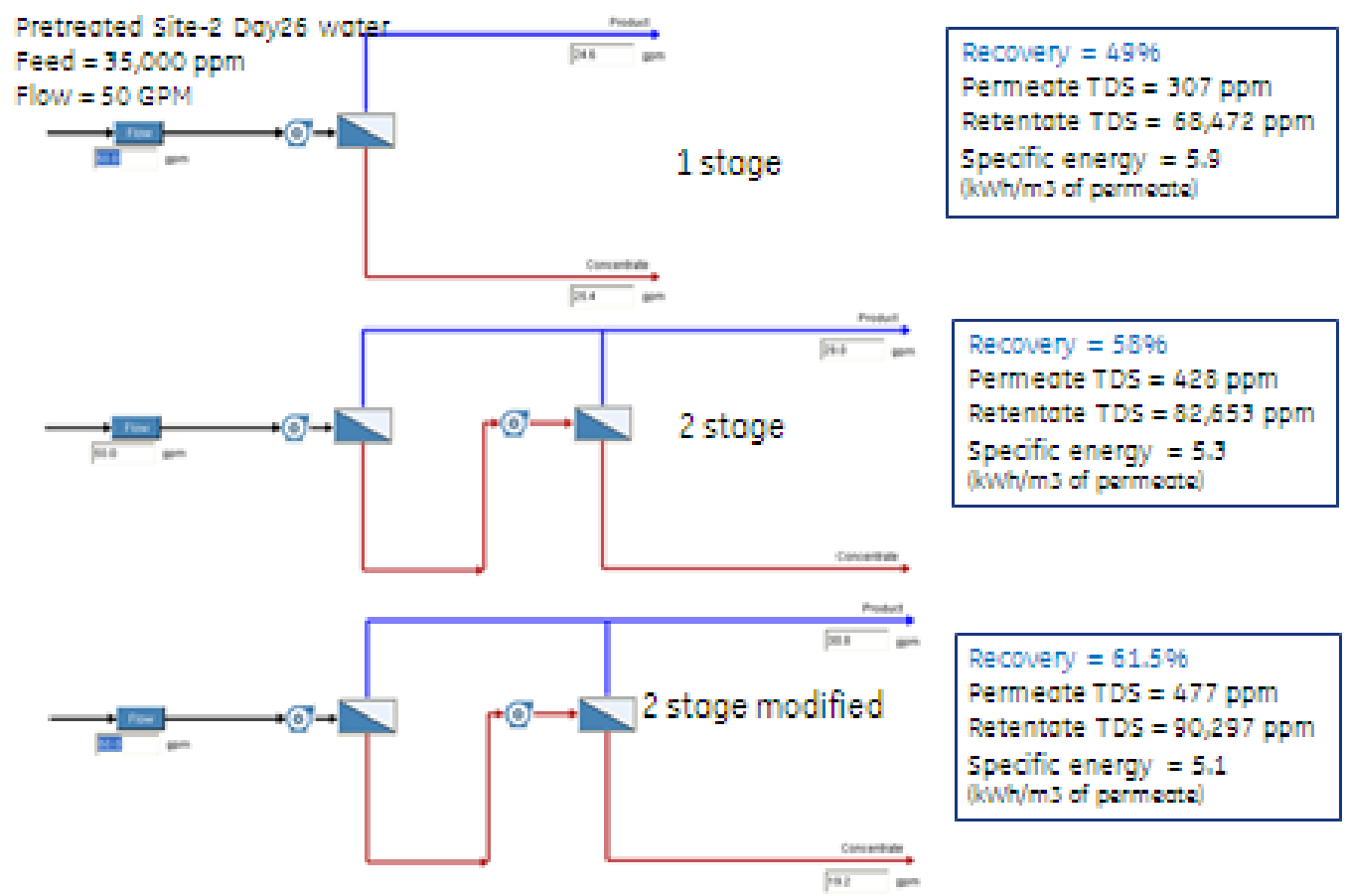

Figure 47. Maximizing RO-desalination water recovery of pretreated Site-2 Day-26 flowback water via simulation studies using GE Winflows software ${ }^{20}$. 


\subsubsection{Process Flowsheets}

Using the information from the bench-scale experiments for the various pretreatment steps, detailed conceptual flowsheets for the treatment processes were constructed for each of the Products 1-4 under consideration. For the case of producing Product-1 quality water, the conceptual flowsheet is illustrated in Figure 48.

\section{Process Concept for Product 1}

Removal of Free Oil, TSS, Microbiologicals, TOC



Figure 48. A conceptual process flowsheet for treating frac flowback waters to produce waters meeting Product-1 quality specs (cf. Figure 30).

Similarly, process flowsheets were constructed to meet the respective quality requirements for Product-2, Product-3 and Product-4. These were evaluated for technical performance, costs and mobility for a 50-gpm feed (frac flowback) mobile rig system. Technical performance evaluation included mass and energy balances, including waste generation and handling. Costs included capital expenses for equipment and assembly, and operating expenses for amortization of capital equipment, rig-setup labor, chemicals, membranes, power, and waste removal. Mobility included the preliminary assessment of the rig configurations suitable to treat $50 \mathrm{gpm}$ of the frac flowback water.

The treatment costs to produce Product-4 - the most challenging and most expensive - is illustrated in Figure 49. As described earlier, treatment costs include $\mathrm{C}_{\text {setup }}$ (Cost of mobile rig transportation and setup at the frac site) and Cprocess (Cost associated with the capital and operating expenses related to the process steps). It does not include the cost of product- and concentrate-disposal. The labor costs associated with setting up the mobile rig are included in $\mathrm{C}_{\text {setup }}$ and thus in the $\mathrm{C}_{\text {Treatment }}$ value. However, the rig operating labor for treating flowback water has not been included since these costs may be accounted differently by different producers as the rig may be run by operators handling multiple responsibilities at the frac site.

We observe the following in Figure 49: 
- The treatment cost, $C_{\text {Treatment }}<\$ 2 /$ bbl feed, which was the target for our verification of success criteria (cf. Figure 32)

- Nearly $75 \%$ of the operating costs are related to "fixed" charges (capital equipment related and rig transportation \& setup), 18\% due to chemicals and solid wastes disposal, while cost of replacement membranes and electricity costs were only $2 \%$ and $5 \%$, respectively. This indicates that for such low throughput mobile rigs, optimizing membrane performance to reduce power consumption will not have significant impact on the overall economics. What really matters is that the overall water recovery is improved while keeping the system capital costs low.

\section{Operating cost breakdown for $50 \mathrm{gpm}$ mobile membrane rig}

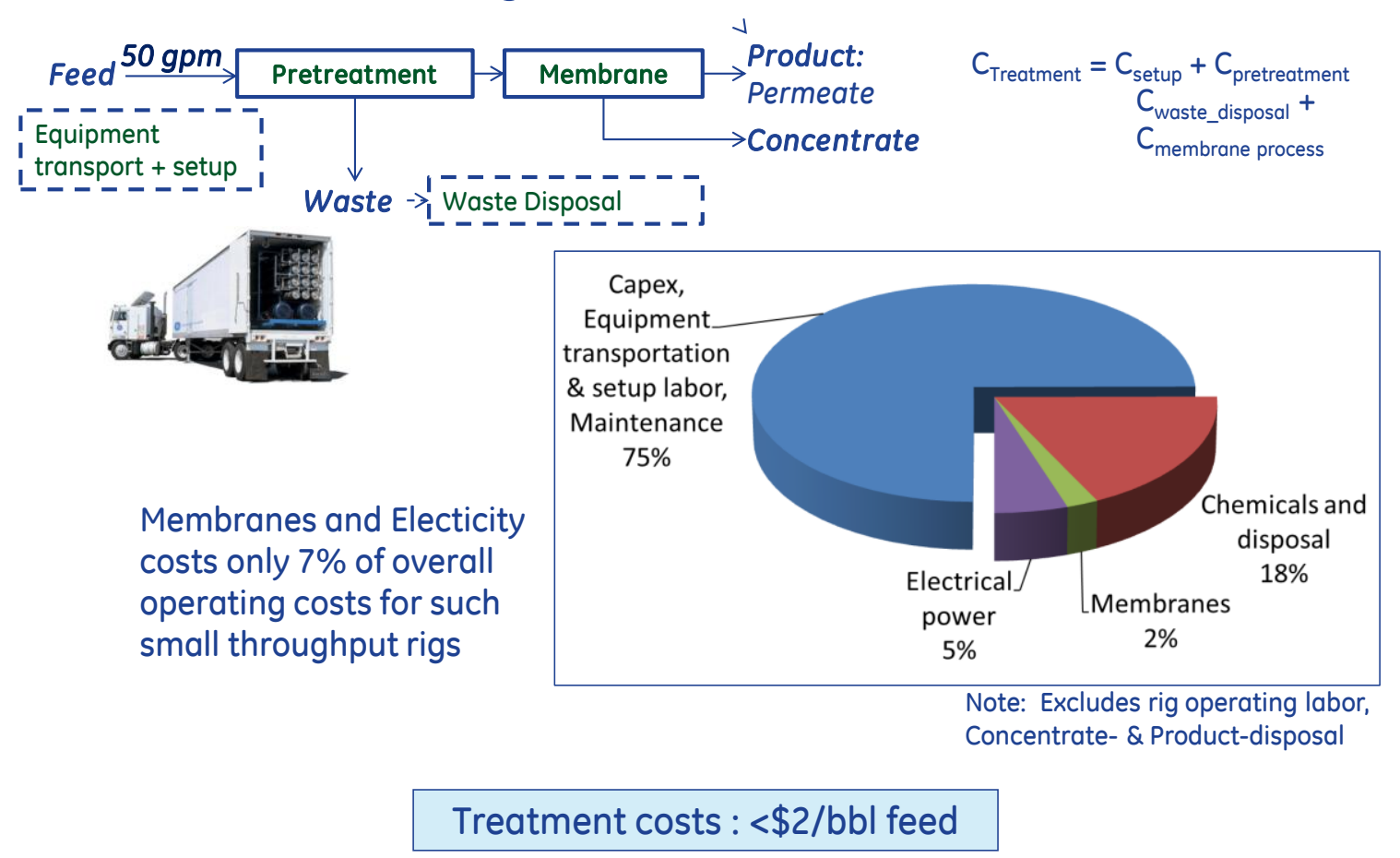

Figure 49. Operating cost breakdown for a $50 \mathrm{gpm}$ mobile membrane rig capable of producing $<500$ ppm TDS product

\subsubsection{Conclusions from Task 4:}

The results of the bench-scale experiments, membrane system simulation and system cost analysis indicated the following in relation to the verification of success criteria for this project (cf. Figure 32):

- Technical Performance: There is a high level of confidence that the conceptual processes will be effective to yield the Products $-1,-2,-3$ and -4 of desired quality since these process flow schemes were constructed based on the bench-scale experimental studies on 
the individual separation technologies using actual frac flowback samples. Many of the initial concerns were mitigated by appropriate choice and verification of process operating conditions in the lab-scale experiments.

- Cost Performance: The estimated costs for the four product options were within the cost criterion of $<\$ 2 / \mathrm{bbl}$ that was established in Task 2 , and in line with preliminary feedback on customer expectations. The cost estimations were based on reliable values obtained either from vendors or internal cost information for the desired equipment. Other cost factors, such as costs of electricity, type and cost of labor, waste handling \& disposal, were also obtained either from appropriate vendors or internal cost information.

- Mobility Performance: Based on vendor information on sizes and operations of the various equipment identified for the conceptual processes, and internal data on mobile rig operations, $50-\mathrm{gpm}$ mobile rig configurations may be achievable for the four products under consideration.

Based on these technical-, economic- and mobility-feasibility analyses on currently available customer information for product quality and cost information, and the supporting lab-scale experimental results, the recommended course of action for the critical go/no-go decision was to go ahead with the project towards Tasks 5 and 6.

\subsection{Task 5: Obtain bench-scale experimental data suitable for process modeling}

\subsubsection{Objectives and Approach}

The objectives were:-

- Obtain membrane performance parameters necessary for system performance modeling.

- Demonstrate the efficacy of the downselected pretreatment methods to treat the field samples for low fouling of the RO-membranes during desalination.

Desalination experiments were conducted in the membrane-module testing rig shown in Figure 50. The rig consists of a feed tank, a high pressure pump, a membrane module housing, and relevant pressure, flow, conductivity and temperature sensors. Water is pumped from the feed tank through the membrane module inside the housing. A portion of that feed water permeates through the membrane (called "permeate"). The remaining portion (called "retentate") is returned to the feed tank. A cooling bath and appropriate heat exchange equipment ensure that uniform temperature is maintained during the entire course of the experiment (note that the pumping energy results in a significant temperature rise of the re-circulating water).

The independent parameters are:

- Feed composition

- Feed rate 
- Pressure

- Temperature

- Membrane module parameters: Membrane type, Surface area, Internal geometry

The dependent \& measured parameters are:-

- Permeation rate

- Permeate concentration

- $\%$ recovery per pass



Figure 50. Membrane module testing rig for conducting desalination experiments with pretreated field frac flowback samples at GE Global Research.

Modes of operation:

- Closed circuit: The permeate is returned to the feed tank. In this case, the net concentration in the feed tank essentially remains constant since the retentate and permeate streams are re-mixed. This mode is useful for determining the stability of the membrane performance as a function of time. We used this mode to evaluate the possible fouling of the RO membranes over a period of 24 hours, as described below.

- Open circuit: The permeate is not returned to the feed tank. In this case, the loss of desalinated permeate volume results in a net increase in TDS concentration in the 
feed tank. This mode is useful for determining the membrane performance properties as a function of feed concentration.

The membrane performance parameters of interest are:

- Water-flux parameter: This is frequently referred to as "A-value" in reverse osmosis literature. A high value of this parameter is preferred as it implies a low membrane surface area requirement for the given separation duty, and thus lower costs and smaller footprint for the ultimate application. Conversely, for a given membrane module configuration (fixed area), a high A-value implies lower pumping pressure requirements.

- Salt-flux parameter: This is frequently referred to as "B-value" in reverse osmosis literature. A low value is preferred for this parameter as it implies low permeation of the salt species through the membrane, which results in a more purified permeate product.

- Salt-rejection parameter: This parameter is an indicator of the separation efficiency of the RO membrane at the operating conditions. A high value is preferred as it yields a more purified permeate product.

These parameters are used for modeling large-scale membrane module performance and also for membrane-system level performance modeling.

\subsubsection{Membrane performance parameters vs. Feed composition}

The field sample Site-2 Day-26 was subjected to appropriate pretreatment process steps to produce 14 liters of solution (approx. 95\% recovery) with a TDS of $\sim 33,000$ ppm. Similarly, the field sample "Day-1" was subjected to appropriate process steps to produce 7 liters of solution (approx. 95\% recovery) with a TDS of $\sim 20,000 \mathrm{ppm}$. Desalination of this treated water was performed using spiral wound modules (2" diameter, $4.5 \mathrm{ft} 2$ membrane area) with highselectivity membranes that are typically used for seawater desalination to produce very low TDS permeate product (<500 ppm TDS).

The experiments were conducted in the open circuit mode to obtain the profiles of the desired membrane performance parameters as a function of feed composition. The permeate TDS for both of the field sample runs are plotted in Figure 51. For the Site-2 Day-26 sample, we observe that the feed concentration increased from $37,500 \mathrm{ppm}$ TDS to $64,000 \mathrm{ppm}$ TDS, with a net permeate recovery of $42 \%$ at an operating pressure of 800 psi. Further experimentation was stopped since the permeation flow rate was too low due to the high osmotic pressure of the feed solution as its concentration increased. For the Site-1 Day-1 sample, we observe that the feed concentration increased from 20,000 ppm TDS to 42,000 ppm TDS, with a net water permeate recovery of about $51 \%$. Further recovery would have been possible but the experiment had to be stopped because of the low levels in the feed tank. Nevertheless, it is interesting to note the smooth nature and overlap of the permeate TDS vs. feed TDS profile for the two different pretreated field flowback samples in Figure 51, which is due to 
the membrane properties and the cleanliness of the pretreated field frac flowback samples. We observe that the permeate TDS concentration rises rapidly as the feed TDS concentration rises for this membrane.

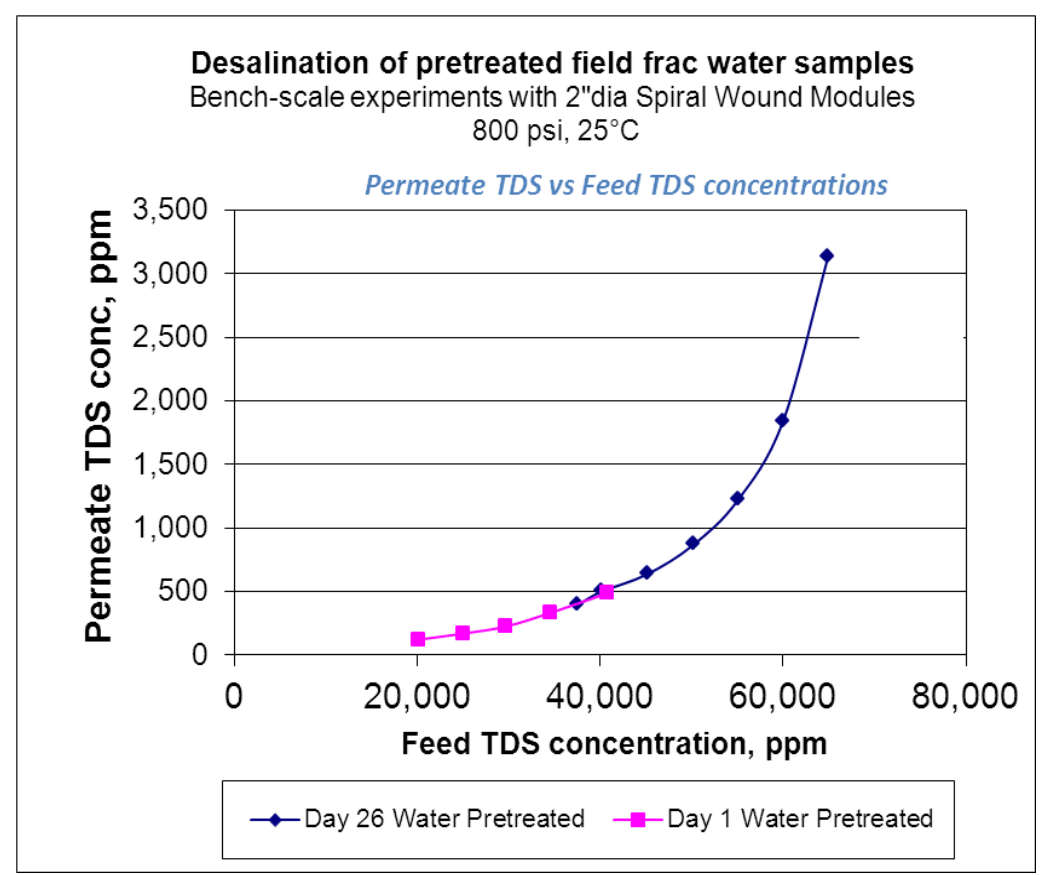

Figure 51. Permeate TDS vs. Feed TDS for the 2" spiral wound RO module runs using 10 15 liters of pretreated field frac flowback samples. See text for details.

The membrane performance parameters, namely water-flux, salt-flux and salt-rejection vs. Feed TDS concentration for these two pretreated field frac flowback samples are shown in Figures 52, 53, and 54, respectively. 




Figure 52. Water flux parameter vs. Feed TDS for the 2" spiral wound RO module runs using 10 15 liters of pretreated field frac flowback samples. See text for details.

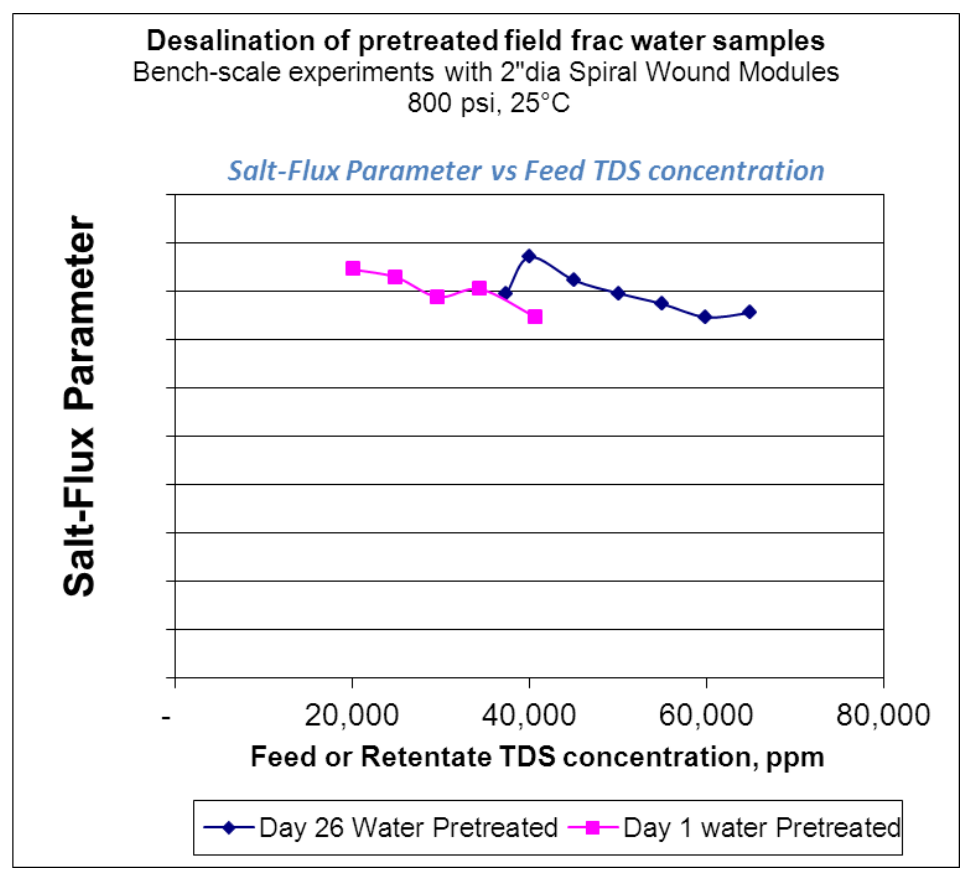

Figure 53. Salt-flux parameter vs. Feed TDS for the 2" spiral wound RO module runs using 10 15 liters of pretreated field frac flowback samples. See text for details. 


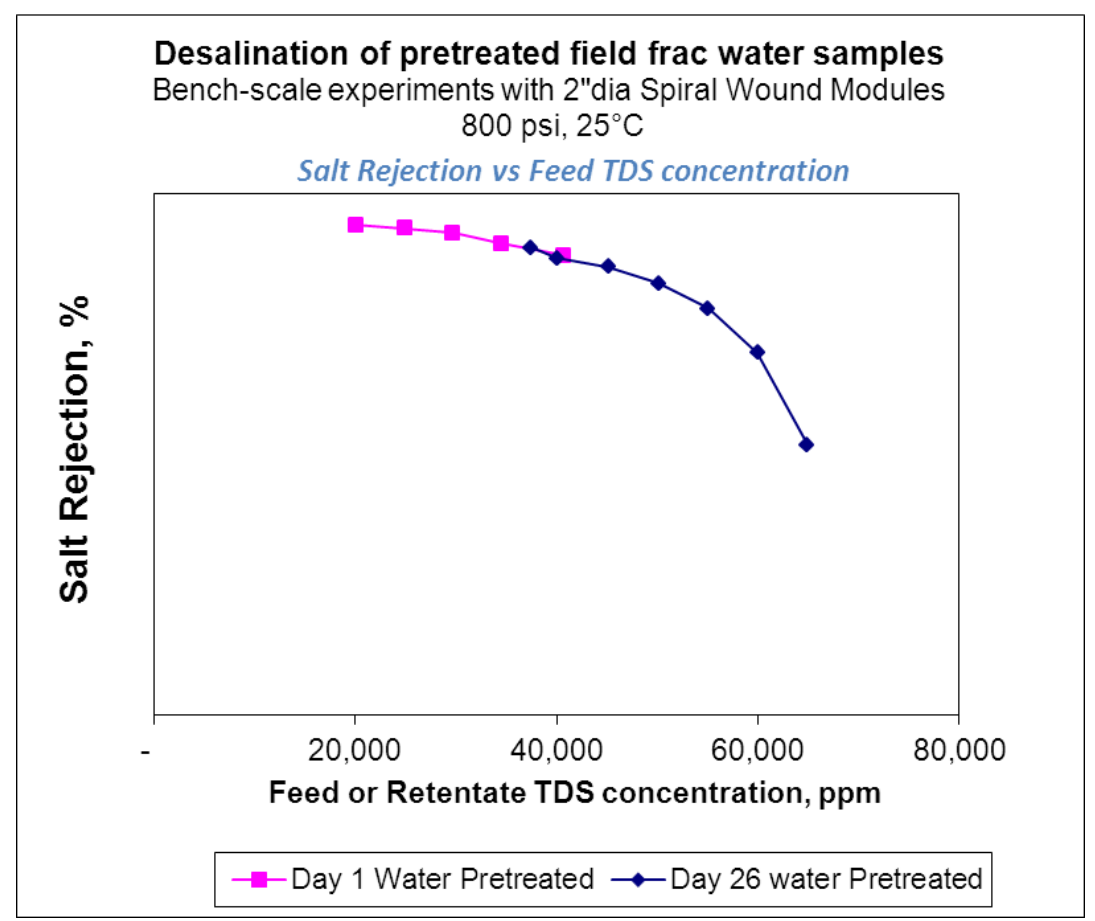

Figure 54. Salt-rejection parameter vs. Feed TDS for the 2" spiral wound RO module runs using 10 15 liters of pretreated field frac flowback samples. See text for details.

As mentioned earlier, these parameters are useful for modeling large-scale membrane module performance and also for membrane-system level performance modeling. Similar data were gathered for other membrane types; especially those with higher flux (perhaps lower salt rejection) to yield lower quality (higher TDS) permeate suitable to meet the Product-3 quality requirements (cf. Figure 30).

\subsubsection{Evaluation of Desalination Membrane Fouling}

The pretreated Site-2 Day-26 field frac flowback sample was used to evaluate the effectiveness of pretreatment on the fouling of a desalination membrane over a period of 24 hours. The parameters considered were the water-flux, salt-flux and salt-rejection. The results for the pretreated Site-2 Day-26 field sample were compared to those for pure 35,000 ppm TDS solution prepared with de-ionized water and pure $\mathrm{NaCl}$. The membrane considered was the high-selectivity desalination membrane typically used for seawater desalination to produce very low TDS permeate product $(<500$ ppm TDS) in the spiral wound modules ( 2 " diameter, 4.5 ft2 membrane area) format.

Experimental procedure:

For the Site-2 Day-26 field frac flowback sample, the fouling runs shown below in Figures 5557 were obtained over 24 hours by operating the system of Figure 50 in a closed circuit mode (Note that immediately following this operation, the system was operated in the open circuit mode to obtain the performance vs. feed TDS profiles reported previously in Figures 52-54). 
After the Site-2 Day-26 sample run, the entire rig assembly shown in Figure 50 was purged and flushed with de-ionized water several times. A new membrane module containing the same membrane type and configuration, and manufactured at the same commercial facility was installed in the membrane housing. This module was flushed with de-ionized water and other treatments were performed as per membrane manufacturer's recommendations. Then about 15 liters of the $\mathrm{NaCl}$ solution in de-ionized water was introduced and the solution was circulated through the system at low pressure to mix the feed solution in the system. The feed concentration was approximately 35,000 ppm TDS when high pressure of $~ 800$ psi was applied and the permeation process was allowed to continue in the closed circuit mode.

The profiles of the 3 parameters of interest, namely water-flux, salt-flux and salt-rejection are shown normalized to the initial values for the pretreated "Day-26" field frac flowback sample with 37,500 ppm TDS and the comparative 35,000 ppm TDS pure $\mathrm{NaCl}$ in de-ionized water in Figures 55,56 , and 57 , respectively.



Figure 55. Comparison of water-flux parameter change due to desalination membrane fouling for pretreated Site-1 Day-26 field frac flowback sample and pure $\mathrm{NaCl} / \mathrm{de}$-ionized water solution. 




Figure 56. Comparison of salt-flux parameter change due to desalination membrane fouling for pretreated "Day-26" field frac flowback sample and pure $\mathrm{NaCl} /$ de-ionized water solution.

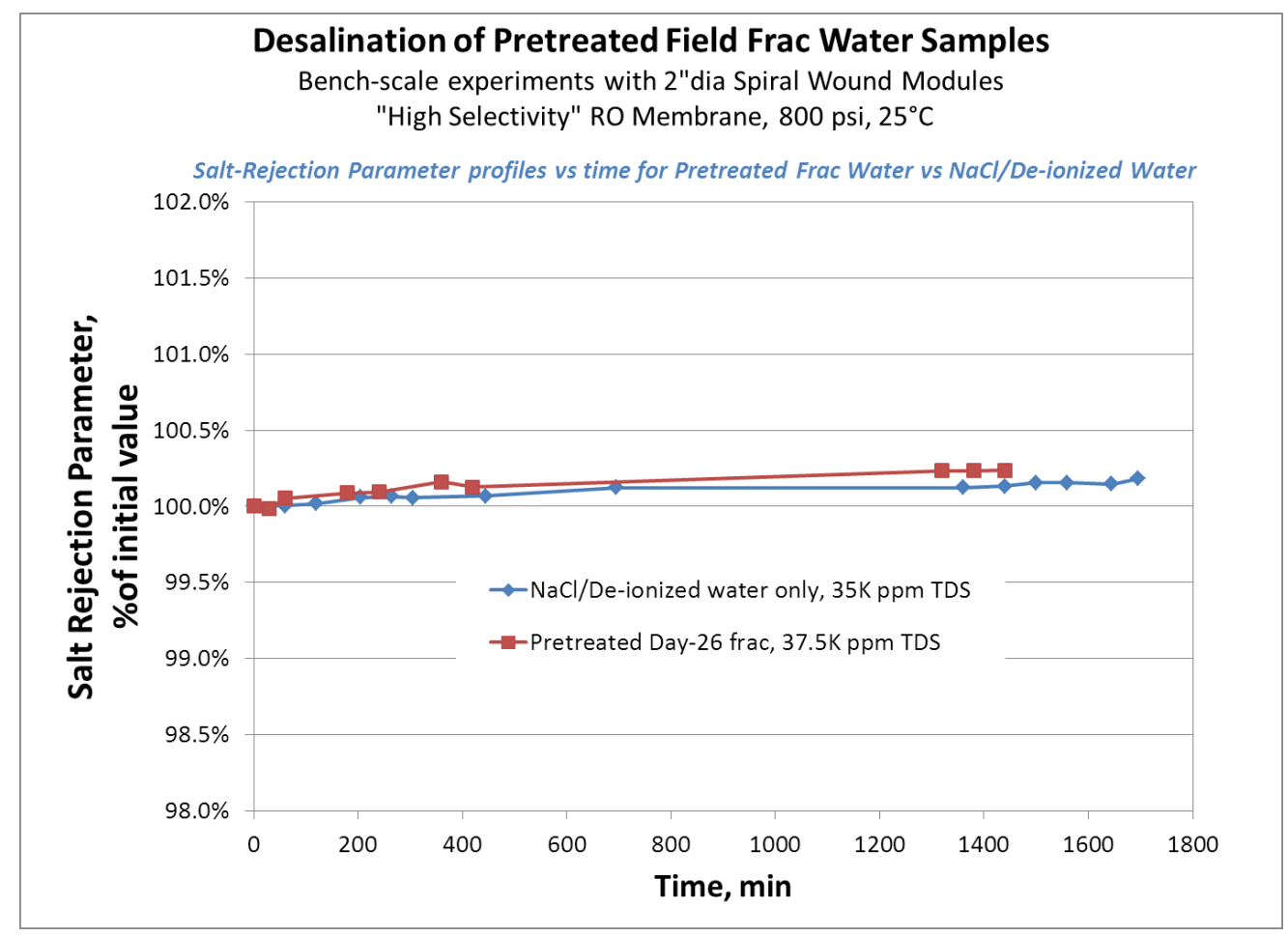

Figure 57. Comparison of salt-rejection parameter change due to desalination membrane fouling for pretreated "Day-26" field frac flowback sample and pure $\mathrm{NaCl} / d e-i o n i z e d$ water solution. 
The composition analyses for the Site-2 Day-26 before and after these 24-hour membrane fouling experiments are shown in Table 5. We observe the extent of hardness (Ca, $\mathrm{Mg}, \mathrm{Ba}, \mathrm{Fe}$, $\mathrm{Sr}$ ) removal by the pretreatment methods, and the permeate product quality (<500 ppm TDS).

Table 5. Composition analyses for the Site-2 Day-26 waters: raw, pretreated by softening, and after 24-hr membrane fouling test.

\begin{tabular}{|c|c|c|c|c|}
\hline Description & Raw & $\begin{array}{c}\text { lime softened, } \\
\mathrm{pH} \text { adjusted \& } \\
\text { filtered through } \\
1 \mathrm{um} \\
\end{array}$ & $\begin{array}{l}\text { Final Retentate } \\
\text { after RO }\end{array}$ & Permeate \\
\hline "B, ppm & 24.8 & 23 & 22.6 & 8.35 \\
\hline "Ba, ppm & 30.7 & 0.147 & 0.161 & $<0.1$ \\
\hline "Ca Hard, ppm & 1160 & 37.4 & 34.7 & $<5.0$ \\
\hline "Cl, ppm & 21600 & 21200 & 19700 & 243 \\
\hline "Cond, ppm & 54000 & 53500 & 50200 & 869 \\
\hline "Fe, ppm & 184 & $<0.5$ & $<0.5$ & $<0.5$ \\
\hline "HEM, ppm & 2100 & $<6.0$ & $<6.0$ & $<6.0$ \\
\hline "Hard-Total, ppm & 301 & 563 & 545 & $<10$. \\
\hline "K, ppm & 559 & 316 & 303 & $<5.0$ \\
\hline "M-alk, ppm & 749 & 334 & 340 & 22.7 \\
\hline "Mg Hard, ppm & 1.19 & 518 & 503 & 8.21 \\
\hline "Mn, ppm & $<0.6$ & $<0.1$ & $<0.1$ & $<0.1$ \\
\hline "Na, ppm & 16900 & 17200 & 16400 & 221 \\
\hline "Ni, ppm & 0.112 & $<0.1$ & 0.309 & $<0.1$ \\
\hline "SO4, ppm & 29 & 31 & 29 & $<1.0$ \\
\hline "SiO2 reactive, ppm & 48 & 40 & 36.2 & $<2.0$ \\
\hline "SiO2-Total, ppm & 185 & 39.9 & 39.9 & $<5.0$ \\
\hline "Sr, ppm & 152 & 6.43 & 6.15 & $<0.1$ \\
\hline "TDS, ppm & 32700 & 30700 & 29100 & 440 \\
\hline "TOC, ppm & 18.4 & 6 & 6.1 & $<1.0$ \\
\hline "TP, ppm & 62.4 & 41.1 & 22.3 & $<4.0$ \\
\hline "TSS, ppm & 776 & 18 & 71 & $<10$ \\
\hline Turb, NTU & 2150 & 0.63 & 0.75 & 0.24 \\
\hline "pH, ppm & 7.36 & 7.54 & 7.84 & 8.34 \\
\hline "NH3-Free, ppm & & 53 & 49.3 & 1.89 \\
\hline
\end{tabular}

\section{Observations and Conclusions:}

There is usually a decline of $\sim 10 \%$ in water-flux parameter during the initial $6 \sim 8$ hours (perhaps due to pressure compaction) as seen with the profiles of both the Site-2 Day-26 and control DI water with only $\mathrm{NaCl}$ (cf. Figure 55). But the trend after this initial period is important to observe from a fouling perspective. A steady decrease in performance over time would have indicated fouling of the membrane surface. However, we observe similar changes in performance over the initial 24-hour period for the two water solutions in Figures 55, 56 and 57. This indicates that there is insignificant fouling of the desalination membrane by the contaminants in the pretreated field frac flowback sample compared to the control sample. In other words, the downselected pretreatment conditions were effective in removing potential fouling contaminants from the field frac flowback sample lat least for this field sample and under these desalination experimental conditions). 


\subsection{Task 6-Develop system performance and cost models}

\subsubsection{Objectives and Approach:}

The key objectives were:-

- Cost modeling for a mobile unit for low-TDS flow back water recovery

- Determination of economical "cut-off" point for low-TDS water recovery process for flowback water treatment

System cost models were developed for the mobile rig configurations for the four products under consideration (cf. Figure 30). However, in the following discussions, only the costs for membrane desalination systems used for Product-3 and Product-4 will be reported as they encompass the pretreatment steps used for Product-1 and Product- 2 as well as the membrane desalination steps.

In Figure 58, the system configurations for the Conventional frac flowback disposal via underground Class II injection and the Flowback Water Recovery Process (FWRP) considered in this project are described.

\section{System cost estimations}


$$
\begin{gathered}
\text { Objectives: } C_{F W R P}<C_{\text {conventional }} \text { for use application } \\
\text { Maximize Recovery }(x)
\end{gathered}
$$

Figure 58. System configurations for the conventional frac flowback disposal via underground saline water disposal and the Flowback Water Recovery Process 50-gpm mobile rig under consideration in this project. 
For this project we have considered the main driver for an FWRP to be financial and hence the key economic criterion at any frac flowback site is assumed to be:

$$
\mathrm{C}_{\text {FWRP }}<\mathrm{C}_{\text {Conventional Disposal }}
$$

However, it is likely that other non-economic drivers, such as regulatory mandates or public relations may also induce the producer to opt for the FWRP. In those cases, the objective may be to minimize $C_{\text {FWrP. }}$

\subsubsection{Membrane Desalination Mobile Rig - FWRP costs \& economical "cut-off" TDS}

The cost correlations and parameters of interest were discussed in Section 3.2.12 and are summarized in Figure 59.

\section{Cost correlations for mobile $50 \mathrm{gpm}$ membrane rigs}

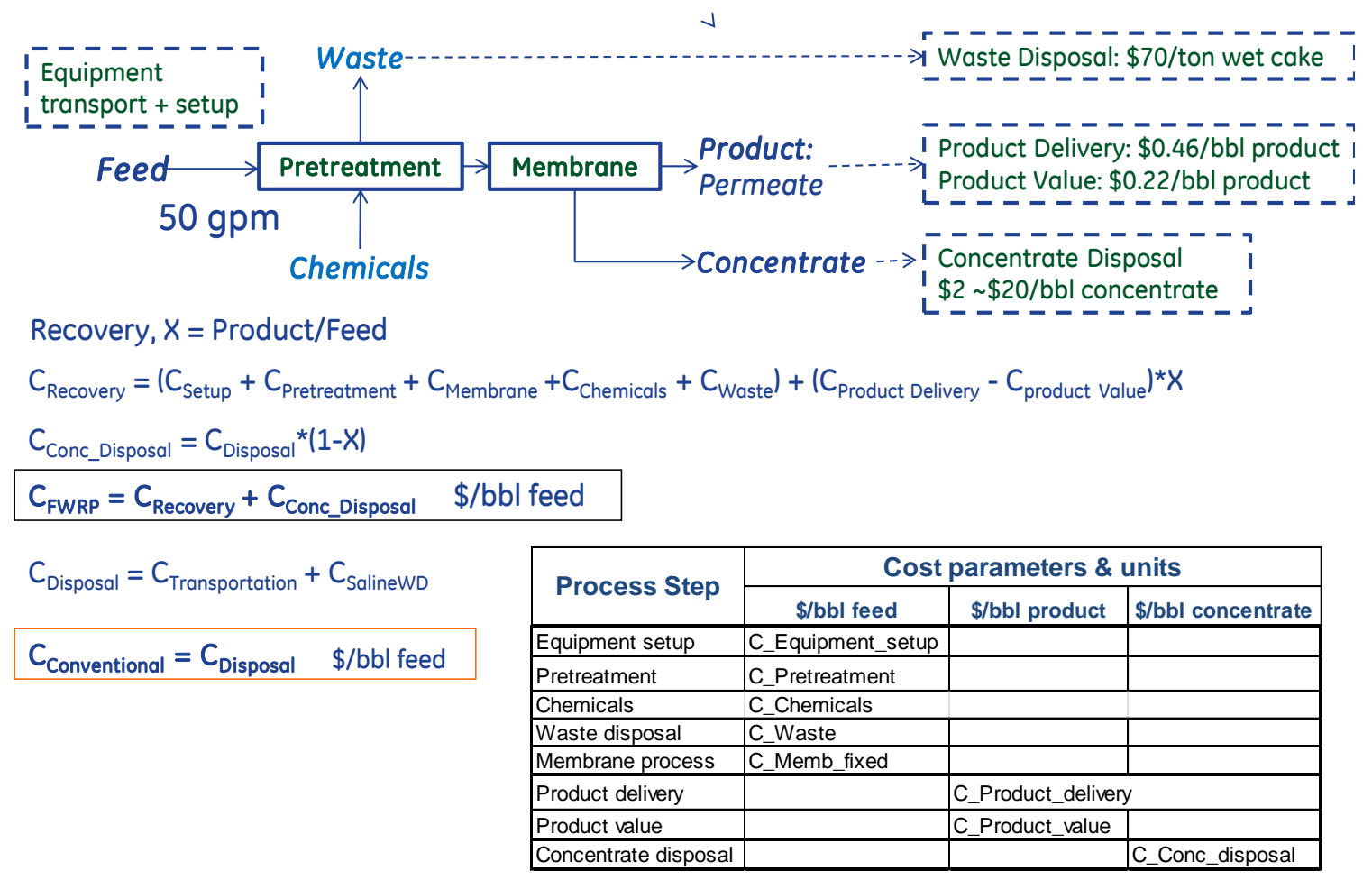

Figure 59. Cost parameters, units and correlations for the FWRP \& Conventional processes described in Figure 58.

The extent of water product recovery expected from a membrane-based desalination system using the pretreatment processes developed in this project is plotted as a function of the feed TDS concentrations in Figure 60. Note that due to the membrane system designs evaluated in Task 4, it is possible to extend the retentate concentration to 90,000 ppm TDS compared to 70,000 ppm TDS typically used in seawater desalination (cf. Figure 47), and thus achie ve greater water recovery at the same feed TDS concentration. This is illustrated for the Product-4 quality (500 ppm TDS) in Figure 60. 


\section{Membrane System: Water recovery for different product requirements}

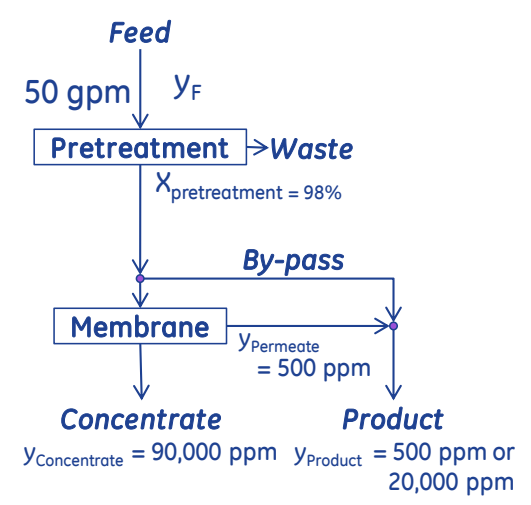

Water Recovery vs. Feed TDS concentration \& operating conditions



Figure 60. Mass balance profiles for membrane desalination based FWRP for Product-3 $(20,000$ ppm) and Product-4 (500 ppm).

Note typical seawater desalination operates at $y_{\text {Retentate }}=70 \mathrm{~K} \mathrm{ppm}$ TDS while choice of pretreatment \& membrane system conditions for flowback recovery allow $y$ Retentate $=90 \mathrm{~K} \mathrm{ppm} \mathrm{TDS}$, and thus higher recovery.

For Product-3, where the desired product TDS is less stringent at $<20,000 \mathrm{ppm}$, we see much higher recoveries compared to Product-4. It is possible to achieve the Product-3 target by either:

- Alternative 1: Use high-flux low-rejection membranes that yield a permeate product with TDS $<20,000$ ppm TDS (as originally conceived for this project) or

- Alternative 2: Use high-selectivity but lower flux membranes typically used for seawater desalination that yield a permeate product with TDS $<500 \mathrm{ppm}$ and achieve the desired Product-3 target by blending with a by-passed portion of the feed to the membrane unit, as shown in Figure 60.

During the cost estimations for the membrane systems described in Section 3.2.12, we had observed that for such small throughput $(50-\mathrm{gpm})$ configurations the overall cost was dominated by the balance of plant rather than the number of membrane modules and power consumption (cf. Figure 49). Hence, from a practical perspective, it is prudent to design the conceptual process to produce the most stringent product, i.e. $500 \mathrm{ppm}$ permeate, and then blend appropriately to meet the less stringent product quality. In other words, we select the Alternative 2 described above. 
The main cost components, $C_{\text {Recovery }}, C_{\text {Concentrate Disposal }}$ and the overall $C_{F W R P}$ are illustrated for a membrane desalination mobile rig producing Product-4 quality (500 ppm TDS) in Figure 61. These costs are plotted as a function of $y F$, the feed TDS concentration for an assumed value


$\mathrm{C}_{\mathrm{FWRP}} / \mathrm{C}_{\text {Conventional }}<1$ would be economically attractive for FWRP.

We observe in Figure 61 that that $C_{\text {Recovery }}$ decreases as $y F$ increases because the extent of water recovery, $X$, decreases with increasing yF (cf. Figure 60), which results in lowering the contribution from product delivery costs. Interestingly, the slope of this decline is very small with increasing y because the recovery costs are dominated by the Treatment Cost components.


$\mathrm{C}_{\text {concentrate Disposal }}$ is much sharper because $\mathrm{C}_{\text {Disposal }}$ is usually much higher than $\mathrm{C}_{\text {product delivery. The }}$ net effect of the profiles of $\mathrm{C}_{\text {Recovery }}$ and $\mathrm{C}_{\text {concentrate Disposal }}$ is that $\mathrm{C}_{\text {FWRP }}$ increases with $\mathrm{yF}$.

\section{Membrane Recovery: Cost vs. Feed TDS}

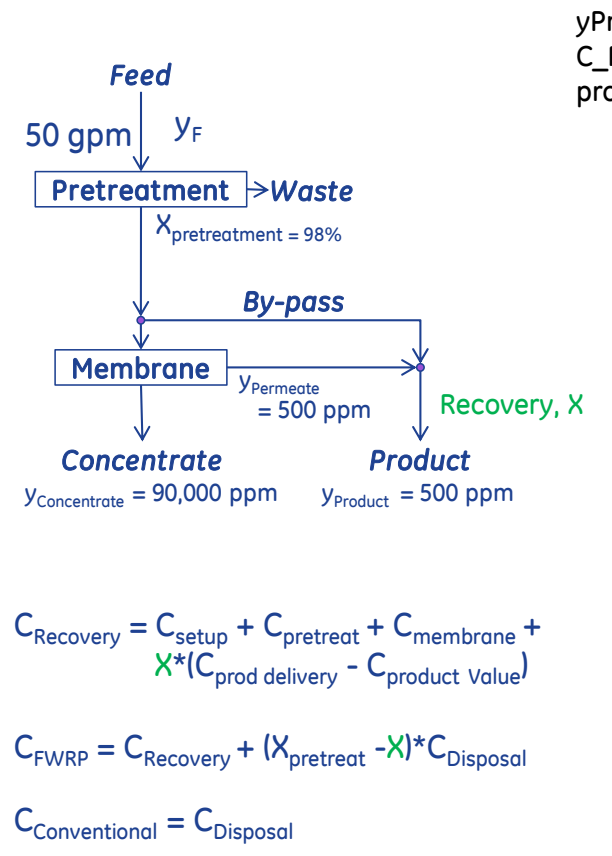

yProduct $=500 \mathrm{ppm} ;$ yPermeate $=500 \mathrm{ppm} ;$ yRetentate $=90,000 \mathrm{ppm}$; C_Product_Delivery $=\$ 0.46 / \mathrm{bbl}$ product; C_Product_Value $=\$ 0.22 / \mathrm{bbl}$ product

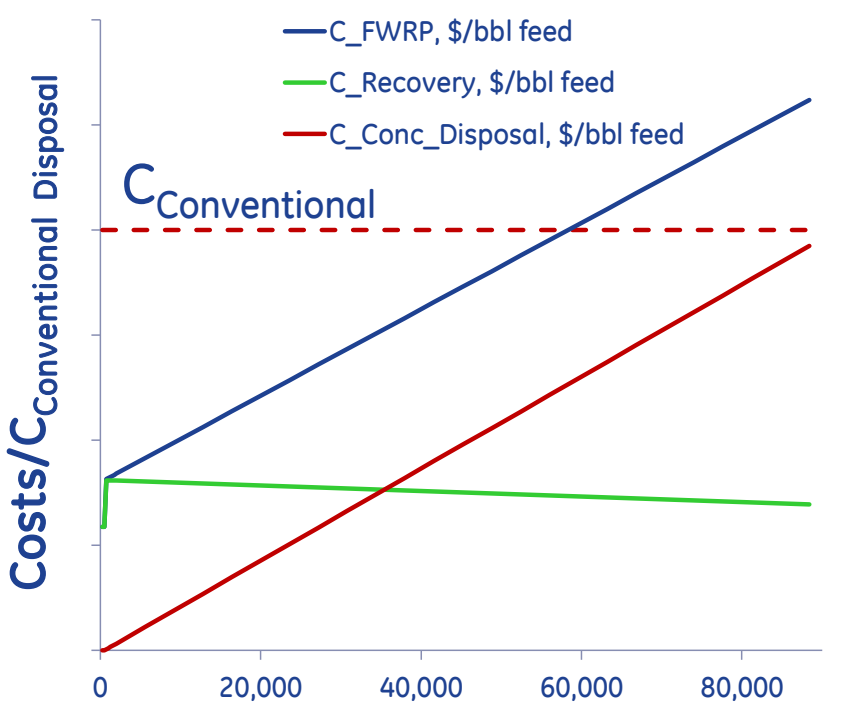

Feed TDS concentration, ppm

Figure 61. Cost components for the membrane-based FWRP: $C_{\text {Recovery, }} C_{\text {Conc_disposal }}$ and $C_{\text {FWRP }}$ for the operating and cost parameters developed in this project and for an assumed value of $C_{\text {Disposal. }}$

Definition of economical "Cut-off" TDS for frac re-use: The value of yF where the $C_{F W R P}$ crosses the Conventional line represents the economical "cut-off" TDS for that particular frac flowback site. 
In Figure 62, the $\mathrm{C}_{\mathrm{FWRP}}$ for membrane-based desalination mobile rig for producing Product-3 $(20,000 \mathrm{ppm}$ TDS) is compared to that for Product-4 $(500 \mathrm{ppm})$ (previously illustrated in Figure 61). We observe that the "cut-off" TDS in this particular case is $y F=58,000$ ppm TDS for Product- 4 and $y F=65,000$ ppm TDS for Product-3; the water recovery is $35 \%$ in both cases (cf. Figure 60).

\section{Membrane Recovery: Cost sensitivity to product TDS requirements}
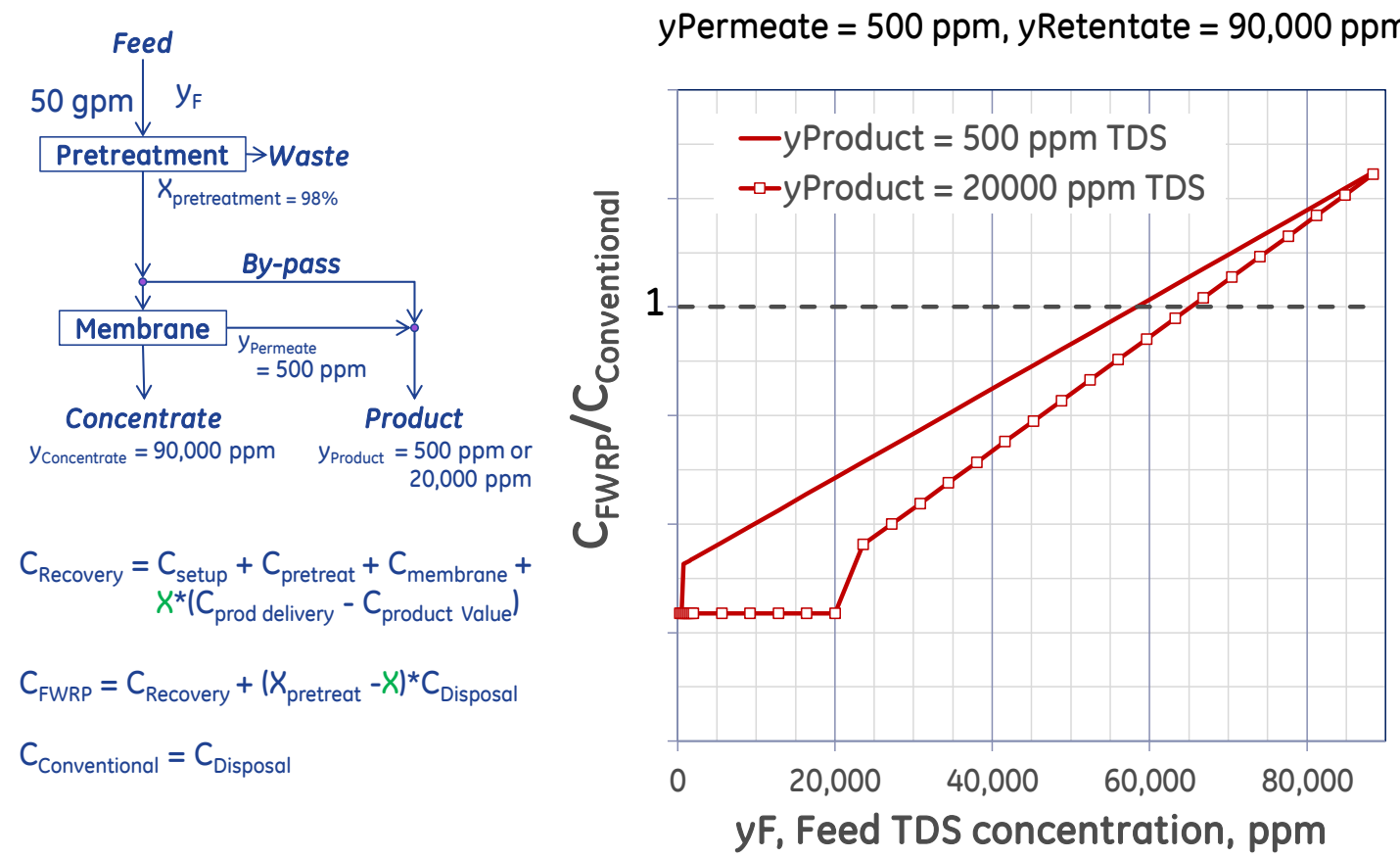

Figure 62. Cost of membrane-based FWRP vs. feed TDS concentrations forProduct-3 and Product4 quality specifications.

This "cut-off" TDS is a strong function of the C Cisposal, the cost of transport and disposal of the saline water in Class II disposal wells. This is illustrated in Figure 63 for a membrane desalination mobile rig producing Product-4 quality (500 ppm TDS) where the $\mathrm{C}_{\mathrm{FWRP}} / \mathrm{C}_{\text {conventional Disposal }}$ ratio is plotted as a function of varying $C_{\text {Disposal }}$ at different values of $y F$. The points where the curves intersect the solid black line representing $C_{F W R P} / C_{\text {Conventional Disposal }}=1$ represent the "cutoff" TDS at the yF and $C_{\text {Disposal }}$ values prevalent at the frac flowback disposal site under consideration. 


\section{Membrane System: Cost sensitivity to concentrate disposal costs}
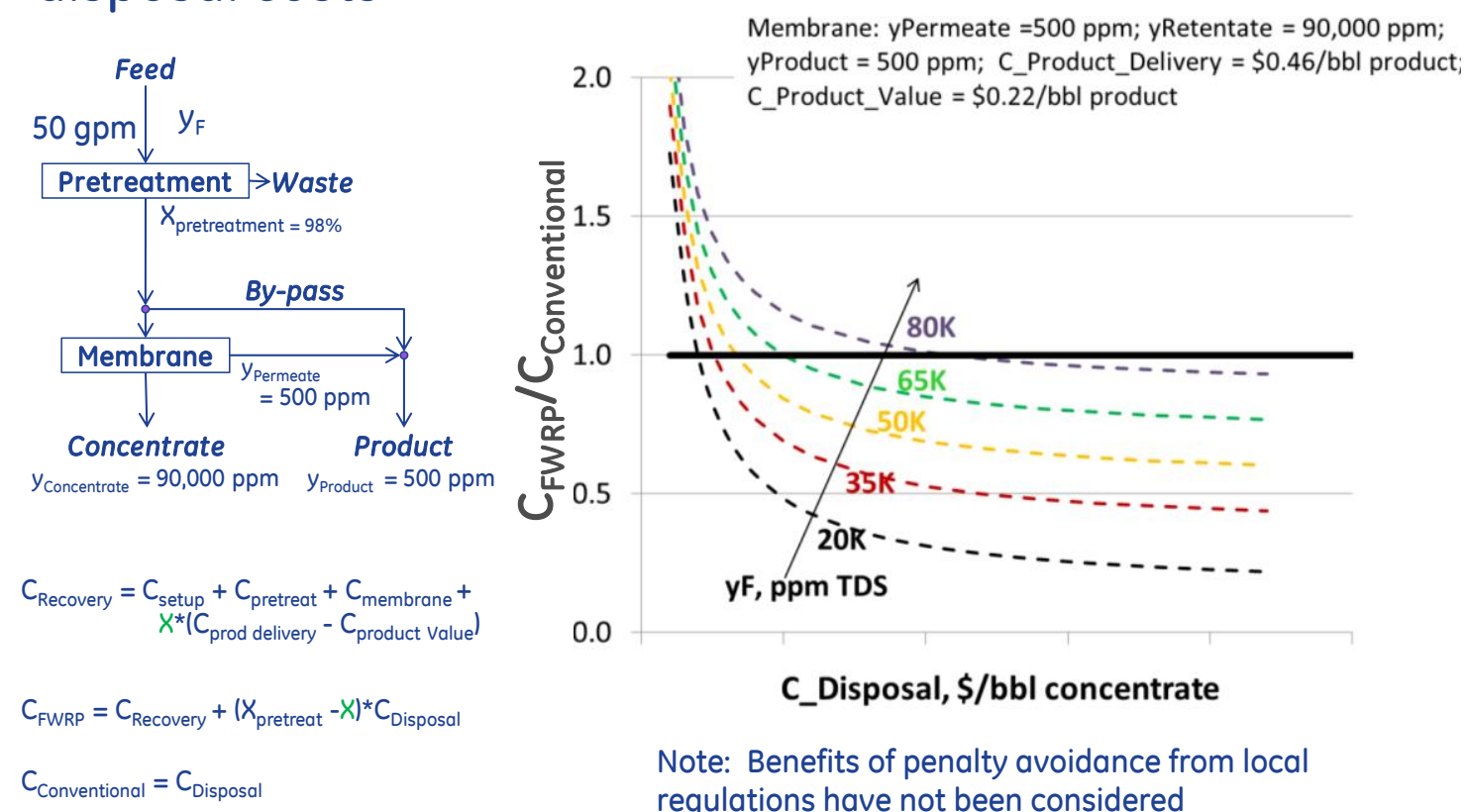

Note: Benefits of penalty avoidance from local regulations have not been considered

Economic benefits of FWRP highly dependent on saline water disposal costs at shale plays

Figure 63. Profiles for CFWRP/CConventional for the membrane system vs. Concentrate disposal costs at varying feed TDS concentrations.

\subsubsection{Hybrid Membrane+Thermal Mobile system - FWRP costs \& economical "cut-off" TDS}

The extent of water recovery in the membrane desalination system is limited by the retentate concentration, as described earlier. Further water recovery from the retentate is possible via thermal desalination. This is illustrated in Figure 64 where a hybrid mobile system is considered for a Product-4 quality (500 ppm TDS). The frac flowback stream is first pretreated and then sent through a membrane desalination rig to produce a $500 \mathrm{ppm}$ permeate product. The retentate with 90,000 ppm TDS is then distilled in a mobile evaporator (such as that introduced by GE Water 22 recently) to obtain distillate with $<500$ ppm TDS and a concentrate with 280,000 ppm TDS. As seen in Figure 64, such a configuration yields much higher recovery than the membrane system alone. For example, for a feed with yF $=35,000$ ppm TDS, the hybrid system yields $85 \%$ recovery vs. $61 \%$ for the membrane rig alone. 


\section{Hybrid Membrane + Thermal Recovery:}

\section{Water recovery}



Hybrid Membrane + Thermal process: Water recovery vs. Feed TDS

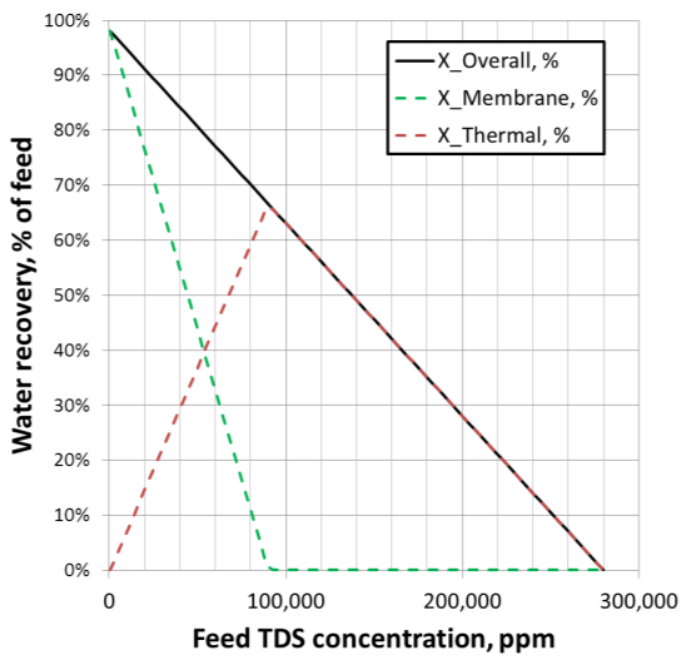

Hybrid yields much higher water recovery than membrane alone.

Figure 64. Hybrid system incorporating pretreatment, membrane desalination and thermal distillation to yield Product-4 quality (500 ppm TDS); the 90K ppm TDS retentate from the membrane unit is distilled in the mobile evaporator to yield a $280,000 \mathrm{ppm}$ TDS concentrate.

Of course, the capital and operating costs for this hybrid system would be greater than the membrane system alone. Hence, the $\mathrm{C}_{\mathrm{FWRP}}$ for the overall hybrid system will have to be considered. This is illustrated in Figure 65, where the $C_{F W R P}$ is plotted as a function of feed TDS, yF for the Membrane system only, Thermal (Evaporator) system only and Hybrid Membrane +Thermal system. For the assumed $C_{\text {Disposal }}$ value in Figure 65 , the Membrane system is cheaper than either of the other systems when the feed TDS concentrations are low $1<35,000$ ppm TDS in this case). The economical "cut-off" TDS for the Hybrid case is higher at 82,000 ppm TDS compared to 68,000 ppm TDS for Membrane system alone. More importantly, at these "cut-off" TDS values, the water recovery is much higher at $69 \%$ for the Hybrid case vs. $28 \%$ for the Membrane alone (cf. Figure 64). 


\section{Hybrid Membrane + Thermal Recovery:}

\section{Cost comparisons}

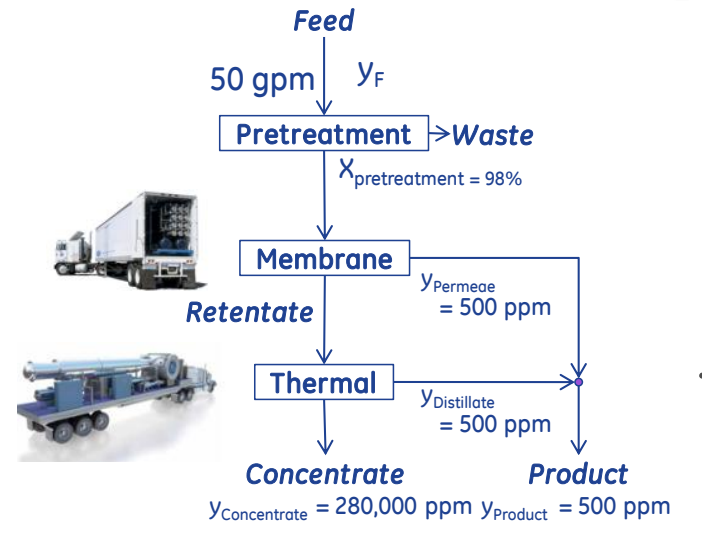

yProduct $=500 \mathrm{ppm} ; \mathrm{yPermeate}=500 \mathrm{ppm} ;$ yRetentate $=90,000 \mathrm{ppm}$; yDistillate $=500 \mathrm{ppm} ; \mathrm{yConcentrate}=280,000 \mathrm{ppm}$

C_Product_Delivery $=\$ 0.46 / \mathrm{bbl}$ product; C_Product_Value $=\$ 0.22 / \mathrm{bb}$ product



Figure 65. Cost profiles for the Membrane system alone, Mobile evaporator alone and the Hybrid membrane+thermal systems as a function of feed TDS concentration.

Again, as discussed earlier for the membrane mobile rig in Section 3.6.3, the economical "cutoff" TDS is a strong function of the local $C_{\text {Disposal }}$ prevalent at the frac flowback site. For the Hybrid system the $\mathrm{C}_{\mathrm{FWRP}} / \mathrm{C}_{\text {Conventional Disposal }}$ ratio is plotted as a function of varying $\mathrm{C}_{\text {Disposal }}$ at different values of $y F$ in Figure 66. The curves for the Hybrid case are compared with those for the Membrane alone (cf. Figure 63).

We observe the following in Figure 66:

- The curves at the different values of $y F$ for the Hybrid case are much closer than for the Membrane case alone due to the increased recovery for the Hybrid case

- The Membrane alone case is more economical for the lower $C_{\text {Disposal }}$ cases mainly due to the lower overall capital costs vs. the Hybrid case. However, the Hybrid case becomes more economically attractive as the $C_{\text {Disposal }}$ rises. 


\section{Hybrid Membrane + Thermal Recovery: Cost comparisons \\ Membrane: $y$ Permeate $=500$ ppm; yRetentate $=90,000$ ppm; Thermal: $y$ Distillate $=500 \mathrm{ppm}$; yConcentrate $=280,000 \mathrm{ppm}$; Hybrid: yProduct $=500 \mathrm{ppm} ;$ C_Product_Delivery $=\$ 0.46 / \mathrm{bb}$ product; C_Product_Value $=\$ 0.22 / \mathrm{bbl}$ product}
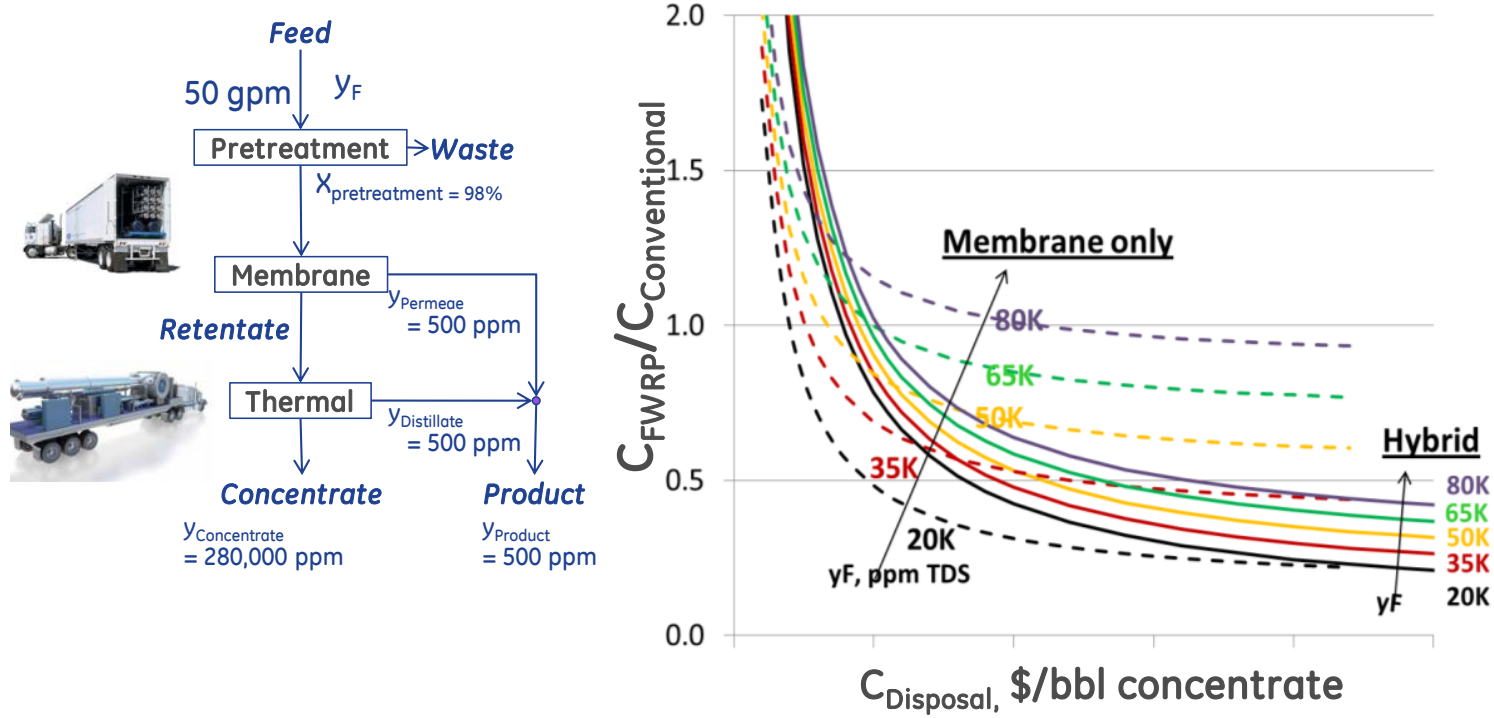

Membrane alone more economical for low disposal cost plays Hybrid more economical at higher disposal cost plays

Figure 66. Profiles for $\mathrm{C}_{\mathrm{FWRP}} / \mathrm{C}_{\text {Conventional }}$ ratio vs Concentrate disposal costs for varying feed TDS concentrations. 


\section{Summary and Conclusions}

- Frac flowback water is not a uniform "raw material" from a process development perspective:

- Flowback rates decrease sharply from as high 50 150 bbl/hr for the first 5-10 days to $<10 \mathrm{bbl} /$ day beyond Day 30 of flowback.

- Flowback composition varies considerably depending on the geological formation and operating conditions (e.g. chemicals introduced during the drilling and fracturing operations, diesel and compressor oils from pumps, etc.), and more importantly, as a function of time at the same well.

- Applicability of low-TDS (< 45,000 ppm) recovery approach is 90-100\% for Fayetteville and Woodford shales, while limited to very early flowback in Barnett, Marcellus and other shales.

- There is no clear consensus on product quality requirements for re-use in hydrofracturing. Based on feedback, 4 product options were identified, namely: Product-1 based on "Clarified only", Product-2 based on "Softened only", Product-3 based on "Desal to 20Kppm TDS" and Product-4 based on "Desal to <500ppm TDS".

- Lab-scale experiments showed that the identified "pretreatment" techniques were successful in clarification and hardness-removal and able to meet the quality requirements for Product- 1 and Product-2, and as pretreatment to the membrane desalination process.

- A novel GCxGC+ToFMS method for analysis of hydrocarbons was found useful in providing a qualitative understanding of the effect of pretreatment methods on the presence and disappearance of organic compounds in the treated frac flowback waters.

- RO membrane fouling experiments conducted using commercially available 2" diameter spiral wound RO modules with pretreated flowback water showed identical water-flux and salt-rejection profiles as the control solution $135 \mathrm{~K} \mathrm{ppm} \mathrm{TDS} \mathrm{NaCl}$ in deionized water). This indicated the effectiveness of the downselected pretreated conditions in removal of potential membrane foulants (inorganic salts and colloidal inorganic and organic compounds).

- For Product-3 and Product-4, that require desalination to TDS levels $<20,000$ ppm and $<500$ ppm, respectively, various membrane system configurations were evaluated and optimized via performance modeling with GE Winflows software to increase water product recovery. For a feed solution composition similar to that obtained after pretreating (lime softened and filtered) Site-2 Day-26 sample, membrane system configurations were identified that increased the recovery from $49 \%$ using the standard seawater-desalination design to as high as $61.5 \%$. The maximum retentate concentration correspondingly increased from $68 \mathrm{~K}$ ppm to $90 \mathrm{~K}$ ppm TDS for these conditions. The increase in capital costs due to additional pumps, membrane modules, interconnected piping and controls for the new configuration was more than offset by the increased water recovery when the overall FWRP was considered. 
- The estimated Treatment Costs for the four product options were within the cost criterion of $<\$ 2 /$ bbl flowback, in line with preliminary feedback on customer expectations. The cost estimations were based on reliable values obtained either from vendors or internal cost information for the desired equipment. Other cost factors, such as costs of electricity, type and cost of labor, and waste handling $\&$ disposal, were also obtained either from appropriate vendors or internal cost information.

- Membrane module and Electricity costs were only $2 \%$ and $5 \%$, respectively, of overall operating costs for such small throughput $(50 \mathrm{gpm})$ mobile rigs capable of producing Product-3 or Product-4. Nearly $75 \%$ of the operating costs are related to "fixed" charges (related to capital equipment and rig transportation \& setup) while chemicals and solids waste disposal accounted for the remaining $18 \%$.

- Costs of the modeled overall Flowback Water Recovery Process (FWRP) were compared to those for the conventional saline water disposal method. For the desired economic consideration of $\mathrm{C}_{\mathrm{FWRP}} / \mathrm{C}_{\text {conventional }} \leq 1$ the "cut-off" feed TDS concentration would depend on the disposal costs prevalent at the frac flowback site. Higher disposal costs would make FWRP attractive as seen in the sensitivity plots of $\mathrm{C}_{\text {FWRP }} / \mathrm{C}_{\text {Conventional VS. }} \mathrm{C}_{\text {Disposal }}$ at different feed TDS concentrations. These charts thus provide a means of comparing the relative value of FWRP for a well flowback treatment opportunity based on prevailing disposal costs and anticipated flowback TDS levels.

- The Hybrid membrane + thermal approach, wherein a 50-gpm pretreatment \& membrane desalination rig is followed by a mobile evaporator to treat the retentate from the membrane unit, provides much higher water recovery (e.g. $85 \%$ vs. $61 \%$ for Membrane alone for a feed containing 35,000 ppm TDS). However, the Hybrid process costs more than individual process options alone due to the high fixed costs for such small throughput $(50 \mathrm{gpm})$ systems. The Membrane alone case is more economical for the lower $C_{\text {Disposal }}$ cases mainly due to the lower overall capital costs vs. the Hybrid case. However, the Hybrid case becomes more economically attractive

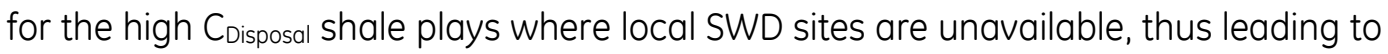
higher flowback water transportation costs for the conventional disposal method.

Overall, based on bench-scale experiments on pretreatment and membrane desalination fouling conducted with typical frac flowback water samples from Woodford shale, membrane desalination system modeling, and cost analysis of the flowback water recovery process, we conclude:

- Technical Performance: There is a high level of confidence that the conceptual processes will be effective to yield the Products-1, $-2,-3$ and -4 of desired quality since these process flow schemes were constructed based on the bench-scale experimental studies on the individual separation technologies using actual frac flowback samples. Many of the initial concerns were mitigated by appropriate choice and verification of process operating conditions in the lab-scale experiments. 
- Cost Performance: The estimated Treatment Costs for the four product options were within the cost criterion of $<\$ 2 / \mathrm{bbl}$ in line with preliminary feedback on customer expectations. Using the CFWRP/CConventional $\leq 1$ as the desired economic criterion, for Product-4 (500 ppm TDS), the "cut-off" TDS for frac flowback water recovery is in the range of 20,000 ppm to 65,000 ppm depending on the local saline water disposal costs. The sensitivity plots of $\mathrm{C}_{\text {FWRP }} / \mathrm{C}_{\text {Conventional VS. }} \mathrm{C}_{\text {Disposal }}$ at different feed TDS concentrations provide a means of comparing the relative value of FWRP for a well flowback treatment opportunity based on prevailing disposal costs and anticipated flowback TDS levels.

- Mobility Performance: Based on vendor information on sizes and operations of the various equipment identified for the conceptual processes, and internal data on mobile rig operations, 50-gpm mobile rig configurations may be achievable for the four products under consideration.

- Hybrid membrane + thermal systems based on membrane desalination and a mobile evaporator may be attractive for treating Low-TDS frac flowback water for high disposal-cost plays.

- It is believed that the parametric value assessment tool approach developed in this project to assess overall economic attractiveness of any Flowback Water Recovery Process (FWRP) relative to conventional disposal, and thus relating sensitivity of water recovery via treatment processes employed and product/reject disposal costs, will provide a rational basis for treatment process selection appropriate to well flowback characteristics and local disposal costs \& regulations. 


\section{APPENDIX: Water Chemistry of Drilling and Hydrofracturing Fluids}

\section{Drilling fluid}

The drilling fluids used depend on the geology of the shale formation and the technology bias/experience of the operator. Most of the information is held proprietary and confidential. However, a good summary of the various components is provided at the DOE NETL website ${ }^{23}$. Information relevant to this project are reproduced below:

- Drilling fluids or muds are made up of a base fluid (water, diesel or mineral oil, or a synthetic compound), weighting agents (most frequently barium sulfate [barite] is used), bentonite clay to help remove cuttings from the well and to form a filter cake on the walls of the hole, lignosulfonates and lignites to keep the mud in a fluid state, and various additives that serve specific functions.

- Mud Additives: Water-based muds (WBMs) would be preferable because they are not only inexpensive but the used mud and cuttings from wells drilled with WBMs can be readily disposed of onsite at most onshore locations. However, for difficult drilling situations, such as wells drilled in reactive shales, deep wells, and horizontal and extended-reach wells, WBMs do not offer consistently good drilling performance. For these types of drilling situations at onshore sites, the industry relies primarily on oilbased muds (OBMs). OBMs perform well, but may be subject to more complicated disposal requirements for onshore wells. OBMs contain diesel or mineral oil as the base fluid and may be harmful to the environment if directly discharged to a water source.

- Synthetic-Based Muds (SBMs): These are nonaqueous fluids (other than oils) as their base. Examples of these base fluids included internal olefins, esters, linear alphaolefins, poly alpha-olefins, and linear paraffins. SBMs share the desirable drilling properties of OBMs but are free of polynuclear aromatic hydrocarbons and have lower toxicity, faster biodegradability, and lower bioaccumulation potential. The EPA has identified this product substitution approach as an excellent example of pollution prevention that can be accomplished by the oil and gas industry. SBMs drill a cleaner hole than water-based muds, with less sloughing, and generate a lower volume of drill cuttings. In offshore drilling, SBMs are recycled to the extent possible, while WBMs are discharged to the sea.

- New Drilling Fluid Systems: Drilling fluid companies are developing variations of fluid systems that are much more amenable to biotreatment of the subsequent drilling wastes. It is likely that companies will continue to develop fluids with suitable drilling properties that contain fewer components or additives that would inhibit subsequent break down by earthworms or microbes. In some circumstances, the constituents of the muds could actually serve as a soil supplement or horticultural aid. 
- Other developments in drilling fluids could lead to entirely different formulations. Drilling fluids based on formate brines have been suggested as being more environmentally friendly than traditional fluids. Formate brines are created by reacting formic acid with metal hydroxides. Common examples are cesium formate (HCOO-Cs+), potassium formate ( $\mathrm{HCOO}-\mathrm{K}+$ ), and sodium formate ( $\mathrm{HCOO}-\mathrm{Na}+)$.

Alternate Weighting Agents: Substitution of some of the key components of drilling fluids with more environmentally friendly products could reduce mass loadings of potentially harmful substances to the environment. Barite is the most commonly used weighting agent. Other readily available weighting agents include hematite (Fe2O3) and calcium carbonate (CaCO3). Other wells have been drilled using ilmenite (FeTiO3) instead of barite as a weighting agent.

\section{Hydrofracturing Fluid}

Hydraulic fracturing of gas shale reservoirs involves sequenced events requiring thousands of barrels of water-based fracturing fluids mixed with proppant materials pumped in a controlled and monitored manner into target shale formations above fracture pressure ${ }^{24}$. Fracturing fluids used for fracturing gas shales include a variety of additive components, each with an engineered purpose to facilitate fractures and the production of gas ${ }^{25}$. Currently, the trends in shale wells are water based or mixed slickwater-fracturing fluids. These are waterbased fluids mixed with friction reducing additives ${ }^{26}$, which allows a fracturing fluid and proppant to be pumped to the target zone at a higher rate and reduced pressure than by using water alone. In addition to friction reducers, other additives including biocides are utilized to prevent micro-organism growth and to reduce bio-fouling of fractures. Oxygen scavengers and other stabilizers which prevent corrosion of metal pipes and acids which are used to remove drilling mud damage near the wellbore area are also common either in fracturing fluids or as part of fracture treatments.

An excellent review of the various components typically used during slickwater hydrofracturing is provided by D. Arthur et al of ALL Consulting ${ }^{25}$ and are reproduced in Figures 18 and 19. Some of the operators have also published information on their practices, most notably, Chesapeake Energy ${ }^{27}$. Fortuna Energy, a subsidiary of Talisman Inc., has provided details on the amounts of chemicals used, and their effective concentrations in the fracturing fluid, as shown in Figure $20^{28}$.

From the flowback water treatment perspective, although it is expected that some or all of these additives may be expected in the flowback, no literature reports confirming the presence and concentrations of these additives could be found. It is likely that these compounds may get chemically, physically or microbiologically altered or destroyed during the hydrofracturing process or become lost in the shale formation. Although some of these additives, such as guar gel, polyacrylamides, petroleum distillates may affect membrane performance; the actual impact would only have to be experimentally determined with flowback water samples. 


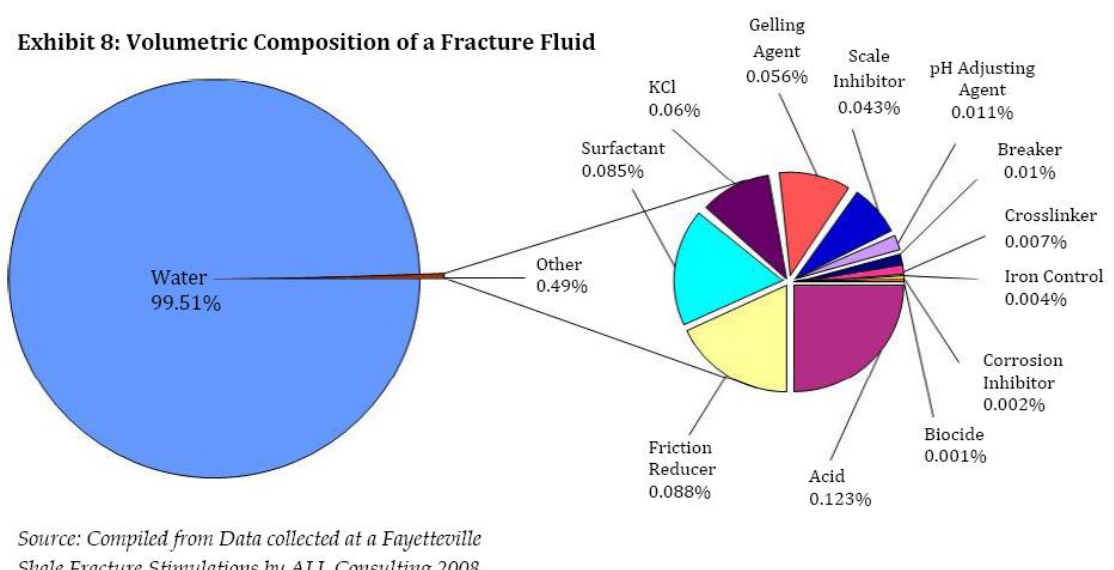

Shale Fracture Stimulations by ALL Consulting 2008.

Figure 67. Volumetric composition of a representative hydraulic fracturing fluid excluding the proppants (reproduced from D. Arthur et al., ALL Consulting ${ }^{25}$ ). 


\begin{tabular}{|c|c|c|c|}
\hline \multicolumn{4}{|c|}{ EXHIBIT 9: FRACTURING FLUID ADDITIVES, MAIN COMPOUNDS AND COMMON USES. } \\
\hline $\begin{array}{l}\text { Additive } \\
\text { Type }\end{array}$ & $\begin{array}{l}\text { Main } \\
\text { Compound }\end{array}$ & Use in Hydraulic Fracturing Fluids & $\begin{array}{l}\text { Common Use of Main } \\
\text { Compound }\end{array}$ \\
\hline Acid & $\begin{array}{l}\text { Hydrochloric } \\
\text { acid or } \\
\text { muriatic acid }\end{array}$ & $\begin{array}{l}\text { For the fracturing of shale formations, acids are used to } \\
\text { clean cement from casing perforations and drilling mud } \\
\text { clogging natural formation porosity, if any prior to } \\
\text { fracturing fluid injection (dilute acids concentrations are } \\
\text { typically about } 15 \% \text { acid) }\end{array}$ & $\begin{array}{l}\text { Swimming pool chemical and } \\
\text { cleaner }\end{array}$ \\
\hline Biocide & $\begin{array}{l}\text { Glutaralde- } \\
\text { hyde }\end{array}$ & $\begin{array}{l}\text { Fracture fluids typically contain gels which are organic and } \\
\text { can therefore provide a medium for bacterial growth. } \\
\text { Bacteria can break down the gelling agent reducing its } \\
\text { viscosity and ability to carry proppant. Biocides are added } \\
\text { to the mixing tanks with the gelling agents to kill these } \\
\text { bacteria. }\end{array}$ & $\begin{array}{l}\text { Cold sterilant in health care } \\
\text { industry }\end{array}$ \\
\hline Breaker & $\begin{array}{l}\text { Sodium } \\
\text { Chloride }\end{array}$ & $\begin{array}{l}\text { Chemicals that are typically introduced toward the later } \\
\text { sequences of a frac job to "break down" the viscosity of the } \\
\text { gelling agent to better release the proppant from the fluid as } \\
\text { well as enhance the recovery or "flowback" of the fracturing } \\
\text { fluid. }\end{array}$ & $\begin{array}{l}\text { Sodium chloride is also used } \\
\text { as a food preservative. }\end{array}$ \\
\hline $\begin{array}{l}\text { Corrosion } \\
\text { inhibitor }\end{array}$ & $\begin{array}{l}\mathrm{N}, \mathrm{n} \text {-dimethyl } \\
\text { formamide }\end{array}$ & $\begin{array}{l}\text { Used in fracture fluids that contain acids; inhibits the } \\
\text { corrosion of steel tubing, well casings, tools, and tanks. }\end{array}$ & $\begin{array}{l}\text { Used as a crystallization } \\
\text { medium in Pharmaceutical } \\
\text { Industry }\end{array}$ \\
\hline Crosslinker & Borate Salts & $\begin{array}{l}\text { There are two basic types of gels that are used in fracturing } \\
\text { fluids; linear and cross-linked gels. Cross-linked gels have } \\
\text { the advantage of higher viscosities that do not break down } \\
\text { quickly. }\end{array}$ & $\begin{array}{l}\text { Non-CCA wood } \\
\text { preservatives and fungicides }\end{array}$ \\
\hline $\begin{array}{l}\text { Friction } \\
\text { Reducer }\end{array}$ & $\begin{array}{l}\text { Petroleum } \\
\text { distillate or } \\
\text { Mineral oil }\end{array}$ & $\begin{array}{l}\text { Minimizes friction allowing fracture fluids to be injected at } \\
\text { optimum rates and pressures }\end{array}$ & $\begin{array}{l}\text { Cosmetics including hair, } \\
\text { make-up, nail and skin } \\
\text { products }\end{array}$ \\
\hline Gel & $\begin{array}{l}\text { Guar gum or } \\
\text { hydroxyethyl } \\
\text { cellulose }\end{array}$ & $\begin{array}{l}\text { Gels are used in fracturing fluids to increase fluid viscosity } \\
\text { allowing it to carry more proppant than a straight water } \\
\text { solution. In general, gelling agents are biodegradable. }\end{array}$ & $\begin{array}{l}\text { Guar gum is a food-grade } \\
\text { product used to increase the } \\
\text { viscosity and elasticity of } \\
\text { foods such as ice cream, and }\end{array}$ \\
\hline & & & salad dressings \\
\hline Iron Control & Citric acid & $\begin{array}{l}\text { Sequestering agent that prevents precipitation of metal } \\
\text { oxides. }\end{array}$ & $\begin{array}{l}\text { Citric Acid it is used to } \\
\text { remove lime deposits. Lemon } \\
\text { Juice is approximately } 7 \% \\
\text { Citric Acid }\end{array}$ \\
\hline $\mathrm{KCl}$ & $\begin{array}{l}\text { Potassium } \\
\text { Chloride }\end{array}$ & Added to water to create a brine carrier fluid. & $\begin{array}{l}\text { Low sodium table salt } \\
\text { substitute }\end{array}$ \\
\hline $\begin{array}{l}\text { Oxygen } \\
\text { scavenger }\end{array}$ & $\begin{array}{l}\text { Ammonium } \\
\text { bisulfite }\end{array}$ & $\begin{array}{l}\text { Oxygen present in fracturing fluids through dissolution of } \\
\text { air causes the premature degradation of the fracturing fluid, } \\
\text { oxygen scavengers are commonly used bind the oxygen. }\end{array}$ & Used in cosmetics \\
\hline Proppant & $\begin{array}{l}\text { Silica, quartz } \\
\text { sand }\end{array}$ & $\begin{array}{l}\text { Proppants consist of grantular material, such as sand, which } \\
\text { is mixed with the fracture fluid and is used to hold open the } \\
\text { hydraulic fractures allowing the gas or oil to flow to the } \\
\text { production well. }\end{array}$ & $\begin{array}{l}\text { Play box sand, concrete or } \\
\text { mortar sand }\end{array}$ \\
\hline $\begin{array}{l}\text { Scale } \\
\text { inhibitor }\end{array}$ & $\begin{array}{l}\text { Ethylene } \\
\text { glycol }\end{array}$ & $\begin{array}{l}\text { Additive to prevent precipitation of scale (calcium carbonate } \\
\text { precipitate). }\end{array}$ & $\begin{array}{l}\text { Automotive antifreeze and } \\
\text { de-icing agent }\end{array}$ \\
\hline Surfactant & Naphthalene & Used to increase the viscosity of the fracture fluid. & $\begin{array}{l}\text { Household fumigant (found } \\
\text { in mothballs) }\end{array}$ \\
\hline
\end{tabular}
Figure 68. Additives in the hydrofracturing fluid
(reproduced from D. Arthur et al, ALL Consulting3) 


\begin{tabular}{|c|c|c|c|c|c|}
\hline $\begin{array}{l}\text { Universal } \\
\text { Product }\end{array}$ & Loading & Density & Components & \% Range & $\begin{array}{l}\text { wt } \% \text { in } \\
\text { frac fluid }\end{array}$ \\
\hline FRP-121 & $5 \# \mathrm{pt}$ & & $\begin{array}{c}\text { Anionic } \\
\text { Polyacrylamide }\end{array}$ & $98-100 \%$ & $0.06 \%$ \\
\hline \multirow{3}{*}{ EC6116A } & \multirow{3}{*}{$0.25 \mathrm{gpt}$} & \multirow{3}{*}{10.4} & Dibromoacetonitrile & $1-5 \%$ & $0.00156 \%$ \\
\hline & & & $\begin{array}{c}\text { 2.2- Dibromo -3- } \\
\text { nitrilopropionamide }\end{array}$ & $10-30 \%$ & $0.00935 \%$ \\
\hline & & & Polyethylene Glycol & $30-60 \%$ & $0.01871 \%$ \\
\hline \multirow{2}{*}{ Flomax 70} & \multirow{2}{*}{$1 \mathrm{gpt}$} & \multirow{2}{*}{7.76} & Methanol & & $0.085 \%$ \\
\hline & & & Surfactant & & $0.085 \%$ \\
\hline \multirow{2}{*}{ Scalehib 100} & \multirow{2}{*}{$0.1 \mathrm{gpt}$} & \multirow{2}{*}{9.8} & Ethylene Glycol & $30-60 \%$ & $0.00705 \%$ \\
\hline & & & Polyacrylate & & $0.009 \%$ \\
\hline
\end{tabular}

Figure 69. Additives used in the hydrofracturing fluid, as reproduced from information published by Talisman Energy, Inc ${ }^{28}$ 


\section{References}

${ }^{1}$ Acharya, H.R., Moore, B., Wang, H., 2010. "Cost effective recovery of Low TDS Frac Flowback Water for Reuse." Ground Water Protection Council Conference, Pittsburgh, PA, September 27, 2010. http://www.gwpc.org/meetings/forum/2010/proceedings/3Acharya_Haris.pdf

${ }^{2}$ Acharya, H.R., Silva, J. M., Wilson, M. "Shale Gas Frac Flowback Treatment." Canada Society for Unconventional Gas, Water Workshop, Calgary, Canada, April 20, 2011. http://www.csug.ca/index.php?option=com_jevents\&task=icalrepeat.detail\&evid=165\&ltemid=57\&y ear=2011\&month=04\&day=20\&title=water-workshop\&uid=ef6a76d3e36931dc9ae8f983582e44e3.

3 D. Arthur et al. ALL Consulting, Hydraulic Fracturing Considerations for Natural Gas Wells of the Fayetteville Shale, 2008 http://www.all-Ilc.com/publicdownloads/ALLFayettevilleFracFINAL.pdf

4 T. Gaudlip, Preliminary Assessment of Marcellus Water Reuse - Operations Manager Water Resources, Coldwater Conference, 20 February, 2010 http://www.coldwaterheritage.org/KCC\%20presentations/Gaudlip.pdf

5 Prof. D. Burnett, Texas A\&M, DOE-NETL Oil Technology E\&P Program, Environmental (Treatment Technology) Projects Kick-Off Meeting, NETL Morgantown, WV, January 12, 2010.

${ }^{6}$ T. Langford, GE Water, Personal communications with well services operators.

7 Chesapeake Energy, Managing Water Resource Challenges in Select Natural Gas Shale Plays GWPC Annual Forum, September 20-24, 2008 http://www.gwpc.org/meetings/forum/2008/proceedings/Ground\%20Water\%20\&\%20Energy/Satte rfieldWaterEnergy.pdf

${ }^{8}$ Chesapeake Energy Company website: http://www.chk.com/Media/CorpMediaKits/Water_Use_Fact_Sheet.pdf

9 Veil, J.A., Puder, M.G., Elcock, D., and Redweik, R.J., "A White Paper Describing Produced Water from Production of Crude Oil, Natural Gas, and Coal Bed Methane," ANL Report under DOE (NETL) Contract W-31-109-Eng-38 (2004).

10 Horn, A.D., Breakthrough Mobile Water Treatment Converts 75\% of Fracturing Flowback Fluid to Fresh Water and Lowers CO2 Emissions, Society of Petroleum Engineers, SPE 121104, 2009

11 Mark Wilson and Todd Langford, GE Water, personal communications, March, 2010

12 Fact Sheet - Using Muds and Additives with Lower Environmental Impacts, DOE NETL website: http://web.ead.anl.gov/dwm/techdesc/lower/index.cfm

13 T. Hook, GE Water, Personal communications with well services operators, 2010. 
14 John A. Harper. The Marcellus Shale - An Old "New" Gas Reservoir in Pennsylvania. In Pennsylvania Geology, Volume 28 Number 1. Published by the Bureau of Topographic and Geologic Survey, Pennsylvania Department of Conservation and Natural Resources. 2008.

15 P. Kaufman, G.S. Penny, and J. Paktinat, Critical Evaluations of Additives Used in Shale Slickwater Fracs, SPE 119900, 2008 SPE Shale Gas Production Conference, Irving, Texas, U.S.A., 16-18 November 2008.

16 T. Gaudlip, Preliminary Assessment of Marcellus Water Reuse - Operations Manager Water Resources, Coldwater Conference, 20 February, 2010 http://www.coldwaterheritage.org/KCC\%20presentations/Gaudlip.pdf

17 T. Langford, GE Water, Personal communications with well services operators.

18 M. Tate and D. Adams, Waste Water Treatment Requirements, Regulatory Analysis Review, Pennsylvania Department of Environmental Protection, Chap 95 Regulation, Independent Regulatory Review Commission, p. 355, May 2010.

19 M. Tate and D. Adams, Waste Water Treatment Requirements, Regulatory Analysis Review, Pennsylvania Department of Environmental Protection, Chap 95 Regulation, Independent Regulatory Review Commission, p. 7, May 2010.

$20 \mathrm{GE}$ Winflows membrane system design software available at: http://www.gewater.com/winflows.jsp

${ }^{21} \mathrm{GE}$ Water website on softening methods for industrial wastewaters: http://www.gewater.com/handbook/ext_treatment/ch_7_precipitation.jsp\#

22 GE's Mobile Evaporator for treatment of frac flowback water. http://www.geunconventionalgas.com/mobile-evaporators.html

${ }^{23}$ Fact Sheet - Using Muds and Additives with Lower Environmental Impacts, DOE NETL website: http://web.ead.anl.gov/dwm/techdesc/lower/index.cfm

${ }^{24}$ Schlumberger Fracturing Services Page of Schlumberger website, www.slb.com September 2, 2008.

25D. Arthur et al. ALL Consulting, Hydraulic Fracturing Considerations for Natural Gas Wells of the Fayetteville Shale, 2008

26 John A. Harper. The Marcellus Shale - An Old "New" Gas Reservoir in Pennsylvania. In Pennsylvania Geology, Volume 28 Number 1. Published by the Bureau of Topographic and Geologic Survey, Pennsylvania Department of Conservation and Natural Resources. 2008.

${ }^{27}$ Chesapeake Energy Company website:

http://www.chk.com/Media/CorpMediaKits/Water_Use_Fact_Sheet.pdf 
28 Talisman Energy (Fortuna Energy), http://www.talismanusa.com/upload/media_element/26/01/microsoft-word---chemicaldescriptions-for-marcellus-shale-wells-fortuna-_2_.pdf 